San Jose State University

SJSU ScholarWorks

Master's Theses

Master's Theses and Graduate Research

Summer 2019

\title{
Monotonic Testing of Steel Anchor Straps for Alternative Installation Methods in Wood Frame Shear Walls
}

Randall Block

San Jose State University

Follow this and additional works at: https://scholarworks.sjsu.edu/etd_theses

\section{Recommended Citation}

Block, Randall, "Monotonic Testing of Steel Anchor Straps for Alternative Installation Methods in Wood Frame Shear Walls" (2019). Master's Theses. 5026.

DOI: https://doi.org/10.31979/etd.ar8b-sf9z

https://scholarworks.sjsu.edu/etd_theses/5026

This Thesis is brought to you for free and open access by the Master's Theses and Graduate Research at SJSU ScholarWorks. It has been accepted for inclusion in Master's Theses by an authorized administrator of SJSU ScholarWorks. For more information, please contact scholarworks@sjsu.edu. 
MONOTONIC TESTING OF STEEL ANCHOR STRAPS FOR ALTERNATIVE INSTALLATION METHODS IN WOOD FRAME SHEAR WALLS

\author{
A Thesis \\ Presented to \\ The Faculty of the Department of Civil and Environmental Engineering \\ San José State University \\ In Partial Fulfillment \\ of the Requirements for the Degree \\ Master of Science \\ by \\ Randall A. Block
}

August 2019 
(C) 2019

Randall A. Block

ALL RIGHTS RESERVED 
The Designated Thesis Committee Approves the Thesis Titled

MONOTONIC TESTING OF STEEL ANCHOR STRAPS FOR ALTERNATIVE INSTALLATION METHODS IN WOOD FRAME SHEAR WALLS

by

Randall A. Block

APPROVED FOR THE DEPARTMENT OF CIVIL AND ENVIRONMENTAL ENGINEERING

SAN JOSÉ STATE UNIVERSITY

August 2019

Kurt McMullin, Ph.D. Department of Civil and

Environmental Engineering

Akthem Al-Manaseer, Ph.D. Department of Civil and Environmental Engineering

Mohamed Soliman, Ph.D. Department of Civil and Environmental Engineering 


\title{
ABSTRACT \\ MONOTONIC TESTING OF STEEL ANCHOR STRAPS FOR ALTERNATIVE INSTALLATION METHODS IN WOOD FRAME SHEAR WALLS
}

\author{
by Randall A. Block
}

Metal wood-connection hardware straps are sometimes installed in ways not intended by the manufacturers; in particular, a shear-wall anchor strap which was manufactured to be used in straight alignment to connect a post above a particular floor of a building to a post below that floor may instead be bent and wrapped around a floor beam. Four specimens using steel straps were constructed and tested in order to simulate building situations. The experimental specimens had wooden posts and engineered-wood floor beams, connected by straps, arranged so that the load paths passed through the straps being tested; the control specimens had post-to-post connections. The specimens were tested monotonically by applying tension, in order to determine whether the performance of the straps was altered when installed in bent configurations. Two tests on each of the MSTA36 and CMSTC16 steel straps intended for wood-connection, manufactured by Simpson Strong-Tie, Inc., were performed, and results were measured. No fracture occurred at a strap bend. All specimens showed evidence of post-yield elongation at time of fracture. Neither of the two straps which were wrapped around the floor beam showed any reduction-of-effective-capacity effect due to the bending of the straps at the corners of the beam. The results suggest that metal straps may, in the situation tested, be used effectively in bent and wrapped configurations. 


\section{ACKNOWLEDGMENTS}

I gratefully acknowledge the help and supervision of my advisor, Professor Kurt McMullin of the Department of Civil and Environmental Engineering on all phases of this project. Professor McMullin suggested the topic of the experiments. He answered

my questions regarding the experiments, and advised me both in designing the specimens and in preparing this thesis. He participated in the testing of the specimens. He read draft versions of the thesis and made useful recommendations.

I also thank the laboratory technician Patrick Joice, for his work in preparing the laboratory specimens, and for helping me with my portion of the specimen construction.

I appreciate the work done by Akthem Al-Manaseer, Professor, and Mohamed

Soliman, Lecturer, for their assistance in reviewing the draft manuscript of this thesis, and for offering valuable commentary.

I thank Simpson Strong-Tie Company Inc., for providing the straps used in these experiments.

Finally, I am grateful to my wife, Colleen, for encouraging me to pursue a Master's degree, for providing moral support during the writing of the thesis, and for helping me with the format of the thesis. 


\section{TABLE OF CONTENTS}

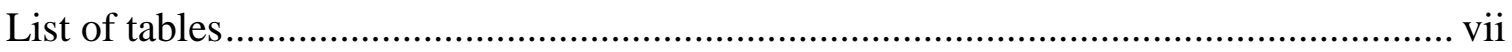

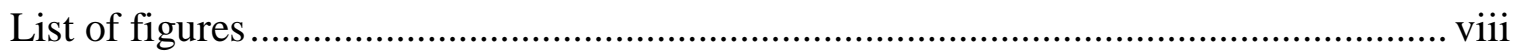

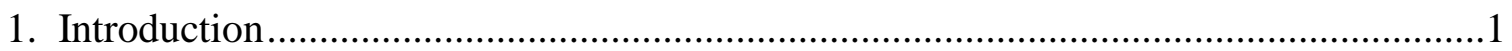

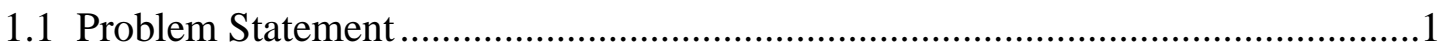

1.2 Project Goals and Objectives .........................................................................

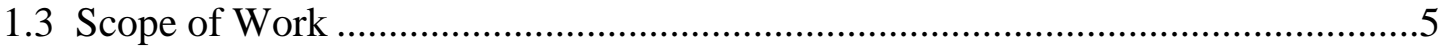

2. Review of Literature …………………………................................................

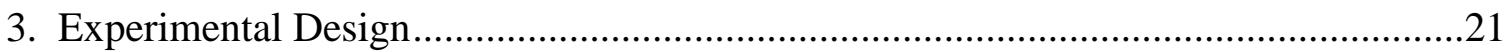

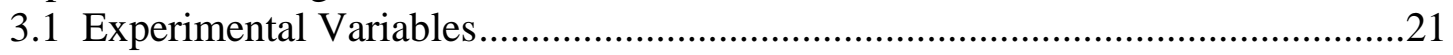

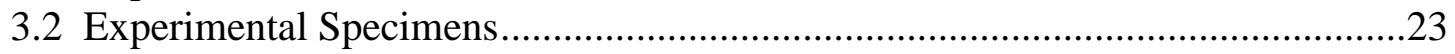

3.2.1 Post-to-Post configuration. .............................................................23

3.2.2 Post-to-Beam configuration .................................................................28

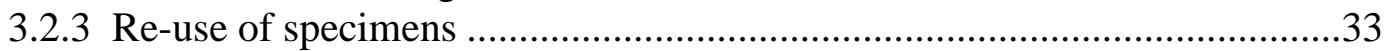

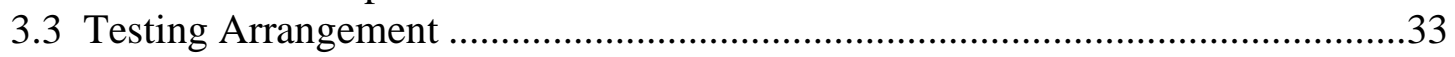

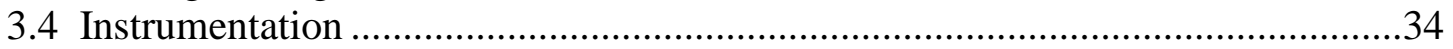

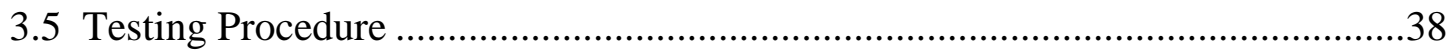

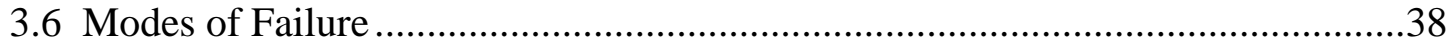

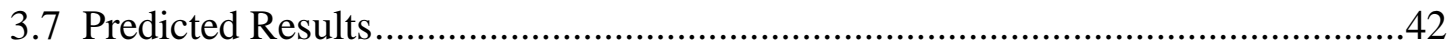

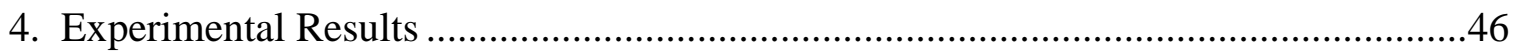

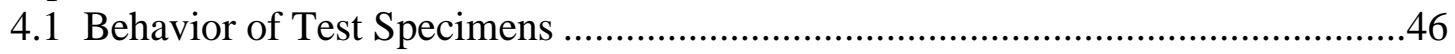

4.2 Results of Individual Tests.........................................................................48

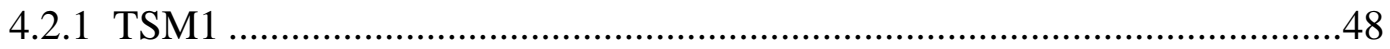

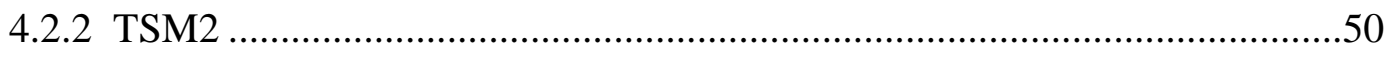

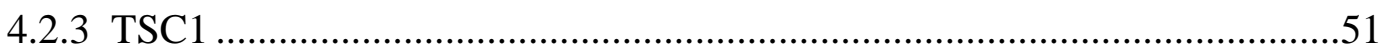

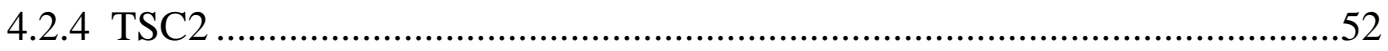

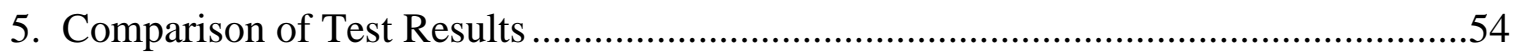

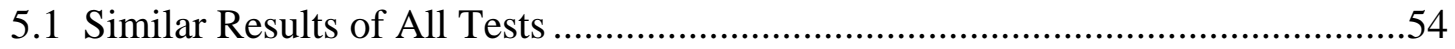

5.2 Comparison between Individual Tests ............................................................55

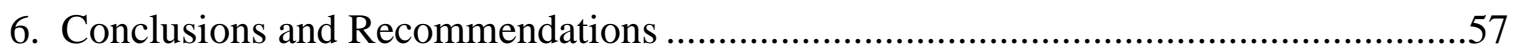

6.1 Results of Original Research Objectives ..........................................................57

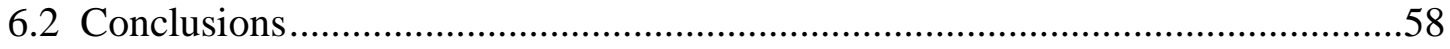

6.3 Recommendations for Continuation of Research …………………......................59

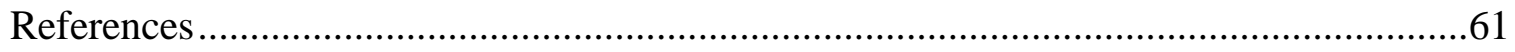




\section{List of tables}

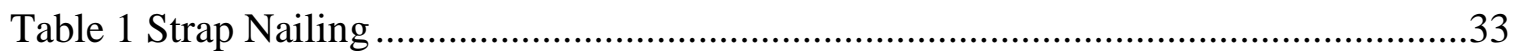

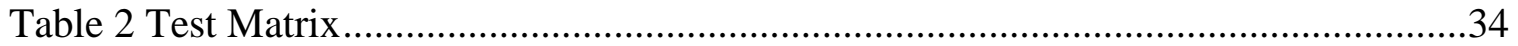

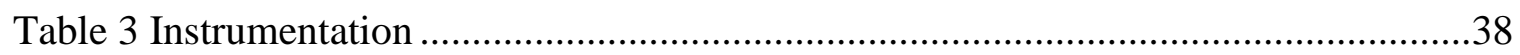

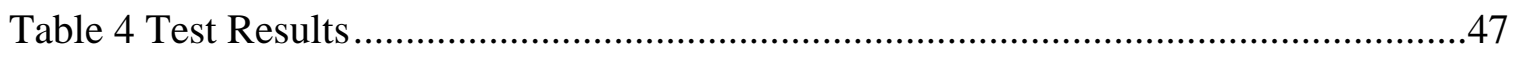

Table 5 Corresponding Nomenclature ............................................................. 47 


\section{List of figures}

Figure 1. Typical shear wall installation, aligned (Post-to-Post) - elevation view......

Figure 2. Typical shear wall installation, discontinuous (Post-to-Beam) elevation view.

Figure 3. Strap test specimen, Post-to-Post, MSTA36 strap (TSM1) longitudinal elevation view.

Figure 4. Strap test specimen, Post-to-Post, CMSTC16 strap (TSC1) longitudinal elevation view.

Figure 5. Strap test specimen, Post-to-Post, MSTA36 strap (TSM1) transverse elevation view.

Figure 6. Strap test specimen, Post-to-Beam, MSTA16 strap (TSM2) longitudinal elevation view.

Figure 7. Strap test specimen, Post-to-Beam, MSTA16 strap (TSC2) longitudinal elevation view.

Figure 8. Strap test specimen, Post-to-Beam, MSTA36 strap (TSM2) transverse elevation view.

Figure 9. Instrumentation, Post-to-Post - transverse elevation view. .36

Figure 10. Instrumentation, Post-to-Beam - transverse elevation view.

Figure 11. Tension strap experiment results - TSM1.

Figure 12. Tension strap experiment results - TSM2 .........................................50

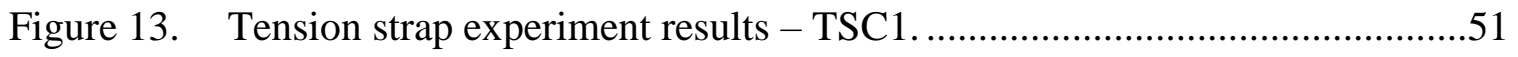

Figure 14. Tension strap experiment results - TSC2 ............................................52 


\section{Introduction}

\subsection{Problem Statement}

Many buildings, particularly houses and other residential buildings, are of wood-

frame construction. All or most of these structures may be called upon to resist lateral loads, that is, those due to wind or earthquake, by what are called shear walls. Shear walls have panels, typically of plywood, oriented-strand board or similar material, which resist the lateral loads by means of shear. When such a wall is loaded laterally, the load is applied at the top and resisted at the bottom, so that the wall sustains an overturning moment. For this reason, the lower corner of the wall at one side (the "upwind" side when wind-loaded) may experience an upward force. In order to prevent the wall from lifting up at this corner, this force must be transmitted to other structural members in the building, and must eventually be carried to the foundation where it can be resisted.

For architectural reasons, many wood structures have discontinuities or offsets, so that a wall at an upper floor may not be aligned on a wall directly below. In these cases, the building designer must arrange that the wall should rest on a beam or horizontal girder, typically part of the floor framing. The beam then will carry not only the weight of the wall and other gravity loads, but also any other loads upon the wall, including those due to wind or earthquake.

Each shear wall will typically be equipped with a post or column at each end. Inplane bending in a shear wall is induced by the shear. This bending is resisted by coupled vertical loads in the posts. 
Because wood cannot be formed like concrete, nor welded like steel, metal connectors are usually used to join one wooden structural member to another. The available connectors include nails, bolts and screws, straps and brackets. Where a post rests on another post or on a beam, only minimal connections such as nails are needed to transmit downward forces. Where uplift forces are encountered, such as in the shear-wall situation described above, stronger hardware, such as steel straps, plates or brackets, is typically used. When walls on one story are located directly above those at another story, the two levels of walls can be connected by metal straps which transfer this load between stories and are attached to the end posts.

In actual practice, connection hardware may not be available for all conceivable situations that the engineer may encounter in wood-frame buildings. In order to account for situations not easily accommodated, the hardware available may sometimes be used in ways not intended by the manufacturer.

Where offsets of shear walls occur, steel straps which are intended to be used in straight alignment may instead be bent and wrapped around beams embedded in floors. Thus, the strap when used in this non-conforming way transfers vertical load (uplift) between a post and a beam.

Figure 1 shows a typical arrangement of a wood-frame structure in which shear walls on two stories are aligned one over the other. In this case, loads from the wall above may be transferred directly into the wall below, without the participation of the floor beam. Figure 2 depicts a situation in which it was found necessary or convenient to place a shear wall at one story at a horizontally-displaced location with respect to the shear wall 
at another story. Here, the floor beam, which must continue to a vertical support located off the edge of the figure on the right-hand side, supports the upper wall for both vertical and lateral forces, and for overturning.

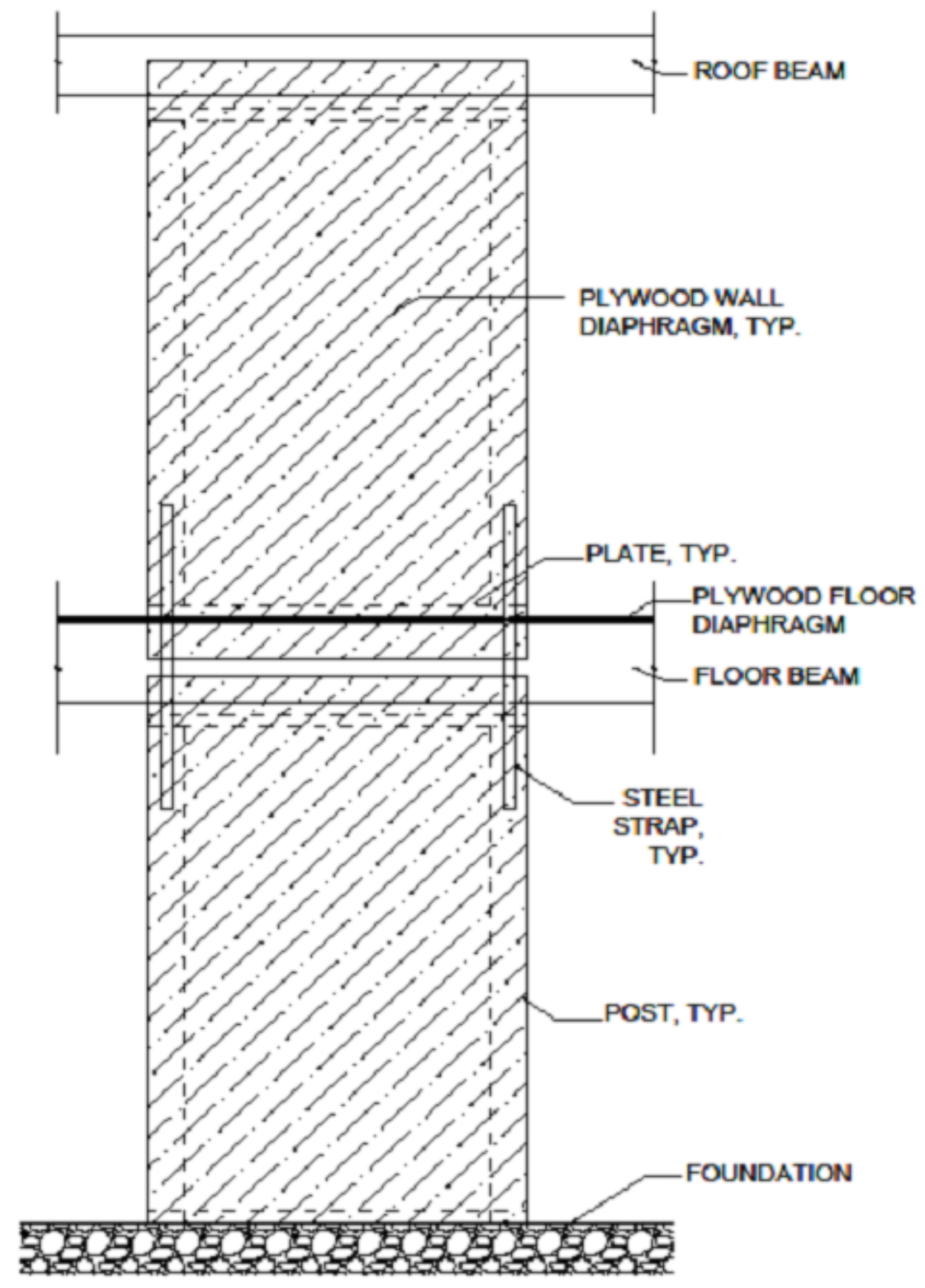

Figure 1. Typical shear wall installation, aligned (Post-to-Post) - elevation view. 


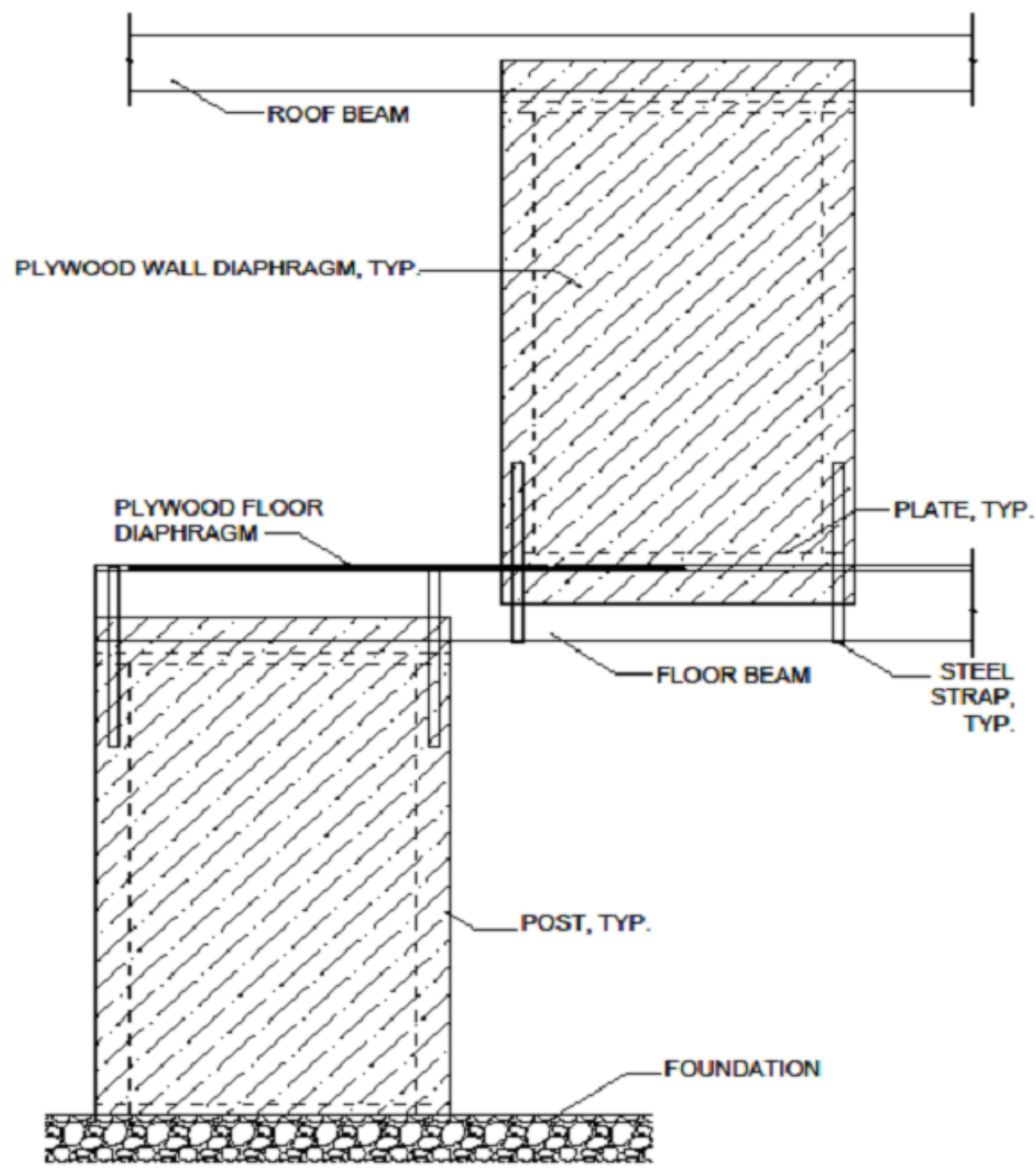

Figure 2. Typical shear wall installation, discontinuous (Post-to-Beam) - elevation view.

\subsection{Project Goals and Objectives}

For the reasons discussed above, research was conducted at the College of Engineering at San José State University on straps in the Post-to-Beam application described above. The intent of the exercises was to discover whether using the straps in this way allows the strap to transfer the same magnitude of force as it would in the configuration prescribed by the manufacturer. In other words, the purpose of the research 
is to determine whether using the straps in this unintended way can fulfill design objectives or if, instead, it frustrates them.

The investigation was intended to evaluate the comparable strength of the straps when used in traditional and non-traditional installations.

The research objectives were:

1. To design two different testing configurations to evaluate the strength and ductility of steel straps used for connecting wood members, one of which represents a control case.

2. To identify and review published research reports of similar connections, if any can be found, and if so, to compare the data collected during the experiments covered here to similar test data from past experiments.

3. To conduct experiments to quantify the strength and ductility of the straps in alternative installations.

4. To observe and record the mode of failure in each instance.

\subsection{Scope of Work}

The work covered in this thesis represented an experimental test program conducted during February and March of 2018. This document is the basis for a 6-credit graduate thesis at San José State University, conducted over a 12-month period.

The Universal Test Machine located in Room 127 of the College of Engineering Building was used for the tests of straps. A total of four experiments with relevant results were conducted: two types of steel straps on each of two different wooden specimens. 
In addition, several experiments were done earlier whose results were not used due to defects of specimen design or improper functioning of instrumentation. Due to the concerns revealed, the data from these prior experiments were considered inappropriate, and results have not been used for this thesis. Modifications were made to the specimens before conducting the tests that were used.

In addition to the material in the text, this thesis includes three appendices. Appendix A contains drawings that show the details of the appurtenances of the specimens.

Appendix B has the calculations which were made in order to predict the capacities of the specimens and appurtenances as well as predicted elongations at yield. Appendix C comprises photographs of the testing arrangements. 


\section{Review of Literature}

A search of the Internet for literature specifically about laboratory tests of metal straps in wood-frame situations yielded no significant results. Among the combinations of keywords searched were "testing of steel connectors for wood framing," "steel straps wood framing research" and "metal connectors for wood framing experiments." Not surprisingly, most of the results returned by the Internet were sales-related.

A similar search was conducted among California State University Library documents, including theses and dissertations, without success.

Several other documents were located which describe experiments that are related to the experiments involving straps connecting wood structures which are treated in this document. This document will report primarily on those findings specifically concerning uplift, vertical anchorage, and those components used to transfer uplift forces between upper and lower levels of a structure, or between a structure and a foundation.

The Consortium of Universities for Research in Earthquake Engineering (CUREE) funded the construction of a two-story wood-frame house on a shake table and related experimentation, which was reported on by Fischer, Filiatrault, Folz, Uang and Seible (2001). An extensive array of tests was conducted on the building during various stages of construction, and on the completed test structure. The experiments were performed at the University of California at San Diego, and were motivated by a need to understand the performance of wood buildings constructed under methods used in the United States, under seismic loading. The plan dimensions of the building were somewhat reduced from that of an ordinary-sized house (to $16 \mathrm{ft}$. by $20 \mathrm{ft}$.) in order to be accommodated on 
the shake table. Apparently, the walls were sheathed with oriented-strand board, and the roof and floors with plywood. The shake table was shaken in the short direction of the building. Among the experiments performed were:

First, according to Fischer et al. (2001), tests were performed for rigidity of the floor diaphragm (at the floor between the two stories in the completed structure), under various conditions of nailing, and the presence or absence of adhesive between plywood and floor joists, and with and without blocking, under "quasi-static" cyclical loads of 2-minute periods, with only the first story installed.

Then, Fischer et al. (2001) reported, tests were conducted using the completed structure, for floor diaphragm stiffness, for damping, and for natural frequency. The floor diaphragm was glued and fully nailed. Hold-down anchors (typically steel rods or steel straps, fastened to wood framing with brackets, used to transfer uplift loads from one story to another, or to a foundation) were attached from the walls to the base at corners of the structure, and for some phases at the bases of studs near door openings in the walls, except where noted. Tests of the fundamental natural frequency of the completed structure were conducted, using random "white noise" shaking. Tests to evaluate damping of the completed structure were done, using applied motion at the fundamental frequency of the structure for a period of time, and then stopping the motion suddenly.

Then time-history seismic motions were applied several different times by Fischer et al. (2001), using the ground motions of the 1994 Northridge Earthquake recorded at Canoga Park but with amplitude scaled up to 120 percent, and with Rinaldi ground 
motion in cases with amplitude scaled up and not scaled, as well as Canoga Park motion scaled down, in order to replicate earthquakes which might occur more frequently. Displacements and accelerations were measured, as was hysteretic behavior. Visible damage was photographed and noted. Forces in anchor bolts were measured, as was sliding of sill plates.

Variations were made in the structure between groups of tests: Among other things, tests were performed by Fischer et al. (2001) to compare performance of walls designed by the "perforated shear wall" design method and those designed by more usual segmented shear-wall engineering, for those walls with openings. For the perforated design model, intermediate hold-downs (those not located at ends of the walls) were inactivated by removing the nuts. Tests were conducted to compare performance of walls built under "conventional construction" and more usual shear-wall engineering. For conventional construction, the hold-downs and shear transfer clips were removed, and intermediate anchor bolts removed; at the ground level, hold-downs were replaced with ordinary anchor bolts. The last phase of tests was performed in order to evaluate the effect of adding non-structural wall coverings (gypsum board, stucco), comparing the structure with or without these finish materials.

Fischer et al. (2001) reported that when tests were performed with architectural coverings applied (Phase 10), anchor bolt forces and hold-down forces on walls parallel to the direction of motion decreased, while forces in anchor bolts in perpendicular walls increased, as compared with Phase 9, the similar situation but without the finish materials; the report states that this occurred because the structure acted as a "shell" when 
the finish items were present at walls, which seems to indicate that adding the finish materials increased the shear stiffness of the walls.

The structure exhibited effects of the seismic simulations. According to Fischer et al. (2001), the fundamental frequency decreased slightly and the maximum uplift at anchor bolts increased moderately after the specimen was loaded using seismic motions, relative to the corresponding values determined before the tests. After seismic loading was applied, the stiffness of the structure decreased and the maximum anchor bolt forces increased.

While the perforated design method predicts a smaller uplift force in the corner holddowns than for ordinary engineered design, the reverse situation was measured by Fischer et al. (2001) in these tests, suggesting inaccuracy of the method in predicting anchor forces in the case of the perforated design method.

During seismic testing, according to Fischer et al. (2001), the "holdown studs" (assumed here to mean those studs to which hold-downs were attached) tended to split at nails attaching the hold-downs.

The uplifts recorded at the "holdown studs" by Fischer et al. (2001) at the ends of shear wall segments in conventional construction were larger than those in engineered construction. Damage was recorded near corners of wall sheathing at door openings in perforated construction, because the end studs were not restrained against uplift.

A possible inference from the Fischer et al. (2001) report is that it is preferable to attach hold-downs at the framing members at the edges of all large openings (doors and perhaps windows), no matter where the openings are located in a wall, and design shear 
walls with openings as segments of walls located between the openings, in order to avoid concentrations of uplift forces at the corners of the structure.

The structure used in the Fischer et al. (2001) study had features which are related to the study made in this thesis. In the first place, the structure had what are called "CS16 straps", installed at the outside walls between the first and second story levels, at edges of shear walls. The Simpson catalog lists CS16 straps, which are similar to the straps tested for this thesis. The Fischer et al. report does not specifically identify the CS16 straps as being manufactured by Simpson, or if it does so, it does so on a reproduction of the structural drawings which is so poorly reproduced that it is impossible to read; however, the Acknowledgements page mentions Simpson Strong Tie Inc. as "providing financial and in-kind support". Second, there were structural discontinuities in the specimen structure in which walls at the upper level did not align with those on the lower level; however, the above-mentioned straps, while present at those locations, were evidently installed in straight alignment, so that at one level the strap connected to a shear-wall panel at the end, while at the other level the strap fastened to the wall at some location other than the end of a shear-wall panel. This installation was unlike the straps intended for such situations which were installed, some straight and some bent, and tested for this thesis. Forces in the straps evidently were not reported in the Fischer et al. article; however, the maximum holdown force at the base of the structure appears (from figure in Appendix L) to be 9519 pounds.

The test results of Fischer et al. (2001) have relevance to this thesis in that the straps and hold-downs used in Fischer et al. are analogous in function to the strap connectors of 
this thesis; that is, both components are used to transfer uplift forces from upper levels of a building to lower levels or to the foundation.

There were several notable differences between the shake-table tests reported by Fischer et al. (2001) and the experiments which were performed in preparation for this report. First, the experimental objective was different; in the tests by Fischer et al., the goal was to determine various characteristics of typical wood-frame buildings constructed in various ways, while for the tests of this thesis the objective is to determine whether a specific hold-down component could perform adequately when used in a non-standard configuration. Second, some of the tests discussed by Fischer et al. simulated either actual earthquakes, which would involve cyclical motion, and other tests by Fischer et al. used other types of cyclic loading, while the tests of this thesis used monotonic loading (in which the load is applied in one direction only, and steadily and gradually increases until yielding or fracture is noted) only.

CUREE also funded experiments of anchorage systems for wood shear walls to foundations, which were reported by Mahaney and Kehoe (2002). The laboratory work involved four groups of tests on wood-frame shear wall panels, anchored to concrete foundations. The test foundation was designed to be stronger than the anchorages. Plywood was used as sheathing on one side of the studs only, and was nailed to framing members. Of these groups of tests, the first two involved applying horizontal forces one foot above the base of a four-foot-long wall, in order that shear load effects on the anchorages might predominate. For the last two groups of tests, horizontal forces were applied to the top of an eight-foot-long-by eight-foot-high wall, representing a typical 
case for most such forces in a wood building, so that the effects of overturning could be studied. Of the tests developed to examine overturning, Group 3 used conventional anchor bolts, but only this type of anchor, while Group 4 used hold-downs at the end stud of the wall, in addition to the anchors. What was called a "target design load" for the anchor bolts was established. For most of the experiments, cyclical loading was used, but for a few tests, the forces were applied monotonically. In the cases of cyclical loading, the amplitudes of forces were based on multiples of the target load, and smaller amplitudes were used at first. "Dead" loads (assumed to be downward vertical loads) were applied to the top plates of the wall.

In addition to the differences noted above, components of the specimens were varied in the Mahaney and Kehoe (2002) study from one test to another. Sill plates were varied among $2 \times 4$ (nominal), $2 \times 6$, and $3 \times 4$ and $3 \times 6$ sizes. In some of the tests in which $2 \times$ 6 plates were used, $2 \times 4$ wall studs were used and blocking was added immediately above the plate, nails were installed from the plywood to the blocking, and the blocking was nailed to the sill plate. Wood members of varying species were used for the sill plates. Anchor bolts of 5/8-inch diameter were used in the tests in which overturning was considered. In most tests doubled ordinary studs were used at the ends of the specimen walls, to which hold-downs were attached in those tests in which they were used, but in several tests the hold-downs were installed to $4 \times 4$ posts at the ends of the specimen wall.

Mahaney and Kehoe (2002) reported that when forces were applied so as to cause sufficient overturning moment, the wall was lifted off the foundation. Because the 
plywood was attached to one edge of the sill plates, and because the anchorage components were located at mid-width of the plates, the plates tended to bend and twist in response. The sill plates tended to split in most of the tests. This splitting happened, evidently, because the upward forces applied through the plywood nails caused crossgrain bending in the sill plates. The 3-inch-nominal-thickness sill plates used performed better in tests than the $2 \mathrm{x}$ plates tested because they had better cross-grain bending strength. The nominal-4-inch-width plates tested did better than the nominal-6-inchwidth plates used because they had less eccentricity in loading, that is, less distance between the plywood and the anchor bolts. In a few of the tests, the plywood nails to the plate failed by pulling out of the sill plates or by pulling through the plywood rather than splitting the plates.

Using hold-downs allowed the test specimens to resist considerably greater lateral forces than was the case for those tests done without them, according to Mahaney and Kehoe (2002). The hold-downs transferred to the foundation the uplift forces that were associated with overturning moments. In tests performed without the hold-downs, some of the anchor bolts, whose function was otherwise to resist shear, also had to resist uplift. Nonetheless, the hold-downs merely delayed the upward displacement of the sill plate until greater lateral forces were applied, which caused the rods in the hold-downs to elongate, allowing the sill plates to lift away from the foundation. After that, the sill plates split in most cases, but the applied lateral forces resisted by the specimens with hold-downs were significantly more than was the case for the specimens without them. 
Mahaney and Kehoe (2002) stated that in their tests, double studs nailed together used at ends of the wall, with plywood nailed to only one stud, did not act as a unit. In several tests, the doubled studs or posts at the hold-downs split along the rows of fasteners attaching the hold-down.

In the tests done for this thesis, the steel straps are intended to serve a purpose similar to that of the hold-downs used in the Mahaney and Kehoe (2002) tests, that is, to transfer uplift loads. In the case of this thesis, shear walls were not modeled as part of the specimens. Based on the results of Mahaney and Kehoe tests, the use of dedicated vertical-load carrying connection components such as the straps and hold-downs appears to improve the efficiency of transfer of uplift force and seems to remove at least some vertical loads from the anchor bolts at the foundation.

Van de Lindt, Pei, Pryor, Shimizu, and Isoda (2010) reported on shake-table tests performed on a full-scale model of a wood-frame building. The experiments were conducted in Japan on a six-story building measuring approximately 60 feet by 40 feet in plan and approximately 56 feet in height, and included a time-history simulation of a 2,500-year-return-period earthquake for Canoga Park, among other simulations. The building had shear walls located directly above each other, with steel rod hold-down devices equipped with shrinkage-compensating components connecting the walls on different levels. Oriented-strand-board shear walls were used in the test specimen, replicating a typical wood-frame building installation. The tie-down rods were equipped with strain gauges. 
Van de Lindt et al. (2010) reported that maximum measured hold-down rod uplift force at the base of the test structure was $384 \mathrm{kN}$ in each of two side-by-side rods $(\approx$ 173,000 pounds, total of the two). The deformations of the structures showed hysteretic behavior, which is consistent with post-yield displacement. The Van de Lindt et al. article suggested that deformation of the rods may have contributed to the total horizontal drift at the building. The article reported no significant damage to the test structure as a result of the experiments.

Among the differences between the shake-table tests reported by van de Lindt et al. (2010) and the experiments performed for this report are these: First, in the tests by Van de Lindt et al., the goal was to determine whether buildings designed under a performance-based seismic design procedure could perform adequately, which differs from the objective of the tests of this thesis. Second, the magnitude of loads reported in the rods of the shake-table test was much more than the forces anticipated to be developed in these tests. Third, the tests discussed by van de Lindt et al. used cyclical motions similar to actual earthquakes, while this thesis covers monotonic loading. Fourth, the walls in the van de Lindt et al. model were arranged so that there (apparently) were no structural irregularities involved, except that between Stories 5 and 6 near the roof there were out-of-plane offsets in the shear-wall system, while the objective of the experiments in this thesis is to test performance of connector components in a situation which would arise specifically from a certain type of structural irregularity.

However, the lessons learned from both the experiments by van de Lindt et al. (2010) and those of this thesis might apply to the same structures. Ductile behavior of the 
critical components including the hold-down connections, as evidenced by the reported hysteretic behavior, is important for energy dissipation in structures during seismic events. On the other hand, too-flexible hold-down components might lead to excessive drift of the structure.

Shirazi (2012) discussed analysis of wooden shear walls with the objective of recording variability in seismic performance, as a function of the random variability in construction of the walls (such as the difference in performance between two walls designed identically, in the same earthquake). Tests were done on components of connections, including nails used in building wall frames, nails used to attach sheathing to framing, and hold-downs. The tests were performed with cyclic loading in most cases, and hysteretic behavior was observed with the cycles. For each test, force-vs.displacement behavior was observed and recorded. The probability distributions of strengths as well as of the stress-strain relationships of the connection components were as much items of concern as were the mean strengths and rigidities, and accordingly, standard deviations as well as means were recorded.

Two modeling procedures for wood shear walls were used by Shirazi (2012) to derive predictions about behavior of such walls in a seismic event, using the computer program "M-CASHEW", which was specifically intended to analyze shear walls. The wall sheathing itself was modeled using panel elements, the frame members as frame elements, and the connecting components as link elements. The framing members and the shear wall panels were assumed to behave elastically. The variability in the connections, measured in the previous phase, was represented in one of the procedures by 
using the Monte-Carlo technique. The previously-derived force-vs.-displacement parameters of the connection elements, including hysteretic behavior, were represented in the computer model, but the inherent variabilities of these functions were modeled by random generation of the quantities involved, which was however constrained in order to account in general for the observed distribution of those variables. A total of one hundred variations was analyzed for each of three types of walls under this modeling procedure. These simulations were used to quantify the amount of variation between shear walls, due to the connections.

A numerical model of the two-story wood structure constructed by Fischer et al. (2001) previously mentioned in this thesis was used by Shirazi (2012) in order to perform another series of simulations by computer using the finite-element method, and considering Phase 9 of Fischer et al. tests in which all structural elements were installed, but the finish elements had not yet been applied. Parameters for the shear walls themselves, previously determined by others, were used as mean values in this study. A simplified simulation method for deriving random wall characteristics, described in the Shirazi paper, was used. A time-history of motion recorded at Rinaldi during the 1994 Northridge earthquake was used for the simulation. One hundred variations of the building were simulated and analyzed by Shirazi. The results of the simulations showed considerable variation, and two of the one hundred models showed collapse (defined as displacement of more than $250 \mathrm{~mm}$.), even though collapse was not predicted by a deterministic model that was developed for the situation. 
In addition, a study was made by Shirazi (2012) using time-history ground motions in which the effects of uncertainty inherent in ground motions was combined with the uncertainty of the buildings themselves. The ground motions modeled were those given in FEMA P-695, scaled to represent three different return periods. The variations of the model building were the same as those of the previous exercise. These combinations of buildings and ground motions were analyzed numerically. As in the previous experiment, one hundred variations of the building were used. The results revealed probability distributions of maximum inter-story drifts for the derived random variations of the model building.

There were several major differences between the multi-stage experimentation reported by Shirazi (2012) and the laboratory work with which this thesis is concerned. First, the objective for Shirazi was different from that of the tests of this thesis; the rationale for those experiments was to observe random variation within connection elements and then use the variations in order to derive a predictive numerical model intended for whole buildings. Second, as with the tests of the van de Lindt et al. (2010) article, the Shirazi experiment modeled cyclic motions. In the experiments performed for this thesis, loads were physically applied to the specimens, while in the tests by Shirazi the physical tests were done on connection specimens, and, later, a computer-simulated mathematical model was used to predict the effects of probabilistic variation in the connections on a whole building.

The work done by Shirazi (2012), however, has relevance to the topic of this thesis, in that the random variability of the connection elements, such as the straps tested in the 
experiments of this thesis, may influence the load and displacement capacities of the entire structures in which they are used. Similar to the results in van de Lindt et al. (2010), hysteretic behavior was observed in the connection elements in the laboratory, and in the computer-modeled structure where variation in the components (only) was applied. As was previously observed, hysteretic behavior allows energy dissipation, which may reduce damage to the building in a seismic event.

The Simpson Strong-Tie Company, Inc., manufacturer of the straps used in the experiments, was contacted by telephone. The company engineering department representative reached said that no research reports on topics related to the research covered in this thesis were available. He mentioned that the company publication High Wind-Resistant Construction Application Guide (Simpson Strong-Tie Company, 2016, p. 48) lists several types of strap connectors, e.g., LSTA24, used in field-bent applications. For the situation described, in which the strap is used to attach roof framing to wall framing, and is bent, the allowable tension force listed for LSTA24 is 965 pounds for Douglas Fir-Larch or Southern Pine framing. The product catalog Wood Construction Connectors (Simpson Strong-Tie Company, 2016, p. 302) lists an allowable tension force for the LSTA24 strap as 1,235 pounds for un-bent use with the same species of wood. It is not apparent whether the capacity is reduced because the strap is bent, or whether the capacity is less because fewer nails are specified to be used in the particular bent-strap case described than in the un-bent case (12 nails in bent-strap, 18 in un-bent-strap; $10 \mathrm{~d}$ nails used in both applications), or for a combination of both reasons. 


\section{Experimental Design}

\subsection{Experimental Variables}

The straps which were tested are intended by the manufacturer to be used to connect portions of wooden structures, and to transfer loads between them by means of tension in the straps. The straps are of sheet steel, previously cut to shape, with nail holes already punched in proper locations, and galvanized during manufacture. They are intended to be fastened to the wood construction by means of nails. The manufacturer provides explicit instructions about how the straps should be installed.

Note that all calculations made in this thesis are in Allowable Stress Design, unless otherwise noted.

Strap types are as follows:

MSTA36 - This strap is manufactured by Simpson Strong-Tie Company, Inc. It is 36 inches long, 1 1/4 inch wide, of 16-gauge ASTM A653 galvanized steel. According to the manufacturer's catalog, it has 2050 pounds allowable tension load. An important feature of the strap is that it has two $1 / 2$-inch-diameter holes, each located approximately $71 / 2$ inches from each end of the strap.

CMSTC16 - This strap is manufactured by Simpson Strong-Tie Company, Inc. It is produced in coils, intended to be cut to the appropriate lengths. The strap stock is 3 inches wide, of 16-gauge ASTM A653 galvanized steel. According to the manufacturer's catalog, it has 4585 pounds allowable tension load. For Test TSC1, a 60-inch strap length (approximate) was used; the length was increased beyond the minimum practical 
length in order to avoid nailing the CMSTC strap too near the nail holes already made in the posts in installing the MSTA strap. For TSC2, 48 inches strap length was used.

Other components are:

Nails -10d common (0.148-inch diameter by 3.00-inch-long) with MSTA36; 16d sinker (0.148-inch diameter by 3.25-inch long) with CMSTC16 (as directed by the strap manufacturer).

Posts -4 x 6, Douglas Fir / Larch (DF/L), (assumed) Grade \#1.

Beam $-3 \frac{1}{2} \times 9 \frac{1}{4}$, laminated-strand preservative-treated manufactured lumber, “Trus-Joist Parallam Plus PSL.”

Top and bottom plates - 2 x 4 DF/L (assumed) Grade \#1.

Plywood - 3/4-inch.

Various steel hardware - used to attach the wooden specimens into the testing apparatus.

The testing apparatus is:

Universal Test Machine (UTM) - The UTM has six vertical posts, three stationary and three moveable. It also has two platforms called "heads," an upper which is stationary, and a lower which is moveable. The stationary posts support the upper head and the moveable posts the lower head. The moveable posts have screw threads which engage the lower head; the posts are rotated by an engine which causes the lower head to raise or lower. Raising or lowering the platform can serve one of two purposes: The distance between platforms can be changed in order to accommodate the test specimens when placing the specimens in the UTM. Then, once a specimen is attached into the 
UTM, lowering the platform causes elongation, and therefore tension, in the specimen, allowing experiments to be performed. The tension in any part of the specimen is thus a derived force, dependent in part on the enforced elongation of the UTM, but also in part on the elongation of other parts of the specimen.

Installation methods being tested are:

- Post-to-Post (as intended by manufacturer; control situation), each of 2 straps;

- Post-to-Beam (strap wrapped around beam; experimental), each of 2 straps.

\subsection{Experimental Specimens}

Two types of specimens were constructed for each type of strap:

3.2.1 Post-to-Post configuration. The tests done on this specimen represent the control cases. The specimen comprised two wooden posts oriented in the vertical direction, one above the other, an engineered-wood beam between the posts, the strap being tested, and other fasteners and appurtenances. Wooden "plates" and a piece of plywood "floor" were included, in order to simulate a real building situation. Nails were used to attach the wooden pieces together.

At the upper end of the upper post and the lower end of the lower post, holes were drilled in order to accommodate bolts to attach to a "collar" assembly, as described in the "Testing Arrangement" section below. Figure 3 shows the MSTA36 strap and Figure 4 the CMSTC16 strap, both in longitudinal elevation views, while Figure 5 shows a view from transverse elevation; for the purpose of clarity, the lateral restraint used is not shown in this view. 


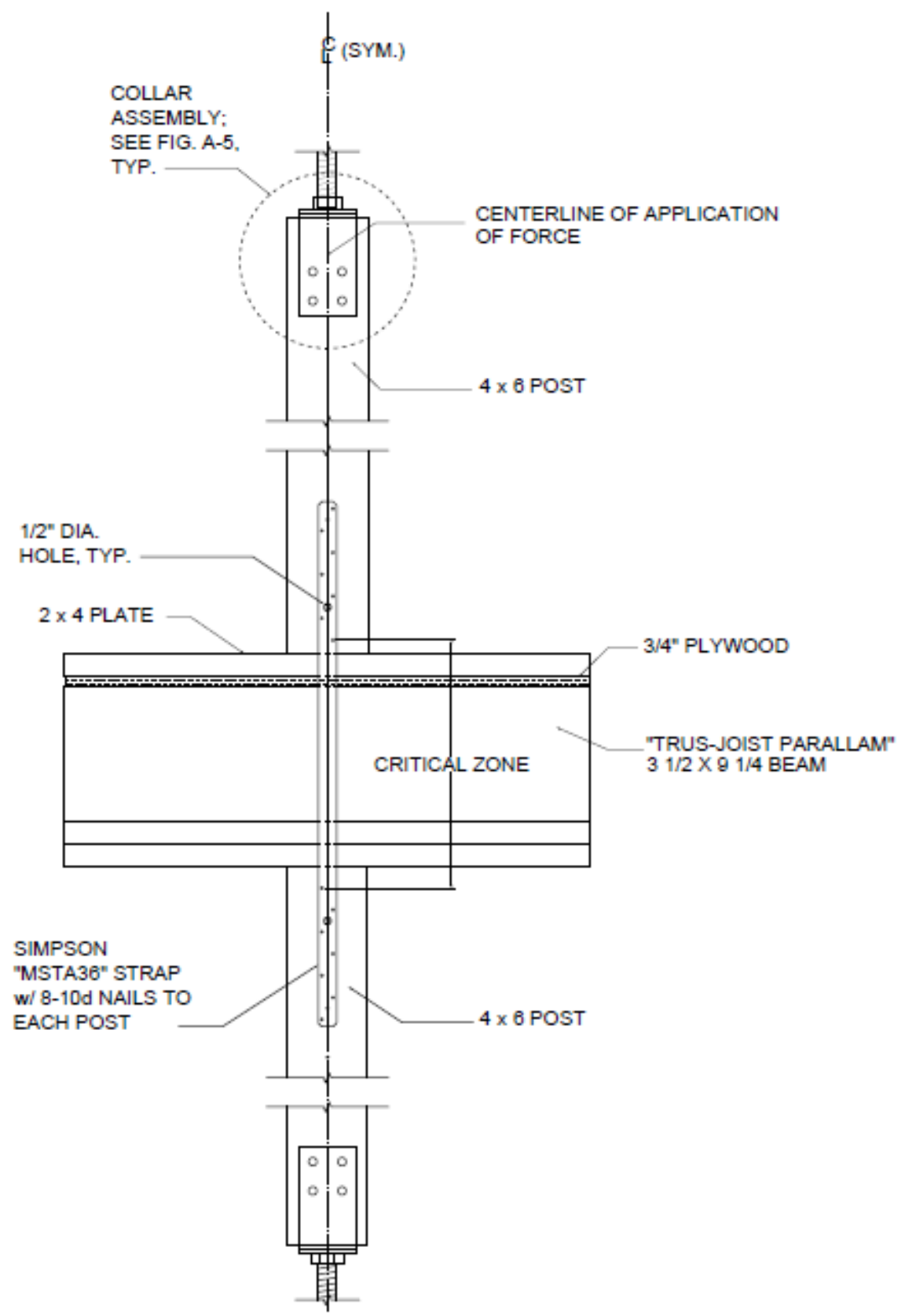

Figure 3. Strap test specimen, Post-to-Post, MSTA36 strap (TSM1) - longitudinal elevation view. 


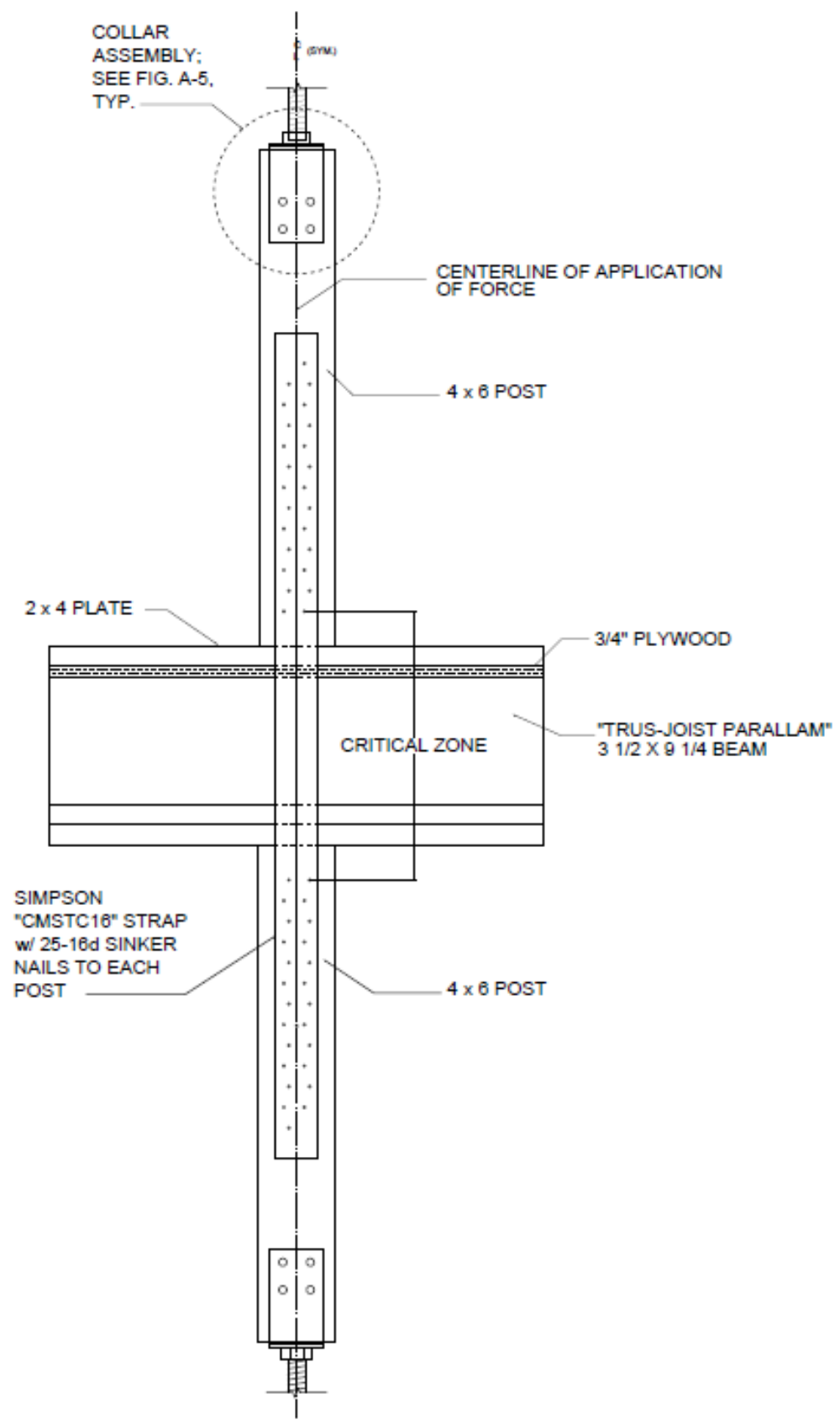

Figure 4. Strap test specimen, Post-to-Post, CMSTC16 strap (TSC1) - longitudinal elevation view. 


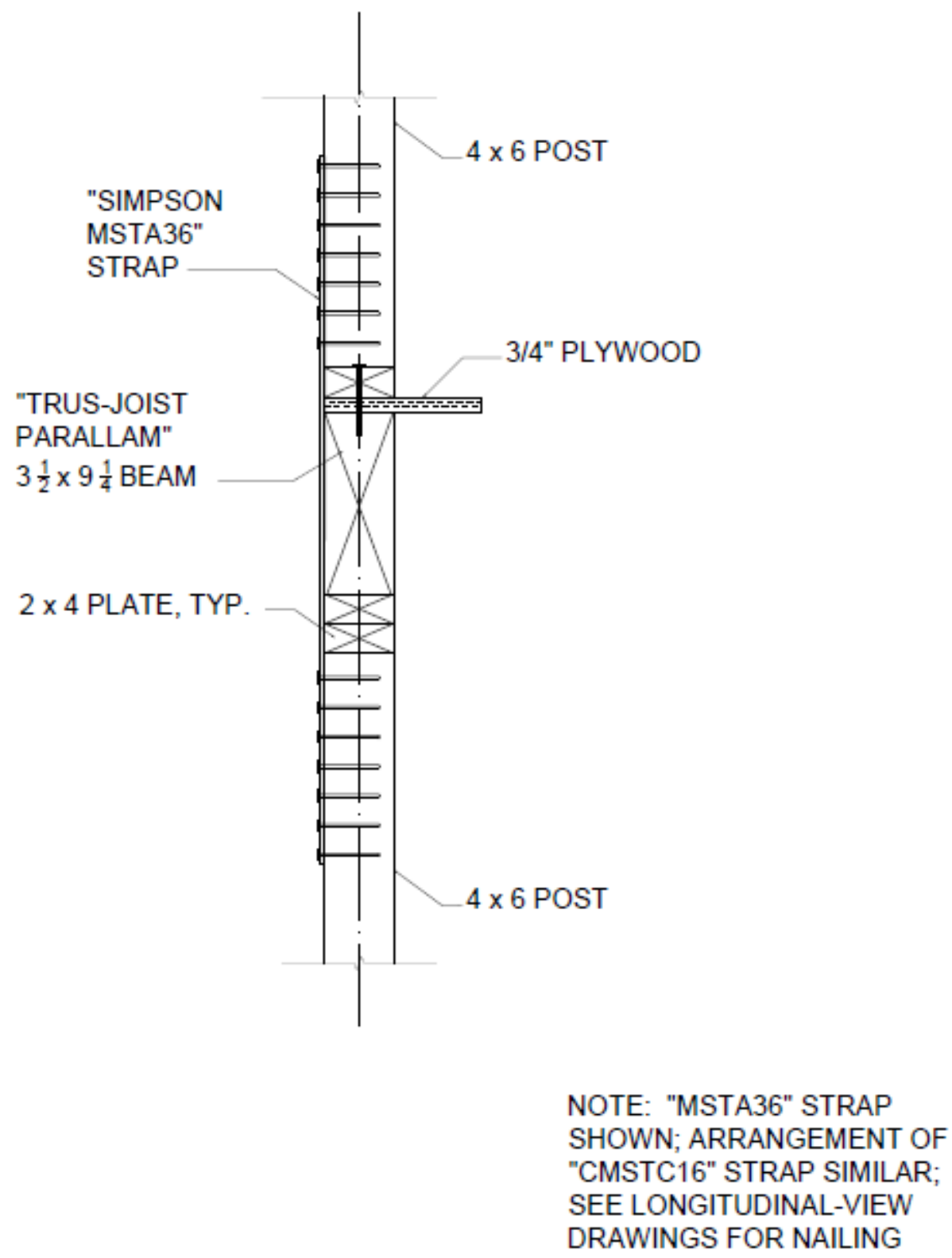

Figure 5. Strap test specimen, Post-to-Post, MSTA36 strap (TSM1) - transverse elevation view.

The Post-to-Post configuration represents the installation of the strap as is intended by the manufacturer, in the situation for which it was tested by the ICC Evaluation Service (2017). The upper and lower portions of the strap were attached to the upper and lower posts respectively by means of nails. The test specimen simulated a portion of an actual 
building, in which a post at the end of a shear wall at one story is positioned directly above the end of another shear wall below, separated by a floor.

The strap was not directly connected in any way to the floor beam, nor to the floor sheathing, nor to the plates, since doing so would not significantly increase the loadcarrying capacity of the system, and also since it was anticipated that such attachments would not be provided in the field. The load path for the applied tension passed through the posts near the upper and lower ends of the specimen, then through nails which transferred the load from the post to the strap at both upper and lower portions, then through the strap only, thus bypassing the floor beam and plates.

The length of the strap which traversed the floor beam and plates is called, for the purpose of this thesis, the "critical zone," measured from the nearest nail at the upper post to the nearest nail at the lower post, since the portion of strap in this zone carried the maximum tensile force. The strap was installed symmetrically about the critical zone; that is, equal lengths of the strap were located above and below the upper and lower boundaries of the critical zone, respectively, with equal numbers of nails. Each of the two large holes in the MSTA36 straps were located a few inches beyond each end of the critical zone.

While the manufacturer's instructions for MSTA36 call for 13 nails to be attached to each of the upper and lower posts, we found that in the actual installation, only 8 nails could be installed at each end of the strap because a significant length of the strap (about 16.5 inches, most of the critical zone) was used to cross the floor assembly. The large holes in the MSTA36 strap described above were thus located between the second and 
third nail holes distant from the ends of the critical zones. The manufacturer-directed number of 25 nails at each end of the strap was used for the CMSTC16.

3.2.2 Post-to-Beam configuration. The tests done on this specimen represent the experimental cases. The specimen had one wooden post similar to the upper post of the Post-to-Post specimen, and the same beam as the Post-to-Post case. In this case, however, the beam was part of the load path. No lower post and no lower plates were used.

At the upper end of the post, holes were drilled similar to the Post-to-Post specimen. See Figures 6, 7, and 8. For the purpose of clarity, the lateral restraint used is not shown in these views. 


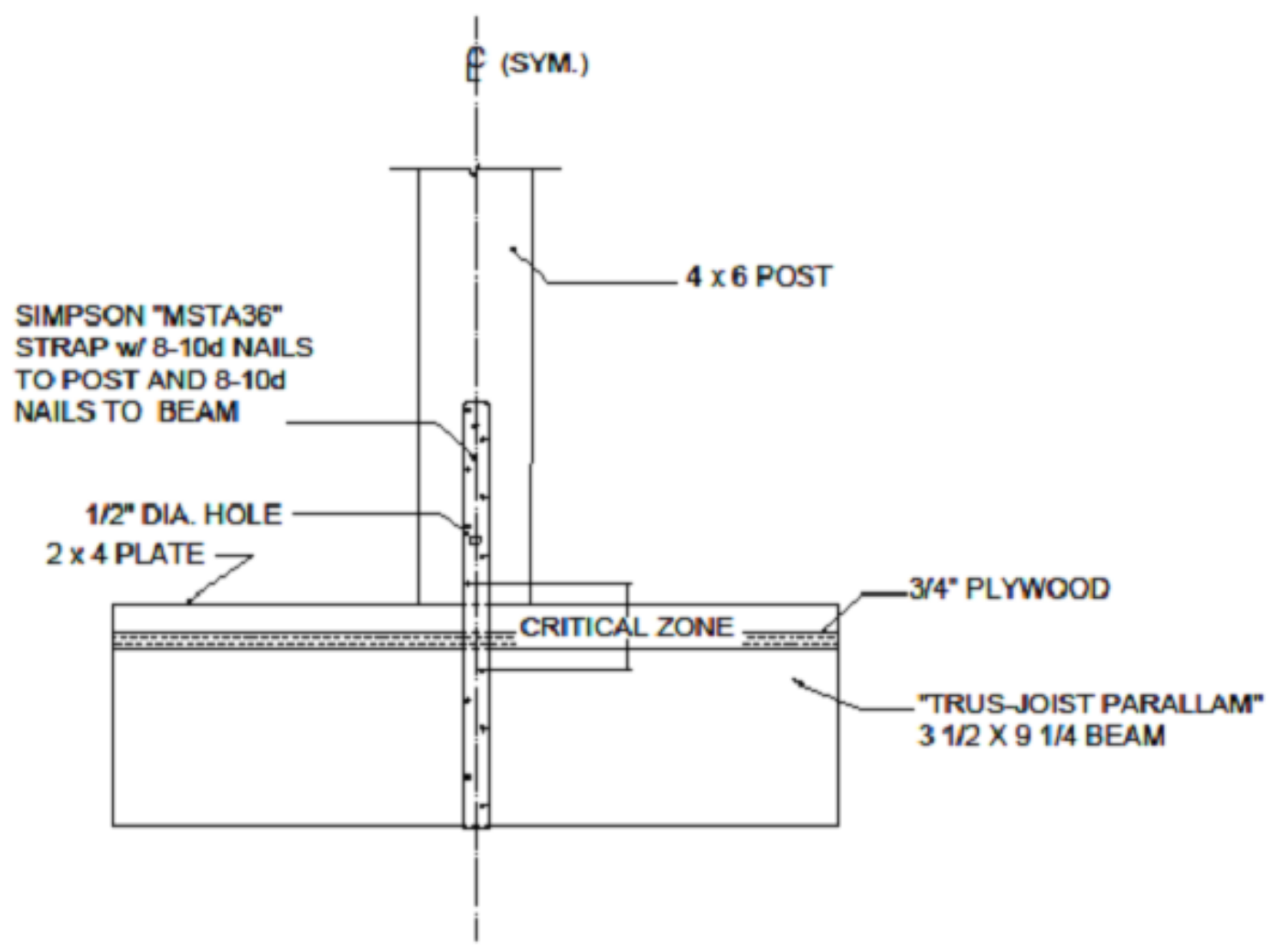

Figure 6. Strap test specimen, Post-to-Beam, MSTA16 strap (TSM2) - longitudinal elevation view. 


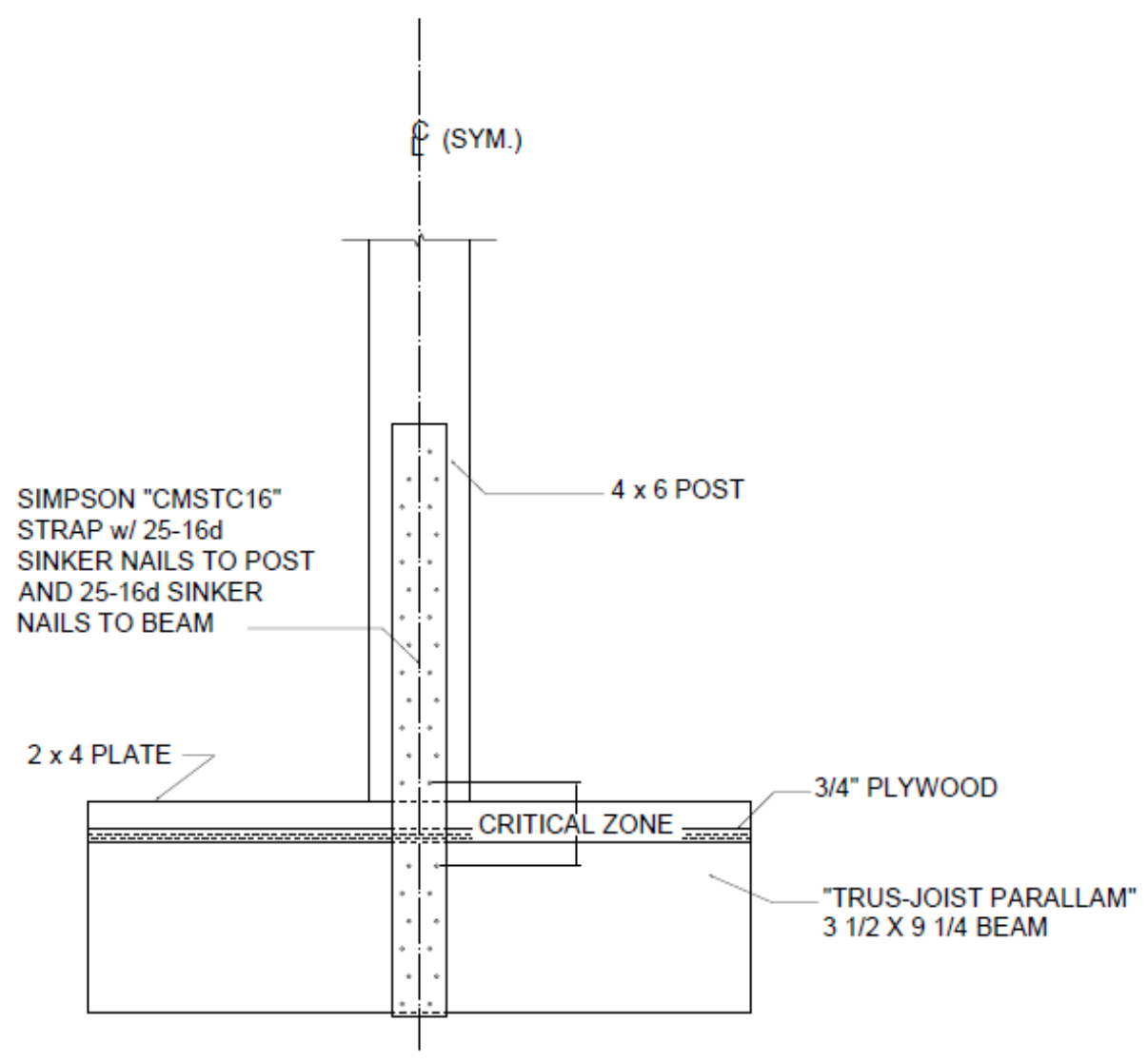

Figure 7. Strap test specimen, Post-to-Beam, MSTA16 strap (TSC2) - longitudinal elevation view. 


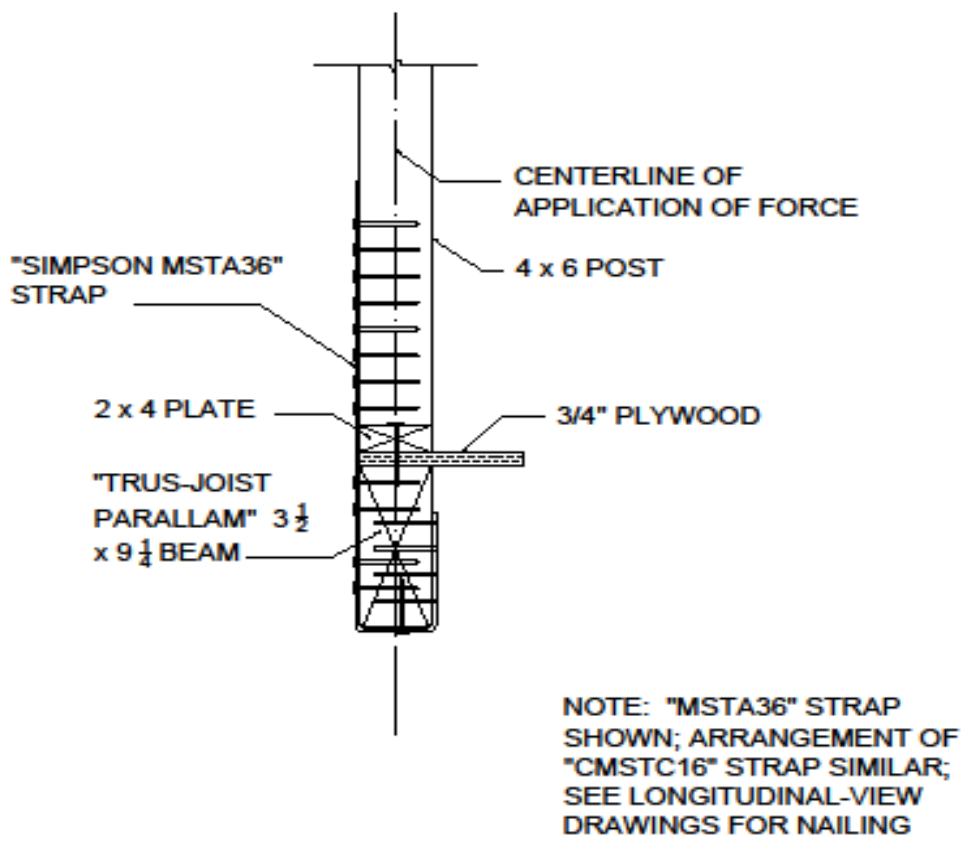

Figure 8. Strap test specimen, Post-to-Beam, MSTA36 strap (TSM2) - transverse elevation view.

Additional steel framing was used in order to transfer the load in the beam to the UTM at the bottom. The wooden beam was attached to a steel beam by means of steel plates, which were intentionally spread along the length of the beam from the strap, so that the wooden beam would have shear and torsion similar to a beam in the same situation in a real building installation. The steel plates were welded to a rectangular tube (HSS) steel section, oriented parallel to the wooden beam. A nut was welded to the tube at a position in order to be aligned with the centerline of the post above.

The strap was installed as follows: The upper portion of the strap was attached to a post by means of nails, similar to the Post-to-Post connection. The lower portion of the strap was bent in the laboratory, wrapped partially around the beam, and attached to the beam on both sides and on the bottom, using nails, which is not, based on catalog 
information, what the manufacturer intended. The load path for vertical tension passed through the upper post, then through nails which transferred the load from the post to the strap, then through the strap only, then into the beam where the load divided into two (presumably) equal parts as shear, then through the metal plates, then through the HSS beam as shear, where the two partial loads were re-united at the central nut.

The test specimen thus simulated a portion of an actual building, in which shear walls are vertically discontinuous, and vertical and lateral loads would need to be transferred by the floor system across a door or window opening, to some other shear wall (or walls) and posts, not represented in the specimen. Thus, the load path for this specimen differs from that of the Post-to-Post configuration.

The critical zone of strap length was located where the strap crosses between the post and the floor beam, measured from the nearest nail at the post to the nearest nail at the beam. Since the strap was directly attached to the beam, the length of strap crossing the critical zone (about 4.25 inches) was much shorter than for the Post-to-Post case. Note that strap bends are outside the critical zone for each type of strap.

For each type of strap, the same number of nails was used as in the Post-to-Post specimen, even though in the case of the MSTA36 strap the full recommended number of nails could have been used in the Post-to-Beam specimen, instead of the reduced quantity used for the Post-to-Post configuration.

In the case of the MSTA36 strap, the end of the strap that was wrapped around the beam was cut off where it would otherwise extend to the location of the floor sheathing. One of the large holes in the MSTA36 strap was located adjacent to the post at the 
location corresponding to that of the Post-to-Post specimen, while the other was located on the back side of the beam, separated from the critical zone by six nails. At the corners of the beam, each strap was bent by hand, simulating what is presumably the most likely practice by contractors in the field. The radius of bend was measured as approximately one-quarter inch at one of the two bends, and about three-eighths inch at the other.

3.2.3 Re-use of specimens. Each specimen was fabricated with a MSTA36 strap. The specimen was mounted in the UTM and was tested. After the test was completed, the MSTA36 strap was removed. A CMSTC16 strap was installed at each specimen after removing the MSTA36 strap. Different nail locations were used for the CMSTC16 straps. After installation of the straps, the CMSTC16 specimens were mounted in the UTM and tested.

Table 1

Strap Nailing

\begin{tabular}{cccc}
\hline Type of strap & Experiment ID & $\begin{array}{c}\text { Number of nails, } \\
\text { each end of strap }\end{array}$ & Type of nails \\
\hline Simpson MSTA36 & TSM1. Post-to-Post & 8 & $10 \mathrm{~d}$ common \\
& TSM2. Post-to-Beam & 8 & $10 \mathrm{~d}$ common \\
Simpson CMSTC16 & TSC1. Post-to-Post & 25 & $16 \mathrm{~d}$ sinker \\
& TSC2. Post-to-Beam & 25 & $16 \mathrm{~d}$ sinker \\
\hline
\end{tabular}

Note. In each case, all of the nails of the upper end of a strap are attached to a post; all of the nails at the lower end are attached to a beam in the Post-to-Beam cases and to a post in the Post-to-Post cases.

\subsection{Testing Arrangement}

In each of the configurations described above, the top of the specimen was attached to the upper head of the UTM, and the bottom of the specimen was attached to the lower head. In each case, four bolts were threaded through the post and the "collar" assembly 
described above, located at the top of the specimen. In the Post-to-Post case, the lower post was attached to a collar in the same way. Threaded rods were attached to the collar devices. The rods were attached to the UTM by passing them through large holes built into the heads, and securing them with assemblies of steel plates and nuts. In the Post-toBeam case, a threaded rod was inserted into the nut at the HSS section and attached to the lower head of the UTM by the means described above.

Table 2

Test Matrix

\begin{tabular}{cccc}
\hline Experiment ID & Arrangement of strap & Type of strap & Loading protocol \\
\hline TSM1 & Post-to-Post & Simpson MSTA36 & applied displacement \\
TSM2 & Post-to-Beam & Simpson MSTA36 & applied displacement \\
TSC1 & Post-to-Post & Simpson CMSTC16 & applied displacement \\
TSC2 & Post-to-Beam & Simpson CMSTC16 & applied displacement \\
\hline
\end{tabular}

Note. Displacement referred to is that of the lower head of the UTM.

\subsection{Instrumentation}

The following instruments were used for data collection:

Load cell - A 25-kip (25,000 pounds) load cell was used to measure the force induced in the specimen by the displacement of the UTM.

Wire potentiometer - A potentiometer, which uses a wire stretched between two points and mounted on a rotating spool at one end, in order to measure the change in distance between the points, was used to measure the elongation of the strap.

Both instruments measured and reported the relevant quantities by measuring changes in voltage. The gauges were calibrated, and were installed as follows: 
Post-to-Post configuration - A load cell was connected in-line to the threaded rods near the upper head, so that the load path passed through the cell. In addition, a wire potentiometer was attached to the lower post below the bottom of the strap. The gauge wire of the potentiometer was stretched to a nail installed at the upper post above the top of the strap. See Figure 9. 


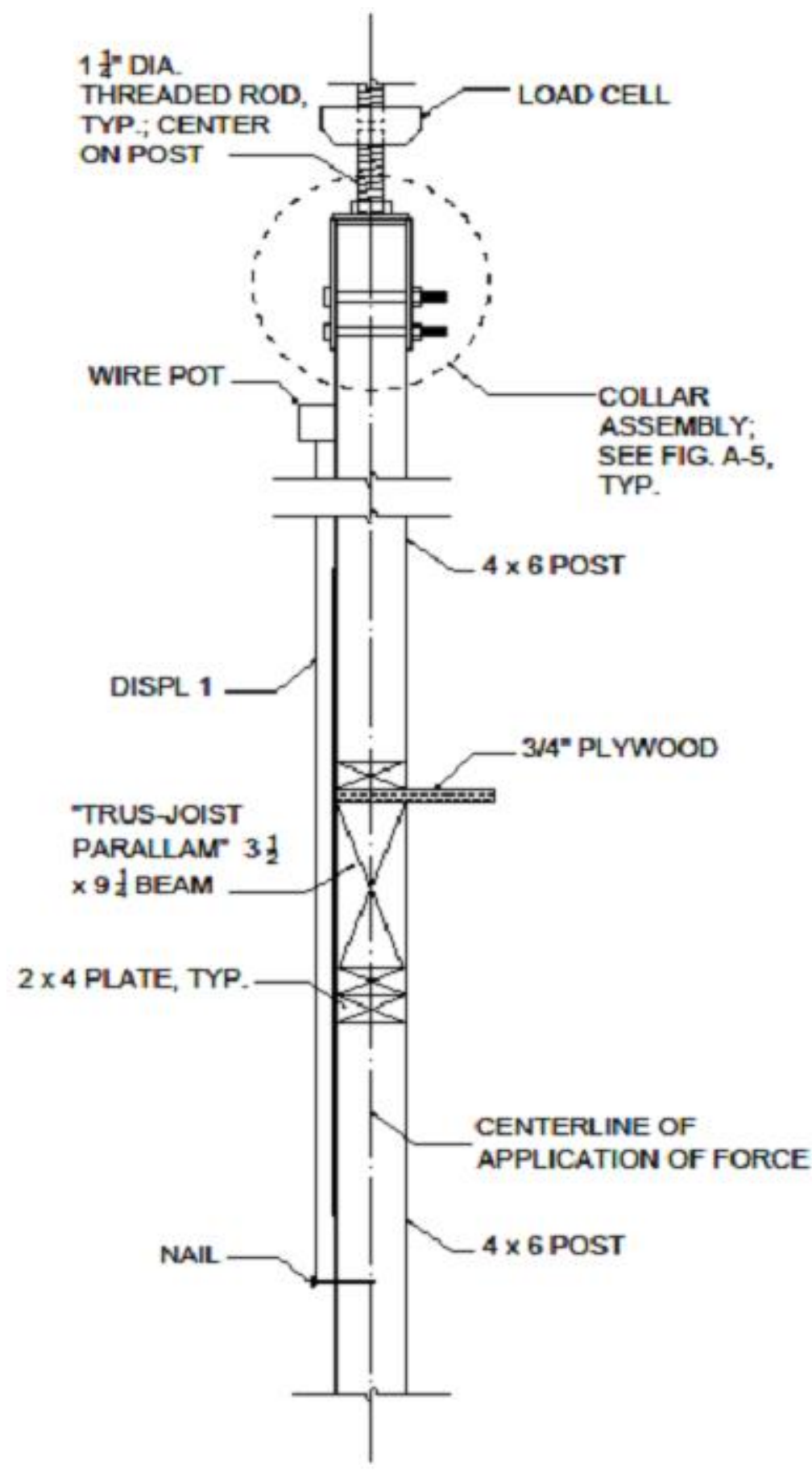

Figure 9. Instrumentation, Post-to-Post - transverse elevation view.

Post-to-Beam configuration - A load cell was connected to the threaded rods similarly to the arrangement for Post-to-Post. A wire potentiometer was attached to the upper post 
above the top of the strap. The wire was extended to a magnet attached to the HSS beam. See Figure 10.

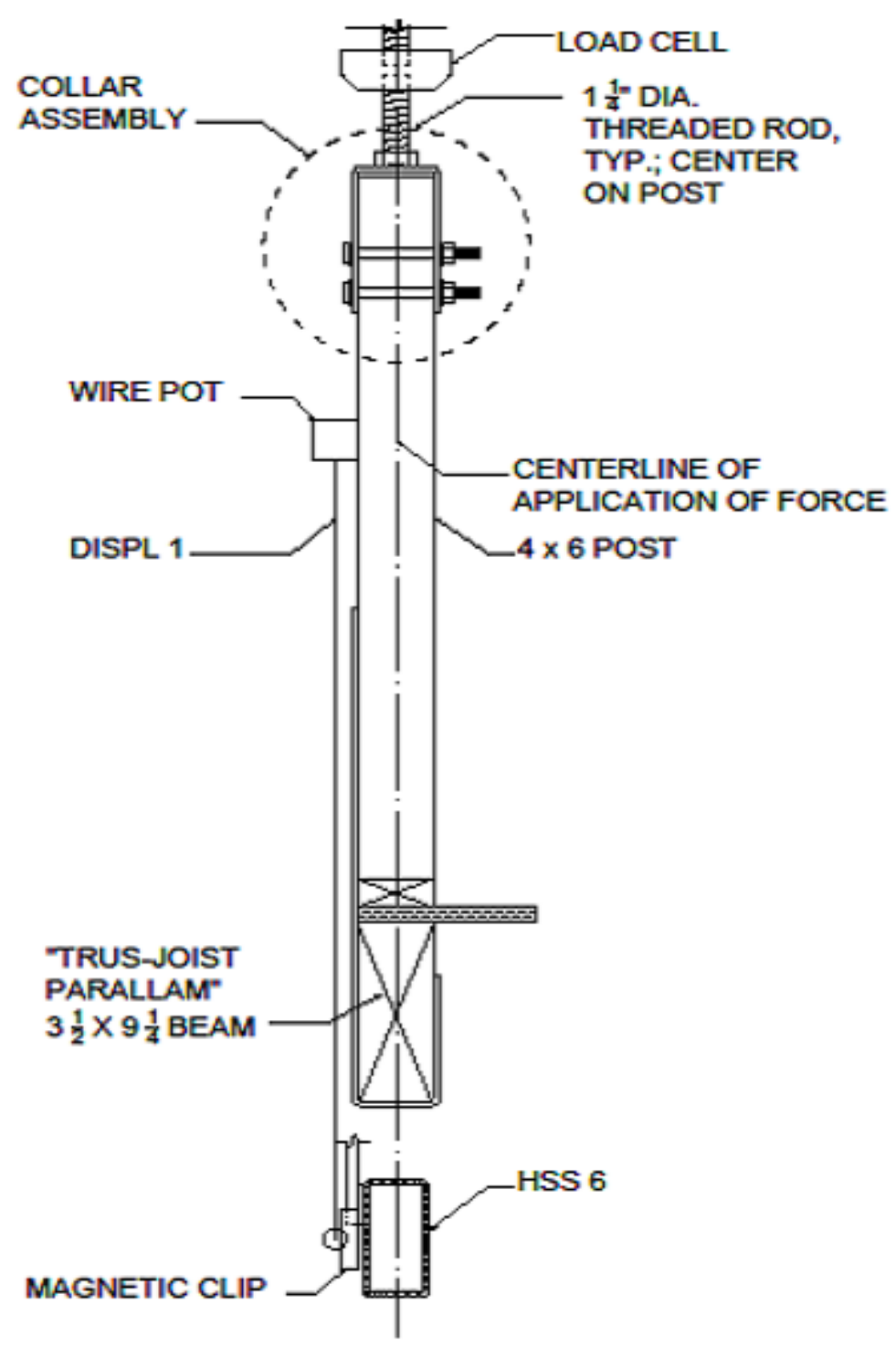

Figure 10. Instrumentation, Post-to-Beam - transverse elevation view.

In each case, wires were attached from the load cell to a data-acquisition system, so that the actual applied force could be measured and recorded. In each case other electric wires were connected between the wire potentiometer and the same system, so that the 
elongation of the straps could be measured and recorded. The computer in the system produced a log of simultaneous readings of forces and elongations.

Table 3

Instrumentation

\begin{tabular}{cccc}
\hline $\begin{array}{c}\text { Channel } \\
\text { number }\end{array}$ & Item & Instrument & Calibration factor \\
\hline 1 & force & load cell; SN 55994 & -10000 \\
2 & strap displacement & wire potentiometer; & +2.32 \\
& & SN B1052679 & \\
\hline
\end{tabular}

\subsection{Testing Procedure}

Each specimen was stretched by lowering the lower head of the UTM, in order to apply tensile force. The straps were tested monotonically, that is, originally a small amount of elongation, inducing a relatively small force, was applied to each specimen, and the resulting displacement was then measured. Additional elongations were applied, inducing incremental amounts of force, each time measuring the displacements, until the fracture became evident, usually by observing a rapid and significant decrease of tension reported by the instruments. The fact that the fracture had occurred and had extended completely across the strap was then verified visually. Hysteretic loading was not performed, that is, no attempt was made to perform cycles of loading and unloading.

\subsection{Modes of Failure}

There are several possible ways in which one of the specimens could reach a failure condition: 
- Fracture of the steel strap through nail holes after yielding of the strap in tension (the preferred mode of failure in each case, since it would test the strength of the strap)

- Crushing of wood in immediate vicinity of nails

- Failure of nails, either by pulling out of wood, or by shearing off the pin portions, or by shearing off the heads and pulling through the straps

- Tensile failure of a post, with bending

- Failure of the beam by shear or by bending

- Fracture of the strap at a bend in a Post-to-Beam case; bending the metal strap at the corners of the beam may weaken the metal there and cause failure of the metal at the bends

- Crushing of the wood in the beam at the corners where strap is bent

- Failure of the bolts at the post-to-collar connection, or at the beam-to-large-steelplate connections (in Post-to-Beam specimen), or failure of the large steel plates in tension and bending; these would be unacceptable failure modes, as they would represent failure to duplicate, in the specimen, actual building conditions.

Because of the geometry of the specimens in some of the tests, two other possibilities for failure, besides those listed above, are added for those tests only:

- Torsional failure of the beam, in Post-to-Beam tests: Because in each Post-toBeam specimen the strap was wrapped around the beam, the force from the strap was eccentrically applied to the beam, which caused twisting. Thus, the beam could fail in torsion. This possibility deserves special consideration, since, 
theoretically, wood has no resistance against torsion. Neither the California Building Code (California Building Standards Commission, 2013) nor the National Design Specification (NDS) for Wood Construction with Commentary (American Wood Council, 2015a), in their current editions, allows for wood strength in torsion, nor did Trus-Joist Parallam Plus PSL Specifier's Guide (Weyerhaeuser NR Company, 2017), the manufacturer's design information for the beam. It is assumed that shear and torsion in the beam would interact with each other, causing failure sooner than it would occur by either mode alone. For the engineered-wood beam that was used, torsional shear unit strength was assumed to be exactly equal to ordinary unit shear strength; as will be seen, this assumption seems reasonable

- A hybrid form of failure, in tests with MSTA36 straps: At the MSTA36 straps, because of the large holes noted, the strap could fracture across the narrow sections of strap at one of the holes, and the two nails located between the hole and the end of the critical zone could continue to resist load.

The mechanism of failure for each test specimen was noted. Since the specimens had been loaded monotonically, under some possible modes of failure, signs of distress could have been evident before the failure itself happened. Evidence of particular modes of yielding or failure in the specimens would likely appear as follows:

- Yielding of the strap, if it occurs, would be indicated by elongation of the strap, which would be expected to be greatest in the region of greatest load, that is, where the strap crosses the floor beam or plates (in the post-to-post specimen) or 
the top plate (in the post-to-beam specimen), and measured by the wire potentiometer. This would be a ductile failure, and evidence of movement would be expected to appear gradually. In this situation, the strap would be permanently elongated.

- Fracture through the holes of the strap would be indicated by observing an actual break in the strap. Elongation of the strap will accompany fracture, if that occurs. After the break occurs, the strap should be permanently elongated, indicating that yielding had occurred through the gross section before the fracture happened.

- Failure of nails by local crushing of the wood would reveal itself if such damaged wood were observed immediately adjacent to the nails, as well as elongation of the nail holes at the surface of the wood. In addition, the strap would have moved with respect to the posts and/or beam. Gradual movement as measured by wire potentiometer could be expected in this case.

- Nail failure by shearing the nails themselves would have been shown by the fractured nails, but could have been sudden.

- If the column had failed, the wood would have broken through. While the column might show some lengthening first, this probably would be a sudden, brittle failure.

- If the beam had failed in shear, the wood would have broken through. This would have been a sudden, brittle failure.

- Failure by bending of the beam was very unlikely, since, due to the short beam span, some other type of failure would almost certainly have occurred first. 
- If the beam had failed in torsion, or by a combination of shear and torsion, the wood would have broken through in a failure somewhat similar to that for shear alone. The torsion would have revealed itself by a twisted failure surface, different from that due to shear alone.

- Some of the nails used to attach the strap to the beam in the Post-to-Beam configuration were on the front of the beam, and some were on the back; therefore, the portions of strap which were bent were outside the critical zone, and did not carry the full strap force. Load must develop in the strap at the corners of the beam before failure of the strap at the corners of the beam could occur. Therefore, even though bending the strap may weaken it, the strap still may have enough capacity to resist failure at that location. Thus, in order that a failure should occur at the bend, it would need to happen at much less than the full strap load, or else the nails between the critical zone and the bend would need to have slipped so much that they no longer transferred significant loads.

\subsection{Predicted Results}

Calculations were made as part of this project, before building the specimens. These calculations are reproduced in Appendix B. They were done for two reasons:

- To predict the failure mode, and

- To try to ensure that, except as described below, the failure would occur in the strap and not somewhere else in the specimen.

Were the failure to occur anywhere but the strap (or the beam, in the specimens that had a beam), the thesis of the research would not have been tested. To the extent that 
inappropriate failure mechanisms were uncovered, the designs of corresponding portions of the specimens were strengthened in order to exceed predicted strap capacity. The exceptions to the rule were:

- If the strap had been found by calculation to be stronger than the total capacity of the strap nailing that was recommended by the manufacturer, that discrepancy would have been allowed to stand.

- The torsion capacity of the beam was unknown, and none was allowed by design standards (see Section 3.6). Since the Post-to-Beam specimen simulated a real situation in which torsion could occur, and since the uplift-restraint system could fail as a result of torsion in the beam, an estimate was made of the torsional strength of the beam.

- The steel plates connecting the beam to the HSS section, already relatively large, were not made still larger.

The standards used for calculation were as follows:

- Simpson Strong-Tie Company (2017), catalog information, for the strap connectors themselves;

- American Wood Council (2015), for ordinary wood members, and for nailed and bolted connections in wood, including the engineered-wood beam; where calculations for the connections in the beam were conducted, Douglas Fir-Larch lumber was assumed for use of tables in NDS Chapter 12;

- Weyerhaeuser NR Company (2017), for the engineered-wood beam, except as noted above; 
- American Institute of Steel Construction (2010) (ANSI/AISC 360-10), for the steel mounting hardware.

The values given in Tables $12 \mathrm{P}$ in the NDS for nail shear capacity, and Tables 12B and $12 \mathrm{G}$ in the NDS for bolt shear capacity for single shear, were considerably less than the values that were determined using the applicable equations provided in the text of the NDS Chapter 12. Because of this, capacities computed by equations were used instead of table values.

For both the MSTA36 and CMSTC16 straps in the Post-to-Post configuration, the straps were predicted to fail before any other possible structural element. In the Post-toBeam configuration, the MSTA36 strap was predicted to fail first in the testing of the relevant specimen; for the CMSTC16 strap, the steel plates connecting the wooden beam with the HSS beam were predicted to fail first, in a combination of tension and bending; however, this mode of failure did not occur.

A calculation was performed in order to be able to verify whether a particular strap had yielded at the time of fracture. This was done by assuming the effective length for straining to be equal to the sum of the length of the critical zone plus one-fourth of the nailing length at each end, then multiplying that value by the yield strain of the straps. This procedure assumes uniform strain over this extended length, and attempts to account for the fact that the force in the strap varies from one end of the nailed length to the other. Yield strain in straps was predicted to be 0.0017. Calculations are in Appendix B.

The allowable-stress design (ASD) method was used to predict the allowable capacities of the structural members. In the ASD method, the measured yield or fracture 
strengths of the various materials have been divided by safety factors in order to determine allowable stresses which are published, or in the case of the straps, allowable tension forces. These safety factors may vary among wood, steel, fasteners, straps, etc. Except in the case of steel plates, welds and the HSS tube, the actual safety factors of members considered in calculations were not known; thus, the real yielding or fracture capacities of the wood members, the straps and the fasteners were not fully predictable from the information used. 


\section{Experimental Results}

\subsection{Behavior of Test Specimens}

The CMSTC16 straps in both configurations broke in nearly straight lines across the straps in the critical zones. Each fracture line included two empty nail holes. No significant nail slip nor other signs of distress, other than the fracture itself, was observed anywhere in the specimens. Elongation was observed in each strap.

The MSTA36 straps in both configurations failed in a "hybrid" manner: Each broke at the net-area portions of the strap through the large (1/2-inch-diameter) hole located alongside a post (the upper post at Post-to-Post specimen). Since there were two nails in the portion of each strap between the large hole and the end of the critical zone, those two nails slipped in the wood. Thus, while the portion of each strap in the critical zone was carrying the full applied strap force, this full load was divided between the narrow portions of strap at the large hole (which apparently transferred most of the force), and the two nails mentioned. Elongation occurred in each strap, both at the large hole that broke through and elsewhere.

A steel structural member may continue to elongate after reaching a maximum load resisted, but without breaking, while the load being transferred is gradually decreasing. For this reason, the displacement recorded in Table 4 is the value that was recorded at the time at which maximum force was measured. 
Table 4

Test Results

\begin{tabular}{ccccc}
\hline $\begin{array}{c}\text { Experiment } \\
\text { ID }\end{array}$ & $\begin{array}{c}\text { Maximum } \\
\text { force, lbf. }\end{array}$ & $\begin{array}{c}\text { Displacement at } \\
\text { maximum force, in. }\end{array}$ & $\begin{array}{c}\text { Failure } \\
\text { type }\end{array}$ & Test date \\
\hline TSM1 & 4,932 & 0.500 & B & Feb. 28, 2018 \\
TSM2 & 5,090 & 0.494 & B & Feb. 23, 2018 \\
TSC1 & 12,316 & 0.306 & A & Mar. 5, 2018 \\
TSC2 & 11,847 & 0.328 & A & Feb. 27, 2018 \\
\hline
\end{tabular}

Note. Displacement shown in this table is the recorded value that occurred at the time at which maximum applied force was recorded. Failure types are: A. Fracture at strap, at net area through nail holes in critical zone. B. Hybrid break: fracture of strap at net area through large hole, with participation of two nails; see Section 4.1.

Note that the experiments treated in this thesis are among a larger group of tests performed under the direction of Professor Kurt McMullin. McMullin uses a system of nomenclature for all of the experiments that he conducts, including those discussed in this thesis. The experiment identifications used in this thesis were chosen for the purposes of brevity and clarity. Concordance between the nomenclature used in this thesis and that reported in other documents by McMullin is shown in Table 5.

Table 5

Corresponding Nomenclature

\begin{tabular}{cl}
\hline Experiment ID & \multicolumn{1}{c}{ McMullin Experiment Identification } \\
\hline TSM1 & MSTA36_18-2-28 - Post to Post \\
TSM2 & MSTA36_18-2-23-RunNo2 - Post to Beam \\
TSC1 & CMSTC16_18-3-5 - Post to Post \\
TSC2 & CMSTC16_18-2-27 - Post to Beam \\
\hline
\end{tabular}




\subsection{Results of Individual Tests}

4.2.1 TSM1. The MSTA36 strap broke in the hybrid fashion described in Section 4.1. This was not exactly what was predicted, since the failure did not occur entirely in the critical zone. The effects of the large holes in the failure mode were inadvertently ignored in the preliminary analysis. Nonetheless, this was a ductile form of failure as described in the discussion of elongation below. Moreover, the fracture at the strap alongside the large hole was similar to what was predicted, in that elongation occurred in the metal there. Since there were two nails in the portion of each strap between the large hole and the end of the critical zone, those two nails slipped in the wood. Elongation occurred elsewhere in the strap as well.

The strap transferred a maximum force of 4932 pounds in the critical zone, approximately 2.4 times the rated capacity of 2050 pounds. See Figure 11 . The nails were calculated to have a capacity of 265 pounds each. Given that there were two nails located between the hole and the end of the critical zone, and assuming the same 2.4 over-strength factor (ratio of actual force carried by nails versus calculated capacity) as for the strap, the internal tensile force of the strap at this point would have been about 3700 pounds, maximum, at the net area across the large (1/2 -inch-diameter) hole before fracture. 


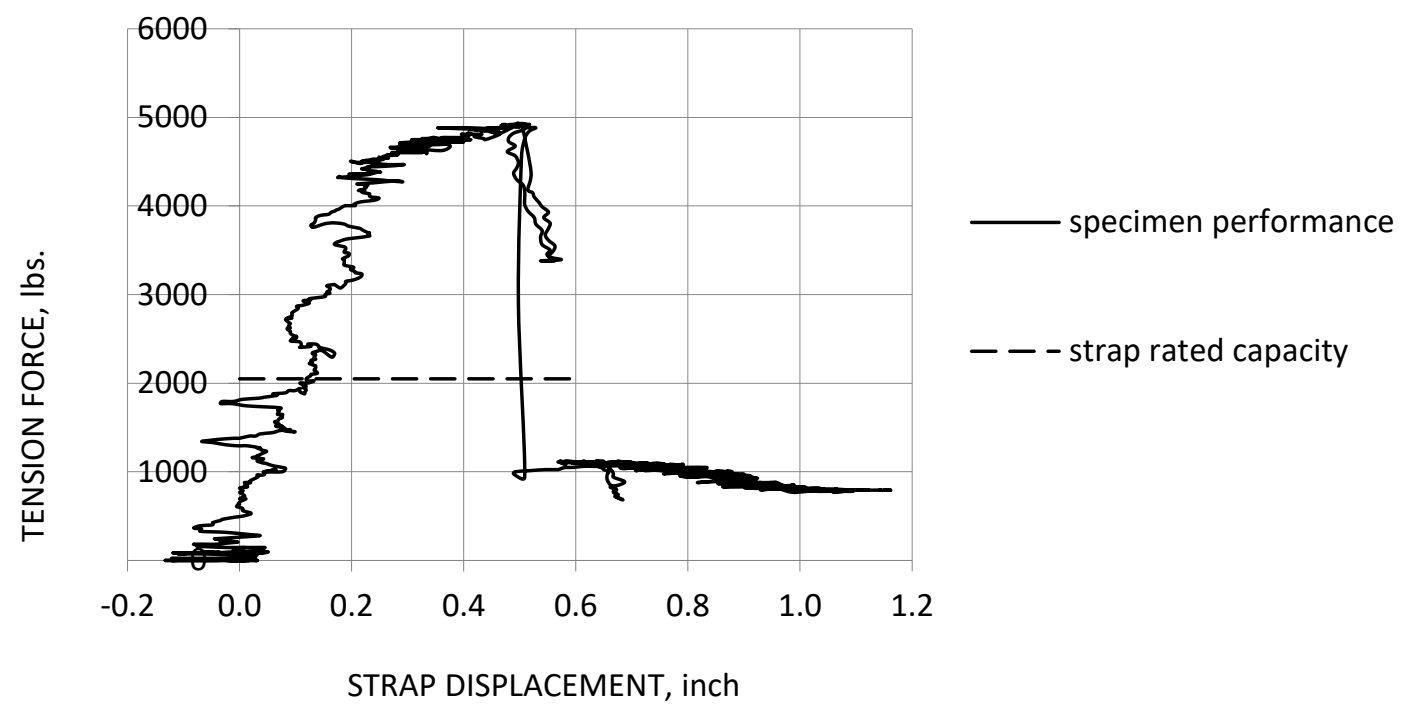

Figure 11. Tension strap experiment results - TSM1.

The specimen elongation measured at time of maximum force was 0.500 inches. The yield elongation of the strap in the critical zone calculated was equal to 0.037 inch at the Post-to-Post specimen. Approximately 1/8 inch of (measured) stretch occurred at the large hole; that amount should be added to the total calculated; nonetheless, the total elongation at yield would be approximately 0.16 inch (1/8 plus 0.037$)$, much less than that recorded at maximum force. As was noted, no significant nail slip was observed beyond the hybrid failure zone; therefore, whatever nail slip which may have occurred outside the zone without being observed cannot account for the difference between specimen elongation at yield and the elongation observed. Therefore, it is reasonable to infer that inelastic stretching occurred in the strap. The strap elongated until fracture occurred, then the force decreased rapidly until reaching a level of approximately 1000 pounds; this lower value represents the resistance of the two nails located above the critical zone which still engaged the lower fragment of the strap. 
Other than the fracture and elongation of the strap itself, and the slipping of the two nails mentioned above, no significant distress in the specimens was noted. The wooden posts and beam, the nails, and the other steel hardware used appeared substantially intact, except that there was slight localized damage from nail slippage.

4.2.2 TSM2. The MSTA36 strap broke in the same hybrid way as for TSM1. Elongation occurred in the strap, both at the large hole that broke through, and elsewhere. Again, this was not precisely what was predicted.

The strap carried a maximum force of 5090 pounds, approximately 2.5 times the rated capacity of 2050 pounds. See Figure 12.

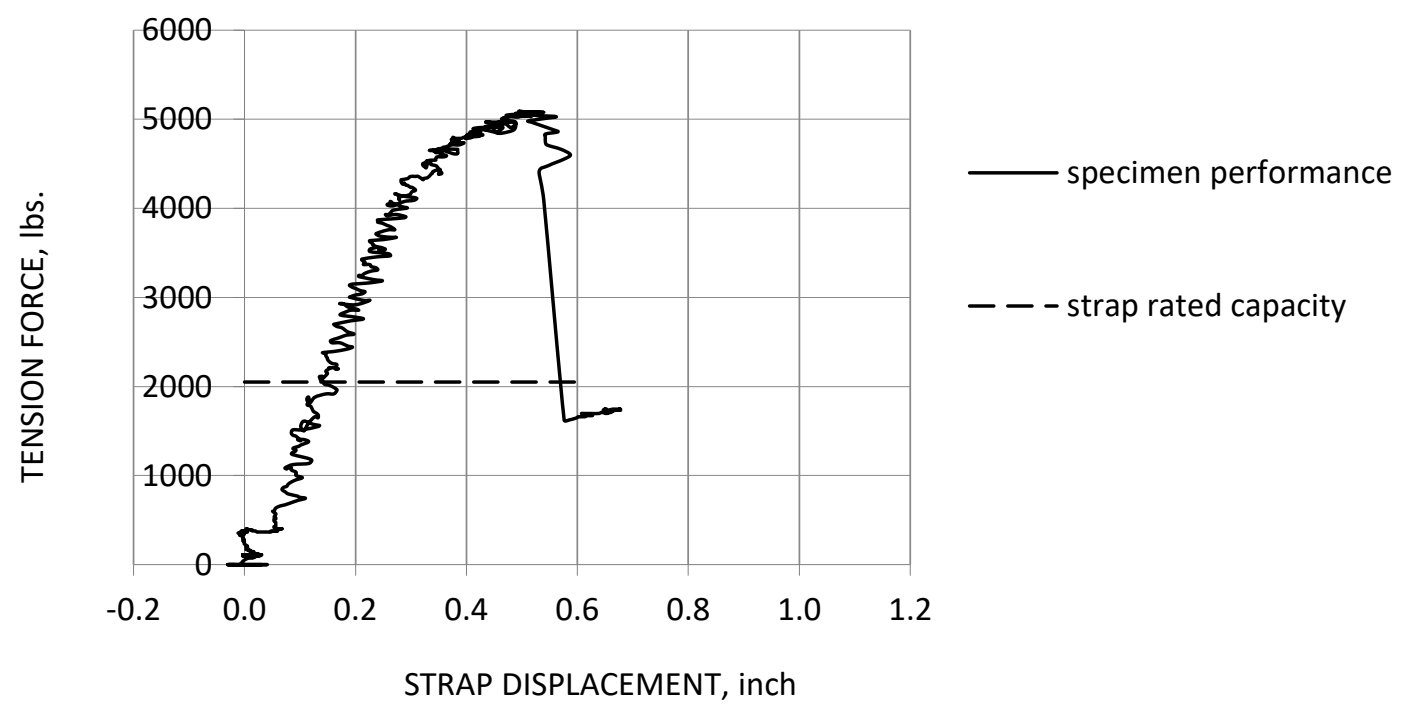

Figure 12. Tension strap experiment results - TSM2.

The elongation measured at maximum force was 0.494 inches. Yield elongation calculated was equal to 0.016 inch at the Post-to-Beam specimen. Similar to TSM1, an approximate $1 / 8$ inch of stretch that was measured at the large hole should be added to 
the total calculated; nonetheless, the total elongation at yield would be approximately 0.14 inch, much less than that recorded at maximum force.

There was no sign of distress in the beam from shear or torsion, or from a combination of the two types of stresses, suggesting that the engineered wood of the beam has some measurable torsion capacity. Similarly to TSM1, any significant distress in the specimens was limited to the hybrid-fracture zone, where strap fracture and elongation, and nail slippage, were noted.

4.2.3 TSC1. The CMSTC16 strap broke in a nearly straight line across the strap in the critical zone. There was no sign of nail slip anywhere in the specimen. Elongation was observed in the strap. This was what was predicted. This was a ductile form of failure; see discussion of elongation below.

The strap resisted a maximum force of 12,316 pounds, approximately 2.7 times the rated capacity of 4585 pounds. See Figure 13.

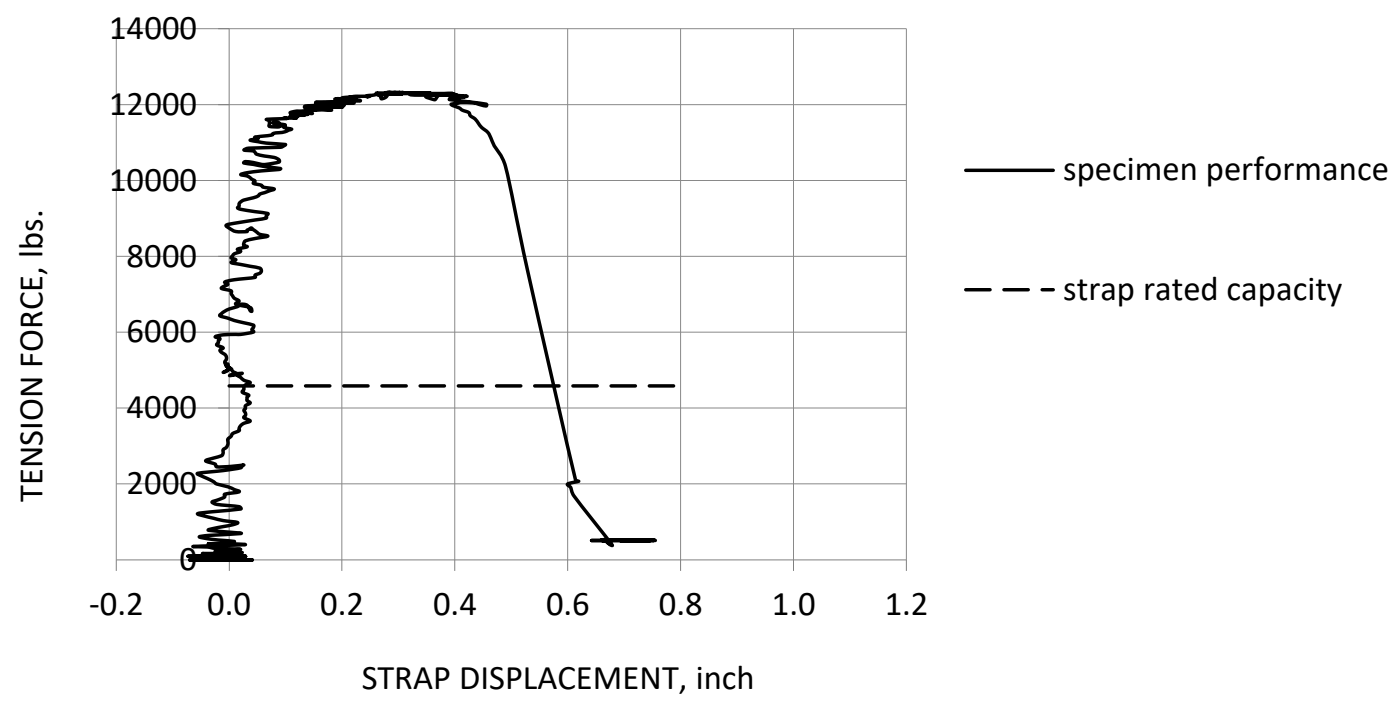

Figure 13. Tension strap experiment results - TSC1. 
The elongation measured at maximum force was 0.306 inches; yield elongation calculated was equal to 0.044 inch at the Post-to-Post specimen, much less than that recorded at maximum force.

4.2.4 TSC2. The CMSTC16 strap broke in the same way as for TSC1. Elongation occurred in the strap. This was not exactly what was predicted, in that the capacity of the steel plates attaching the wood beam to the HSS steel beam (which should have experienced bending as well as tension) was calculated to be less than that of the strap itself. The reasons why the steel plates should have endured without apparent damage, while the strap fractured, are not fully understood, but this sequence of events allowed the strap to be tested as intended. This was a ductile form of failure; see discussion of elongation below.

The strap transferred a maximum force of 11,847 pounds, approximately 2.6 times the rated capacity of 4585 pounds. See Figure 14 .

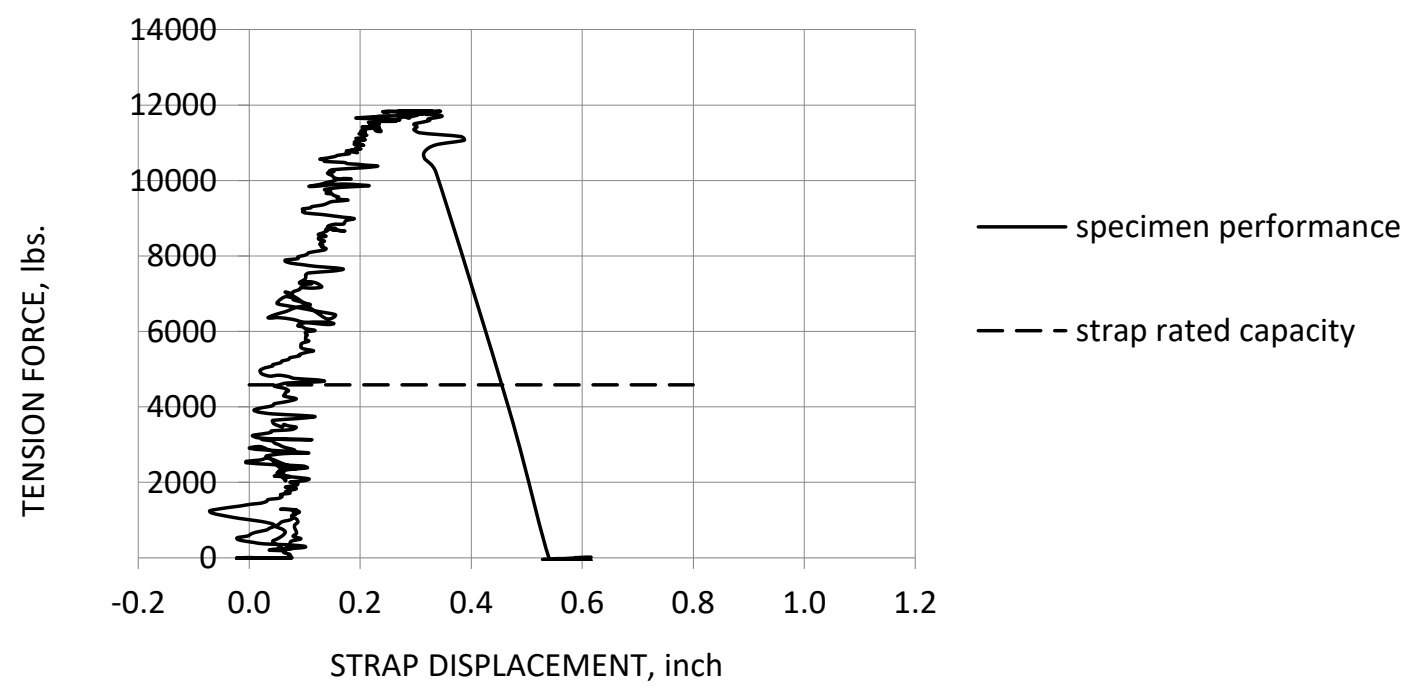

Figure 14. Tension strap experiment results - TSC2. 
The elongation measured at maximum force was 0.328 inches; yield elongation calculated was equal to 0.023 inch at the Post-to-Beam specimen, much less than that recorded at maximum force.

As was the case with TSM2, there was no sign of distress in the beam from shear or torsion, or from a combination of the two types of stresses, suggesting that the manufactured lumber of the beam has some measurable torsion capacity. By calculation, the torsional moment in the beam-and-plate assembly near the strap attachment must have been approximately 10,600 pound-inches on each side of the strap. (The nails attaching the post to the top plate may have resisted a small portion of this). At the magnitude of torsional moment calculated, the maximum torsional shear stress in the engineered-wood floor beam would have been about 335 pounds per square inch. This calculation ignores resistance of nails attaching the post to the wooden top plate, but includes strength of the wood plate as well as strength of the beam. 


\section{Comparison of Test Results}

\subsection{Similar Results of All Tests}

Failure of all of the test specimens occurred due to fracture of the straps, although in the case of the MSTA36 straps, as was seen, the failure mode was slightly complicated. All of the straps failed at a measured force at least 2.4 times the rated capacity. All the tests lasted at least three minutes before reaching maximum force. All of the straps elongated at least three times the predicted yield elongation; in the case of the CMSTC16 straps, the elongation was at least seven times the yield, thus confirming ductile failure.

The wooden beam in the Post-to-Beam specimen did not fail, nor did it appear distressed, even though torsion of the beam must have occurred.

There was no sign of distress in the posts of either specimen, though none had been expected.

Most nails showed little or no effect of being loaded. The exception is that in each MSTA36 strap, the two nails located between the large hole where fracture occurred and the critical zone (see TSM1 and TSM2 results) showed incipient failure in slipping or withdrawal. Few of the nails in the MSTA36 straps showed evident damage, even though the straps were installed with fewer nails than required by the strap manufacturer. Nail slip was not a problem, except that the two nails in each specimen compromised by the large holes of the MSTA36 straps slipped.

The tension-with-bending failure predicted for the large steel plates joining the wooden and steel beams in the Post-to-Beam configuration of CMSTC strap loading did not occur. 
The straps all yielded before fracture occurred, based on comparison with our calculated yield displacements, thus demonstrating ductility.

The fact that, in both cases, each of the two straps of a particular type failed at a load that was within 4 percent of that of the other of the same type suggests mere random variation. It also emphasizes the predominance of the steel fracture mode which occurred in the critical zones, independent of any damage which may have occurred as a result of bending the straps while they were at room temperature.

Elongation of the specimen by lowering the lower head of the UTM had the general effect of increasing the force, but the relationship was not linear. When the elongation was originally applied in each case, the force increased relatively rapidly; after a while, the forces increased more slowly, then leveled off even as the elongation continued to increase. Finally, the strap fractured, and the force decreased immediately. In the case of the CMSTC straps, force declined to zero, or nearly so. For the MSTA straps, the force declined to a larger value, approximately 1000 pounds; this difference was due to the continued resistance provided by the two engaged nails.

\subsection{Comparison between Individual Tests}

Failure of all of the test specimens with CMSTC16 occurred at maximum forces about 2.4 times that of the MSTA36 straps, though, as mentioned, two nails carried a portion of the force in each of the MSTA36 specimens. The larger straps were of the same thickness as were the smaller ones, but were about 2.4 times as wide. The MSTA36 straps might have been expected to have a smaller capacity than was the case, 
due to the large holes, even allowing for the participation of the nails in transferring loads.

The two CMSTC16 straps broke in nearly straight lines across the straps in the critical zones. Each break line included two empty nail holes.

The two MSTA36 straps broke in the "hybrid" way described: across the two narrow $(3 / 8$-inch-wide) portions of the strap adjacent to the large hole that was located about $31 / 4$ inches above the post-to-top-plate joint. The two nails in the portion of each strap located between the large hole and the end of the critical zone slipped in the wood. 


\section{Conclusions and Recommendations}

\subsection{Results of Original Research Objectives}

The specific research objectives, and the relevant conclusions reached, were:

1. To design two different testing configurations to evaluate the strength and ductility of steel straps used for connecting wood members, one of which represented a control case. This was done, and the specimens performed adequately.

2. To identify and review published research reports of similar connections. Several reports were found of experimental studies and/or computer simulations regarding wood shear walls and their connections, which are briefly described in Chapter 2. A manufacturer's guide describing bent steel straps was located; other than that, no research was found specifically describing field-bent steel strap connectors for wood construction.

3. To conduct experiments to quantify the strength and ductility of the straps in alternative installations. This was done, for two different sizes of straps, in the one experimental situation envisioned. The tentative conclusion is that bending the strap around the bottom of the beam did not significantly affect the effective strength of the connection. Since only one experimental (as opposed to control) test was done for each of only two types of straps, it can be said that this function has not been completed to a sufficient degree in order to have confidence in the results. 
4. To observe and record the mode of failure in each instance. This was done. In each instance, the straps themselves (both in experimental and in control situations) failed before any other mode, though, as mentioned, with MSTA36 straps, the nails participated in the failure mode.

\subsection{Conclusions}

For each type of strap, exactly one experimental test and one control test were performed. This is much too small a sample from which to infer a definite conclusion. In order to have a valid statistical base of reference, there would need to be a large enough sample to yield a standard deviation for each of load and displacement for each type of specimen, and that deviation would need to be narrow enough to reach meaningful inferences. In this case there is by definition no statistical deviation.

For the most part, the test specimens failed in such a way as to imply that the bent straps, installed as they were, were capable of carrying as much force as the straight ones installed in accordance with manufacturer's instructions. Moreover, in each case the strap was experimentally demonstrated to be the "weak link" of its respective load path, even in the CSMTC16 Post-to-Beam case in which another part of the specimen had a lesser calculated capacity.

Most important, if bending the steel straps at the corners of the beam in the Post-toBeam specimen had contributed to weakening the straps to a critical degree, one would expect to observe failure of the straps at one of those locations, but the failures did not occur there. Moreover, the nails at the front face of the beam (nearest the critical zone) would have slipped if that type of failure, or local crushing of the wood at the corners of 
the beam, had occurred, and neither nail slippage nor crushing appeared to happen. The effective capacities of the straps did not appear to be reduced by the action of bending them. That is to say, the load carried by the bent straps through the critical zones was nearly the same as that of the un-bent straps of the same type, as discussed in Section 5.1 above. Although the strength of the straps may have been less at the bends than in the critical zones, the straps were not required to transfer the full strap loads at the bends, because the nails to the beam nearest to the critical zone could transfer part of the strap loads. Whether the strap capacities were reduced at the bends is not known, since the independent tests which would be required to determine such a reduction were not performed.

Though it was not an objective of the experiments, the experimental results tentatively imply that the engineered-wood beam has some measurable torsion capacity. No attempt was made to test whether a similar statement could be made about beams made of ordinary naturally-grown wood.

Though not nearly enough tests were run in order to be conclusive, the results suggest that metal straps may in some cases be used effectively in bent configurations in which the strap is wrapped around a beam, provided that the bends do not lie within a critical zone as defined in Section 3.2 of this thesis.

\subsection{Recommendations for Continuation of Research}

It should be emphasized that the conclusions of this thesis are preliminary and should not be relied upon without further validation. Clearly, many more tests of the straps in wrap-around configurations need to be performed in order to confirm the tentative 
conclusions. The tests should be run with beams of different sizes, and straps, not only of different sizes but manufactured by different companies, in order to establish empirical and statistical confidence, if in fact such confidence is warranted. If further testing does not corroborate these preliminary conclusions, then straps bent in the way that has been done here should not be used.

At the same time, a wrap-around configuration depends on torsional strength in the beam, as much as it does the strength of the strap. The magnitude of this beam strength has not been established with any more confidence than the experimental objective regarding straps has been. If the straps are to be used in wrap-around configurations, then an allowable unit torsional strength of wood must be assigned for each type of wood to be used, whether natural or engineered. In order to do that, many more experiments testing beam torsional strength must be performed. At the same time, a distinction must be made between natural and manufactured lumber in conducting these experiments. In order for beams of either type to be used in these bent-strap-wrap-around applications, tests must be done on beams of various cross-sections, in order to establish allowable torsion stresses. Results of tests done on either type of wood would apply only to that type, and even more narrowly, would apply only to natural beams of the species tested, or manufactured beams from the particular manufacturer. Unless or until further tests show reliable torsional strength, the bent-strap configuration should not be used. 


\section{References}

American Institute of Steel Construction. (2010). Specification for structural steel buildings (ANSI/AISC 360-10). Author.

American Institute of Steel Construction. (2003). Manual of steel construction - load and resistance design, third edition: Author.

American Wood Council. (2015a). National design specification (NDS) for wood construction with commentary (ANSI/AWC NDS-2015). Leesburg, VA: Author.

American Wood Council. (2015b). National design specification (NDS) supplement: Design values for wood construction. Leesburg, VA: Author.

ASTM International. (2017). Standard specification for steel sheet, zinc-coated (galvanized) or zinc-iron alloy-coated (galvannealed) by the hot-dip process (A653/A653M - 17). West Conshohocken, PA: Author.

California Building Standards Commission. (2013). 2013 California building code California code of regulations, Title 24, Volume 1 of Part 2. Sacramento, CA: Author.

Fischer, D., Filiatrault, A., Folz, B., Uang, C-M., \& Seible, F. (2001). Shake table tests of a two-story woodframe house (CUREE Publication No. W-06). Richmond, CA: Consortium of Universities for Research in Earthquake Engineering.

Mahaney, J. \& Kehoe, B. (2002). Anchorage of woodframe buildings: laboratory testing report (CUREE Publication No. W-14). Richmond, CA: Consortium of Universities for Research in Earthquake Engineering.

Shirazi, S. M. H. (2012). Propagation of uncertainty in light-frame wood buildings (Doctoral dissertation). Retrieved from https://tigerprints.clemson.edu/all_ dissertations/1008

Simpson Strong-Tie Company. (2016). High wind-resistant construction application guide. Retrieved from https://embed.widencdn.net/pdf/plus/ssttoolbox/ kxp9dytivz/F-C-HWRCAG16.pdf

Simpson Strong-Tie Company. (2017a). Simpson Strong-Tie wood construction connectors - CS/CMST. Retrieved from https://embed.widencdn.net/pdf/plus/ ssttoolbox/lzzzvzegka/C-C-2017-p305.pdf

Simpson Strong-Tie Company. (2017b). Simpson Strong-Tie wood construction connectors - HRS/ST/HST/HTP/LSTA/LSTI/MST/MSTA/MSTC/MSTI. Retrieved from https://embed.widencdn.net/pdf/plus/ssttoolbox/aewxjpfas4/C-C-2017p301and302and304.pdf 
van de Lindt, J. W., Pei, S., Pryor, S. E., Shimizu, H., \& Isoda, H. (2010). Experimental seismic response of a full-scale six-story light-frame wood building. Journal of Structural Engineering, 136(10). Retrieved from https://ascelibrary.org/doi/full/10.1061/\%28ASCE\%29ST.1943-541X.0000222

Weyerhaeuser NR Company. (2017). Trus-Joist Parallam Plus PSL specifier's guideTJ-7102 - October 2017. Author.

Young, Warren C., \& Budynas, Richard G. (2002). Roark's formulas for stress and strain, Seventh edition. New York: McGraw-Hill. 


\section{Appendix A. Drawings of Test Specimens}

\section{Appendix Contents}

Figure A-1. Strap test arrangement - Post-to-Post - transverse elevation view A-2

Figure A-2. Strap test arrangement - Post-to-Post - longitudinal elevation

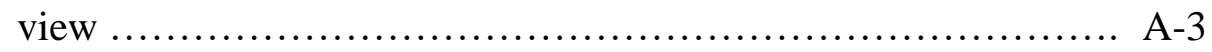

Figure A-3. Strap test arrangement - Post-to-Beam - transverse elevation

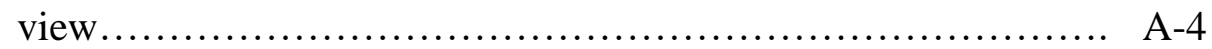

Figure A-4. Strap test arrangement - Post-to- Beam - longitudinal elevation view .................................................. A

Figure A-5. Collar assembly - transverse elevation view ................. A-6

Figure A-6. Collar assembly - longitudinal elevation view............... A-7

Figure A-7. Lateral restrainer assembly - transverse elevation view......... A-8

Figure A-8. Lateral restrainer assembly - longitudinal elevation view........ A-9 


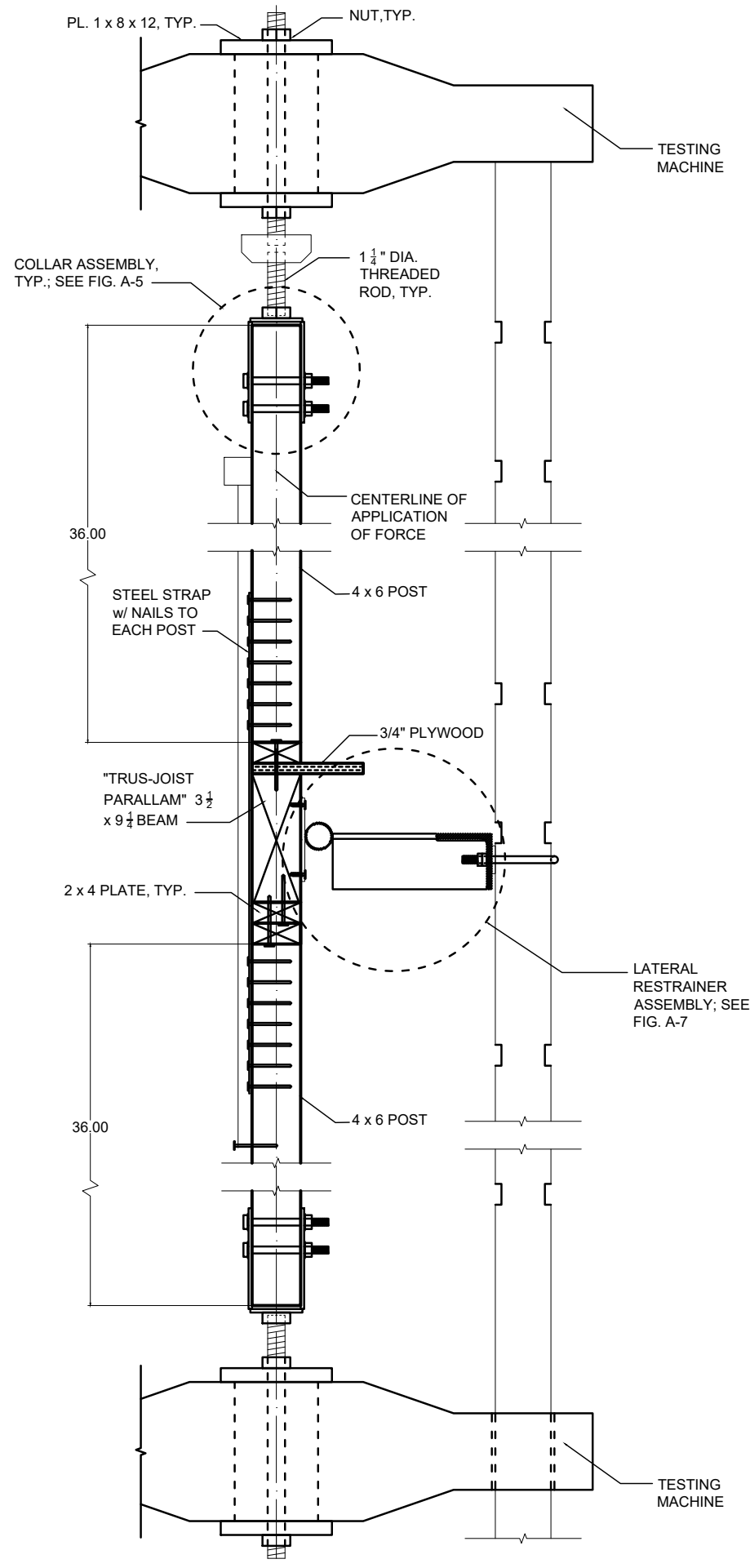

FIGURE A-1. STRAP TEST ARRANGEMENT - POST-TO-POST TRANSVERSE ELEVATION VIEW 


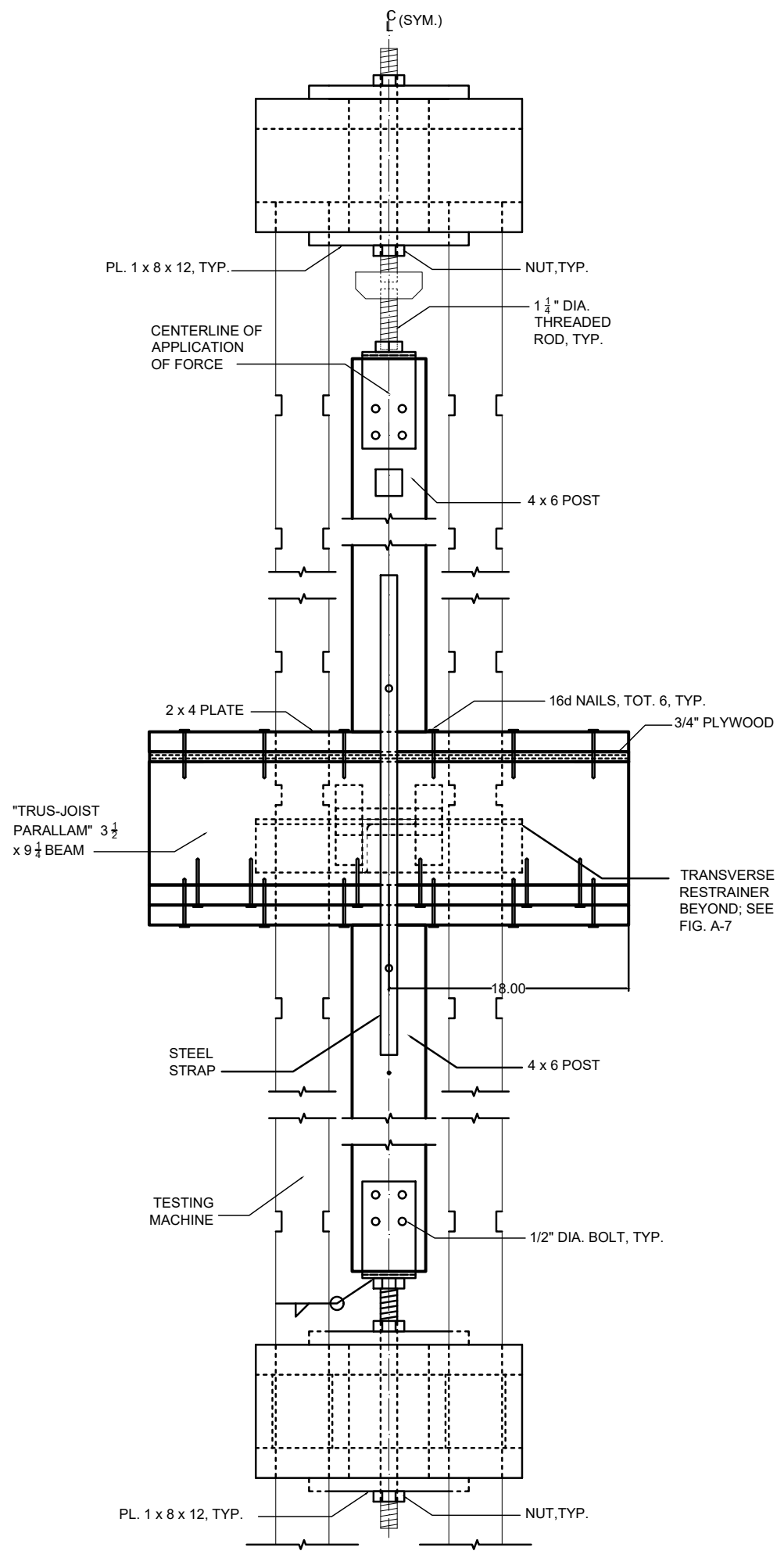

FIGURE A-2. STRAP TEST ARRANGEMENT - POST-TO-POST MSTA36 STRAP (TSM1) LONGITUDINAL ELEVATION VIEW 


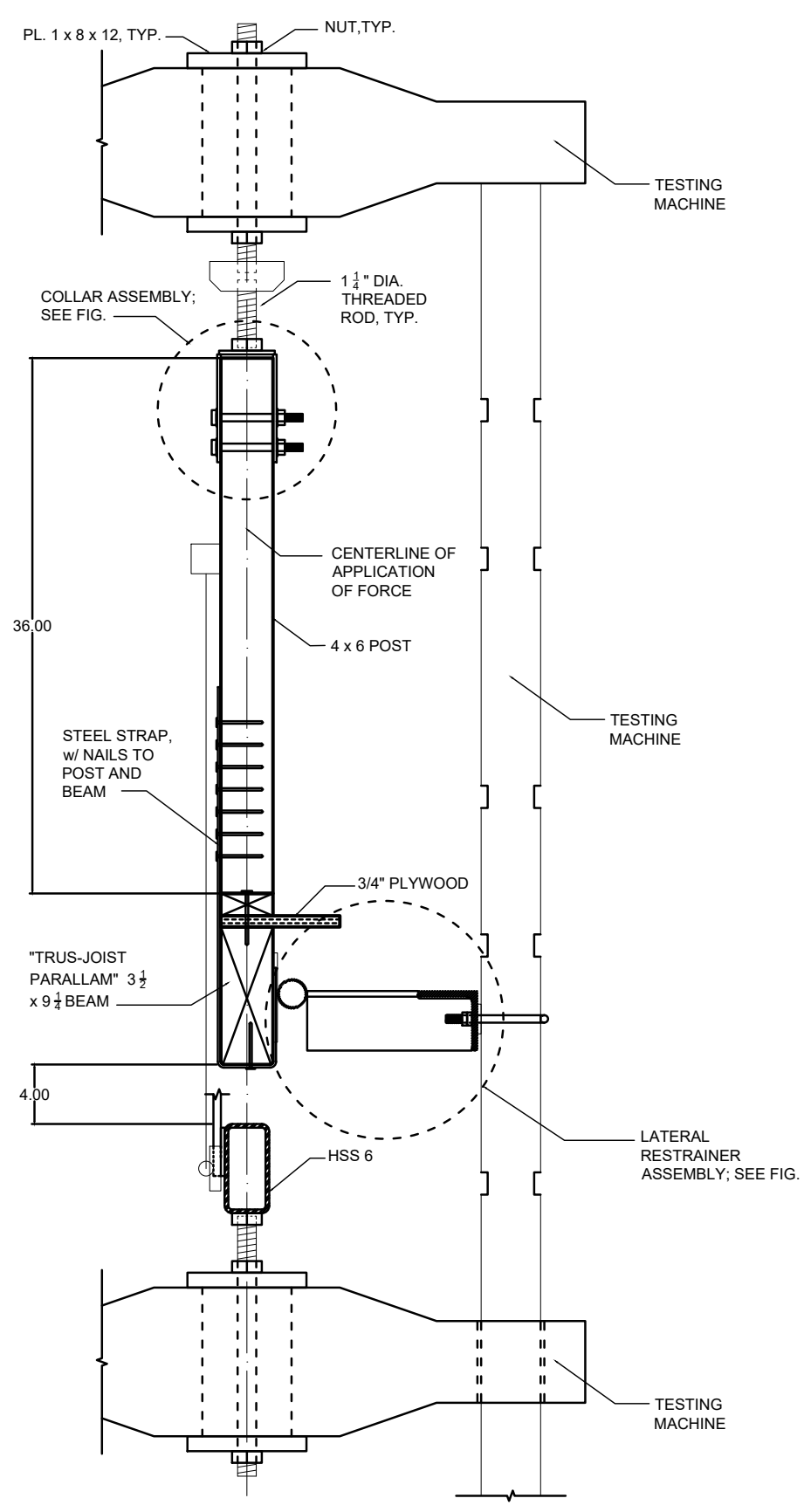

FIGURE A-3. STRAP TEST ARRANGEMENT - POST-TO-BEAM TRANSVERSE ELEVATION VIEW 


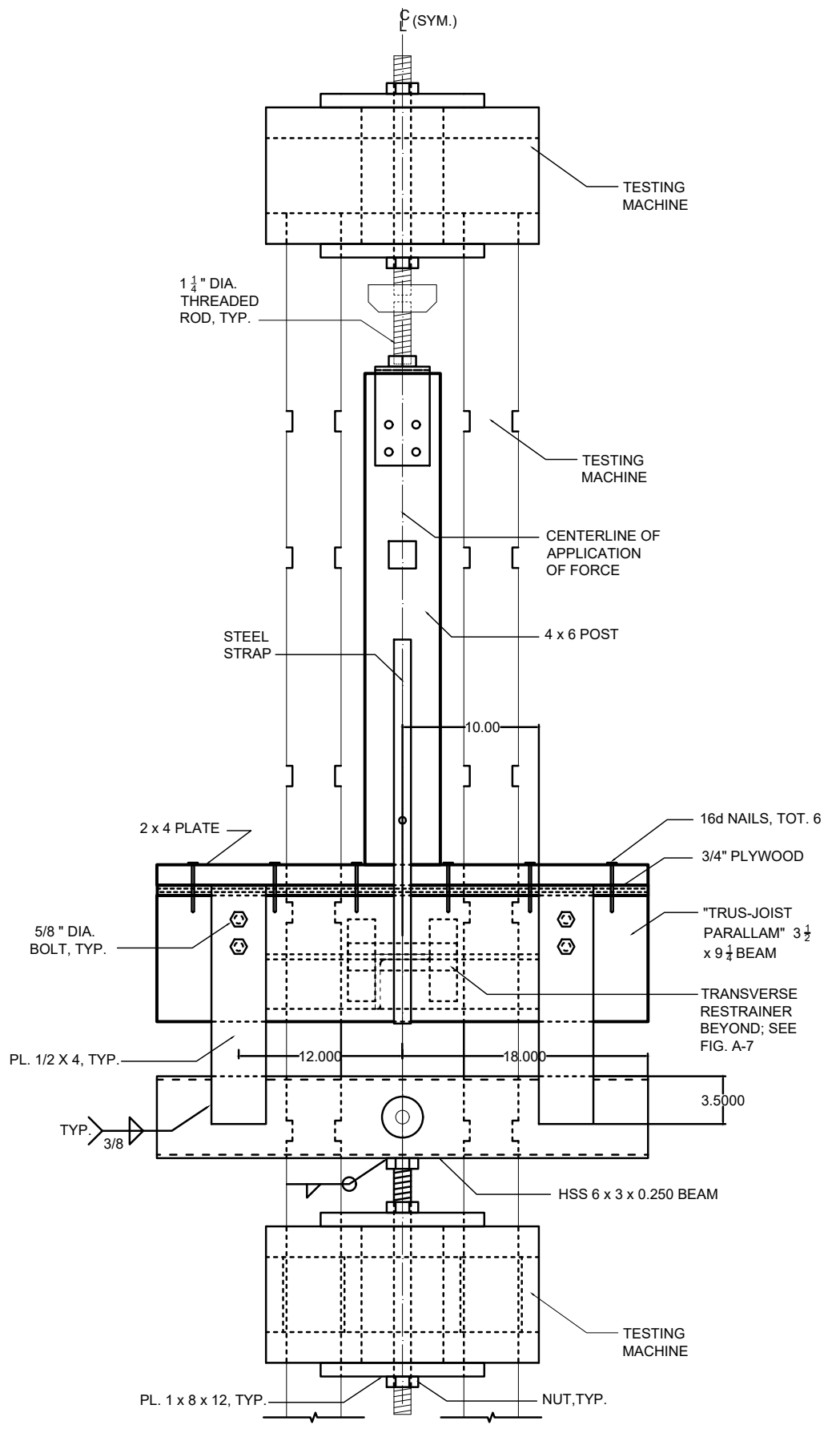

FIGURE A-4. STRAP TEST ARRANGEMENT - POST-TO-BEAM MSTA36 STRAP (TSM3) LONGITUDINAL ELEVATION VIEW 


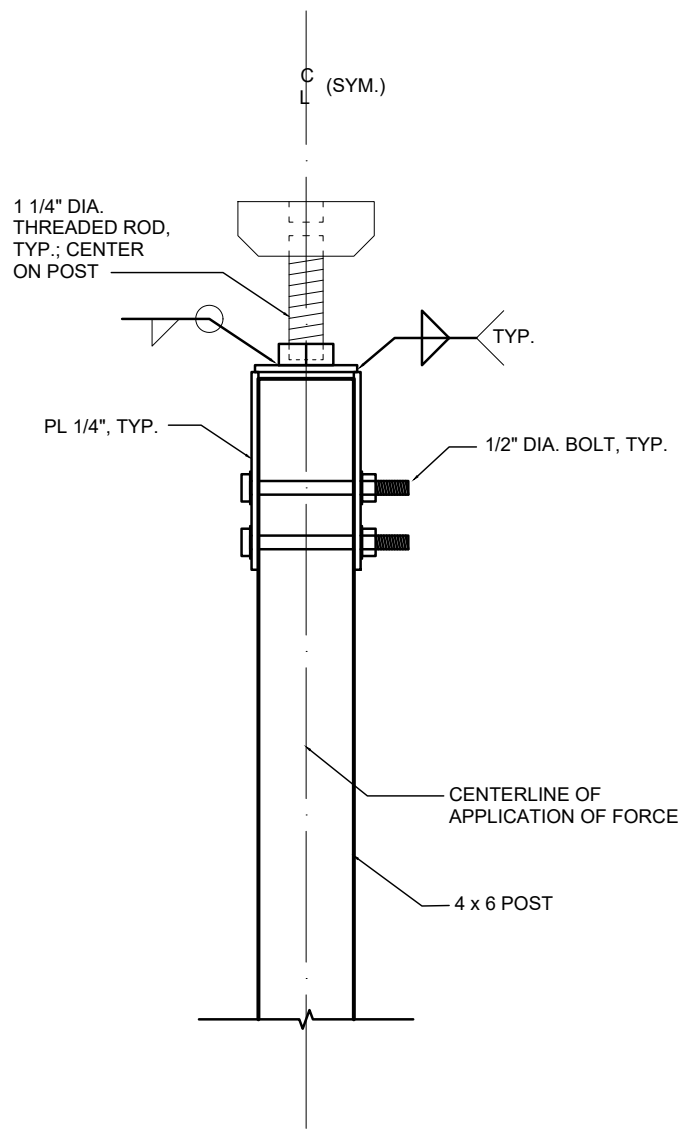

FIGURE A-5. COLLAR ASSEMBLY

TRANSVERSE ELEVATION VIEW 


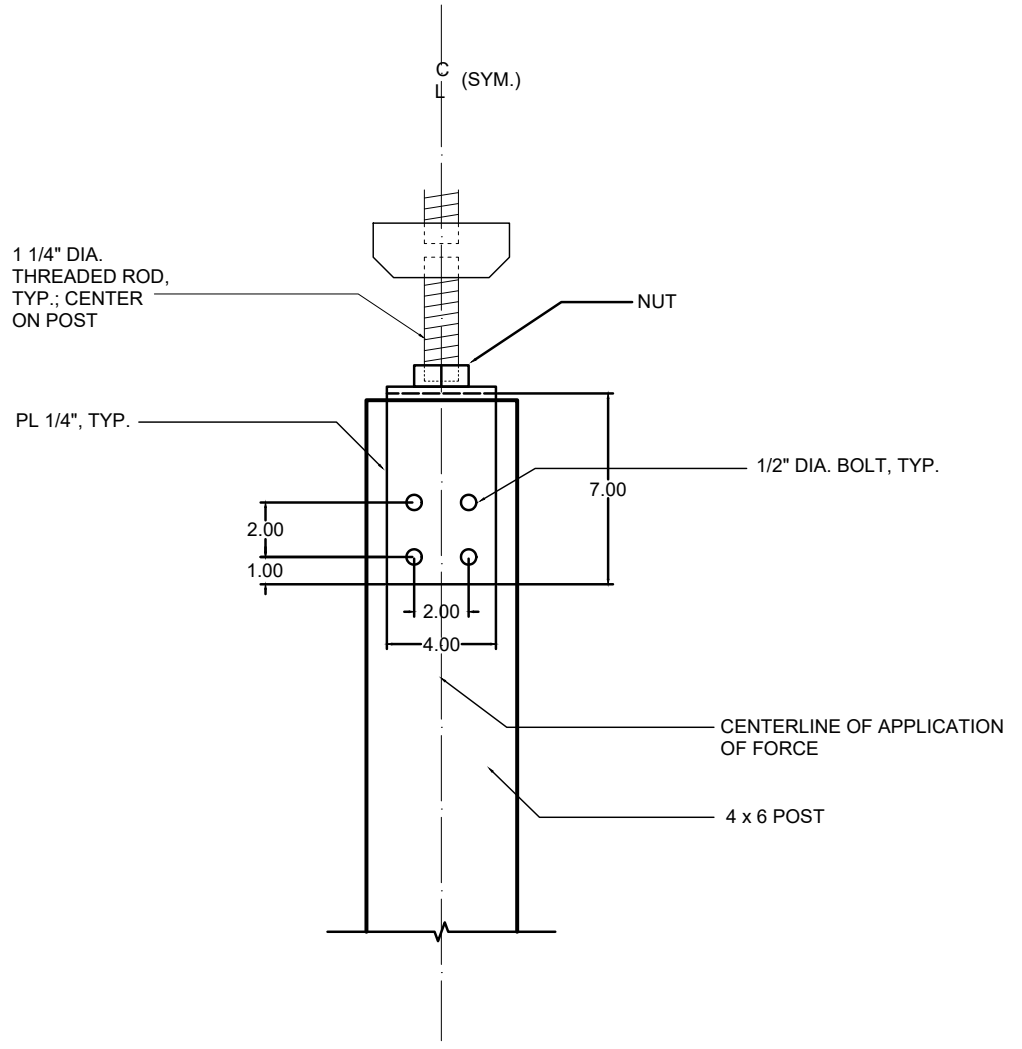

FIGURE A-6. COLLAR ASSEMBLY LONGITUDINAL ELEVATION VIEW 


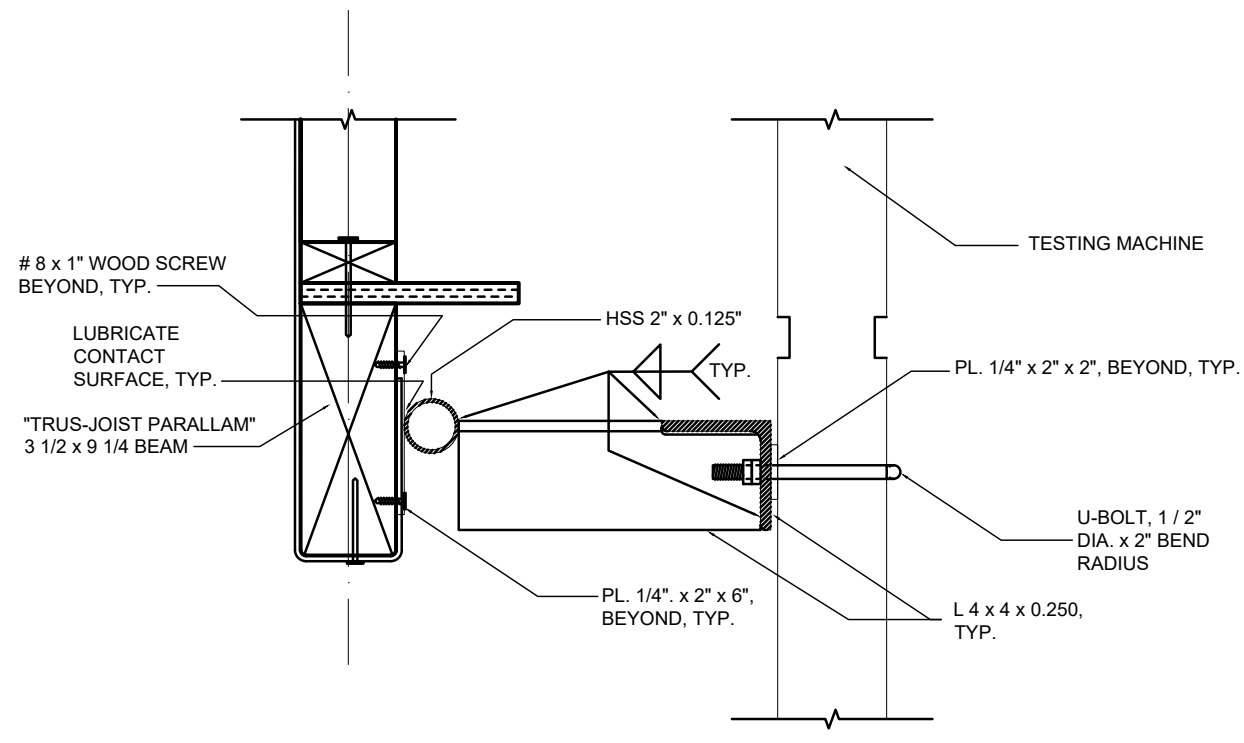

FIGURE A-7. LATERAL RESTRAINER ASSEMBLY

TRANSVERSE ELEVATION VIEW 


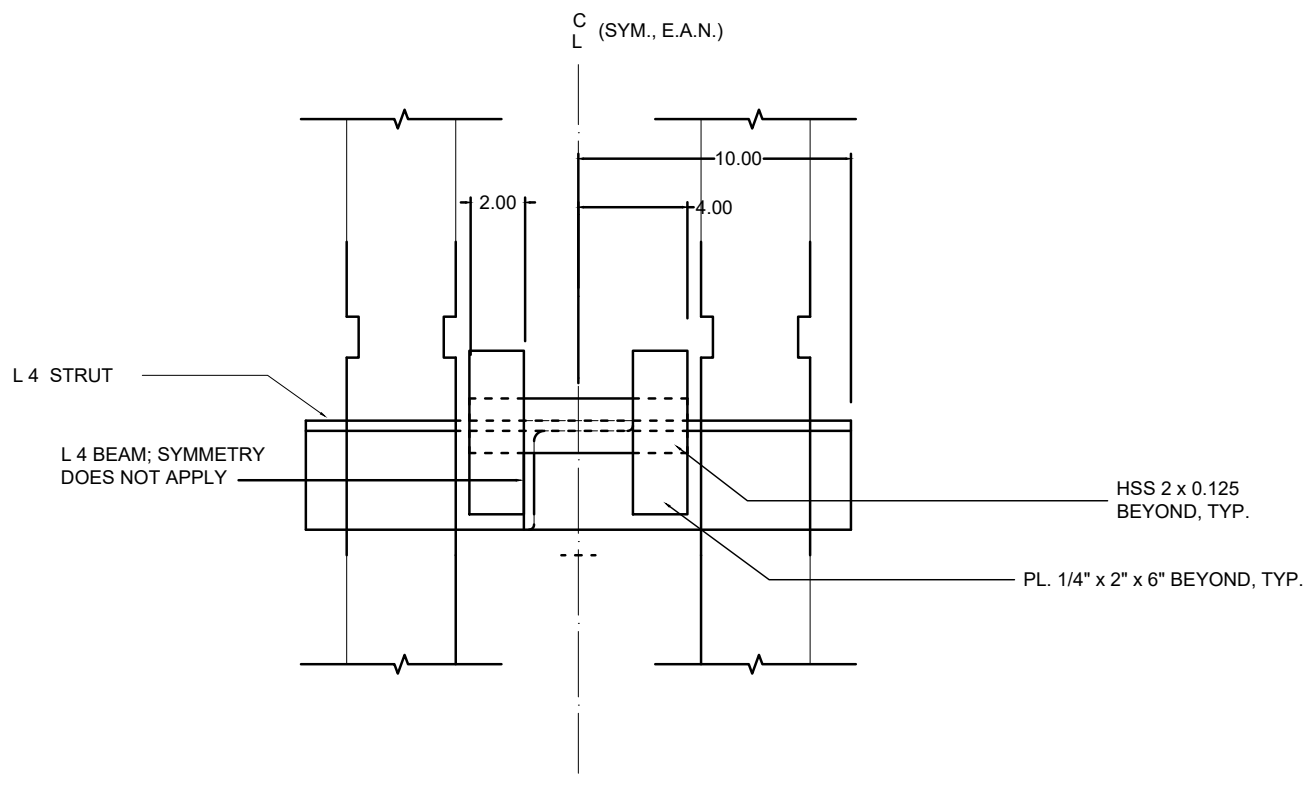

FIGURE A-8. LATERAL RESTRAINER ASSEMBLY

LONGITUDINAL ELEVATION VIEW 
Appendix B. Capacities of Wood Members and Steel Connectors

\section{Appendix Contents}

$\begin{array}{ll}\text { List of symbols } & \text { B-2 }\end{array}$

$\begin{array}{ll}\text { Wood members } & \text { B-8 }\end{array}$

$\begin{array}{ll}\text { Steel straps } & \text { B-11 }\end{array}$

$\begin{array}{ll}\text { Nails, steel-straps-to-wood } & \text { B-15 }\end{array}$

$\begin{array}{ll}\text { Steel members } & \text { B-20 }\end{array}$

$\begin{array}{lr}\text { Bolts, steel-members-to-wood } & \text { B-24 }\end{array}$

$\begin{array}{ll}\text { Summary - Vertical force capacities } & \text { B-26 }\end{array}$

$\begin{array}{ll}\text { Design of lateral restraint } & \text { B-28 }\end{array}$

$\begin{array}{ll}\text { Bending capacity of posts of Universal Test Machine (UTM) } & \text { B-30 }\end{array}$

$\begin{array}{ll}\text { Geometric considerations } & \text { B-33 }\end{array}$

$\begin{array}{ll}\text { Assumptions made } & \text { B-36 }\end{array}$

NOTE:

All calculations in this Appendix are based upon Allowable Stress Design capacities, equations and values, except where Strength Design (SD) is specifically noted. 
LIST OF SYMBOLS

\begin{tabular}{|c|c|}
\hline$A_{b}$ & area, beam \\
\hline$A_{p}$ & area, wood post \\
\hline$A_{p n}$ & cross-section area of post of Universal Test Machine at narrow portions \\
\hline$A_{t s}$ & effective rod cross-section area \\
\hline$a_{g}$ & lever distance at weld at HSS \\
\hline $\mathbf{b}_{\mathrm{b}}$ & width of manufactured-lumber beam \\
\hline$b_{c}$ & width of steel plates at collar \\
\hline$b_{p}$ & thickness of wood post \\
\hline $\mathbf{b}_{\mathrm{pl}}$ & width of steel plate connectors, wood beam to HSS beam \\
\hline $\mathbf{b}_{\mathrm{pn}}$ & net width of steel plates at collar \\
\hline $\mathbf{b}_{\mathrm{s}}$ & width of MSTA36 strap \\
\hline$C_{D}$ & load duration factor \\
\hline $\mathrm{C}_{\mathrm{Fp}}$ & size factor, post \\
\hline $\mathrm{C}_{\mathrm{Fb}}$ & size factor, beam \\
\hline $\mathrm{C}_{\mathrm{g}}$ & group-action factor for fasteners \\
\hline$c_{\Delta}$ & geometry factor for connections \\
\hline$C_{n}$ & width of nut at threaded rod \\
\hline$D_{\text {pn }}$ & diameter of post of UTM at narrow portions \\
\hline$d_{b}$ & diameter of bolts \\
\hline$d_{\text {bh }}$ & effective bolt hole diameter \\
\hline$d_{n}$ & diameter of nails \\
\hline$d_{r}$ & diameter of steel threaded rods \\
\hline$E_{s}$ & modulus of elasticity of steel \\
\hline $\mathbf{E}_{\mathrm{w}}$ & modulus of elasticity of wood \\
\hline $\mathbf{e}_{\text {aa }}$ & eccentricities of loading, beam and post \\
\hline $\mathbf{e}_{\mathrm{pl}}$ & $\begin{array}{l}\text { eccentricity of steel plate connectors, wood beam to HSS beam, relative to applied } \\
\text { force }\end{array}$ \\
\hline $\mathbf{e}_{\text {st }}$ & eccentricities of loading, beam and post (both types of straps) \\
\hline $\mathbf{F}_{\mathrm{bb}}$ & allowable stress, bending, wood (or manufactured-lumber) beam \\
\hline $\mathbf{F}_{\mathrm{bp}}$ & allowable stress, bending, wood post \\
\hline $\mathrm{F}_{\mathrm{cr}}$ & critical stress in compression (SD) \\
\hline $\mathbf{F}_{\mathrm{e}}$ & Euler elastic buckling stress in compression (SD) \\
\hline $\mathbf{F}_{\mathrm{em}}$ & wood dowel bearing strength \\
\hline $\mathbf{F}_{\mathrm{emb}}$ & allowable lateral force per nail by Eq'ns. 12.3-1 thru 12.3-6, NDS \\
\hline
\end{tabular}




\begin{tabular}{|c|c|}
\hline $\mathbf{F}_{\text {es }}$ & steel dowel bearing strength \\
\hline $\mathbf{F}_{\mathrm{tp}}$ & allowable stress, tension, wood post \\
\hline $\mathbf{F}_{\mathrm{u}}$ & ultimate stress, steel; assumed: ASTM A36 \\
\hline $\mathbf{F}_{\text {ub }}$ & ultimate stress, steel threaded rod; assumed: ASTM A449 \\
\hline $\mathbf{F}_{\text {ust }}$ & strap ultimate stress, given: ASTM A653 steel \\
\hline $\mathbf{F}_{\mathrm{vb}}$ & allowable stress, shear, wood (or manufactured-lumber) beam \\
\hline $\mathbf{F}_{\mathrm{vt}}$ & $\begin{array}{l}\text { (assumed) allowable torsion strength of wood (or manufactured-lumber) beam, } \\
\text { being same as ordinary shear strength }\end{array}$ \\
\hline $\mathbf{F}_{\mathbf{w}}$ & weld stress capacity, steel; assumed: E70 \\
\hline $\mathbf{F}_{\mathrm{y}}$ & yield stress, steel (other than straps or fasteners); assumed: ASTM A36 \\
\hline $\mathbf{F}_{\mathrm{yn}}$ & strength of nails; each; assumed: low- to medium-carbon steel, not hardened \\
\hline $\mathbf{F}_{\mathrm{yp}}$ & UTM post yield stress capacity; assumed \\
\hline $\mathbf{F}_{\mathrm{yst}}$ & strap yield stress, given: ASTM A653 steel \\
\hline$h_{b}$ & depth of manufactured-lumber beam \\
\hline $\mathbf{h}_{\mathrm{p}}$ & width of wood post \\
\hline$h_{\mathrm{pl}}$ & depth of wood plate \\
\hline $\mathrm{K}_{\theta}$ & factor used in calculating bolt capacity in steel-to-wood connections \\
\hline $\mathbf{k}_{1}$ & intermediate factor used for calculating nail strength \\
\hline $\mathbf{k}_{2}$ & intermediate factor used for calculating nail strength \\
\hline $\mathbf{k}_{3}$ & intermediate factor used for calculating nail strength \\
\hline $\mathrm{L}_{\mathrm{b}}$ & span length of beam, between steel plates \\
\hline $\mathrm{L}_{\mathrm{cz} \_\mathrm{pP}}$ & $\begin{array}{l}\text { Length of floor "critical zone": beam with plates and plywd., Post-to-Post, in } \\
\text { specimen }\end{array}$ \\
\hline $\mathrm{L}_{\mathrm{CZ} \_\mathrm{PB}}$ & Length of floor "critical zone": plates and plywd., Post-to-Beam, in specimen \\
\hline $\mathbf{L}_{\text {e_CMSTC }}$ & end length of strap, CMSTC16 \\
\hline $\mathrm{L}_{\mathrm{m}}$ & length of nail in wood, aprox. \\
\hline $\mathrm{L}_{\text {MSTA }}$ & length of strap, MSTA36 \\
\hline \multicolumn{2}{|l|}{$\mathbf{L}_{n_{-} \text {MSTA }}$} \\
\hline & length of MSTA36 strap available for nailing, each side of floor, in Post-to-Post case \\
\hline $\mathrm{L}_{\mathrm{n}_{-} \mathrm{CMSTC}}$ & nailing length, CMSTC16 \\
\hline $\mathbf{L}_{\mathrm{p}}$ & length of post \\
\hline $\mathrm{L}_{\mathrm{t}_{-} \mathrm{CMSTC}}$ & minmum total strap length required in Post-to-Post \\
\hline $\mathrm{L}_{\mathrm{t}_{\text {_CMSTC }}}$ & minmum total strap length required in Post-to-Beam \\
\hline$L_{\text {S_PP_MSTA }}$ & stretch length: for MSTA36, Post-to-Post \\
\hline $\mathrm{L}_{\text {s_PP_CMSTC }}$ & stretch length: for CMSTC16, Post-to-Post \\
\hline $\mathrm{L}_{\text {S_PB_MSTA }}$ & stretch length: for MSTA36, Post-to-Beam \\
\hline $\mathrm{L}_{\mathrm{S}_{-} \mathrm{PB} \_\mathrm{CMSTC}}$ & stretch length: for CMSTC16, Post-to-Beam \\
\hline
\end{tabular}




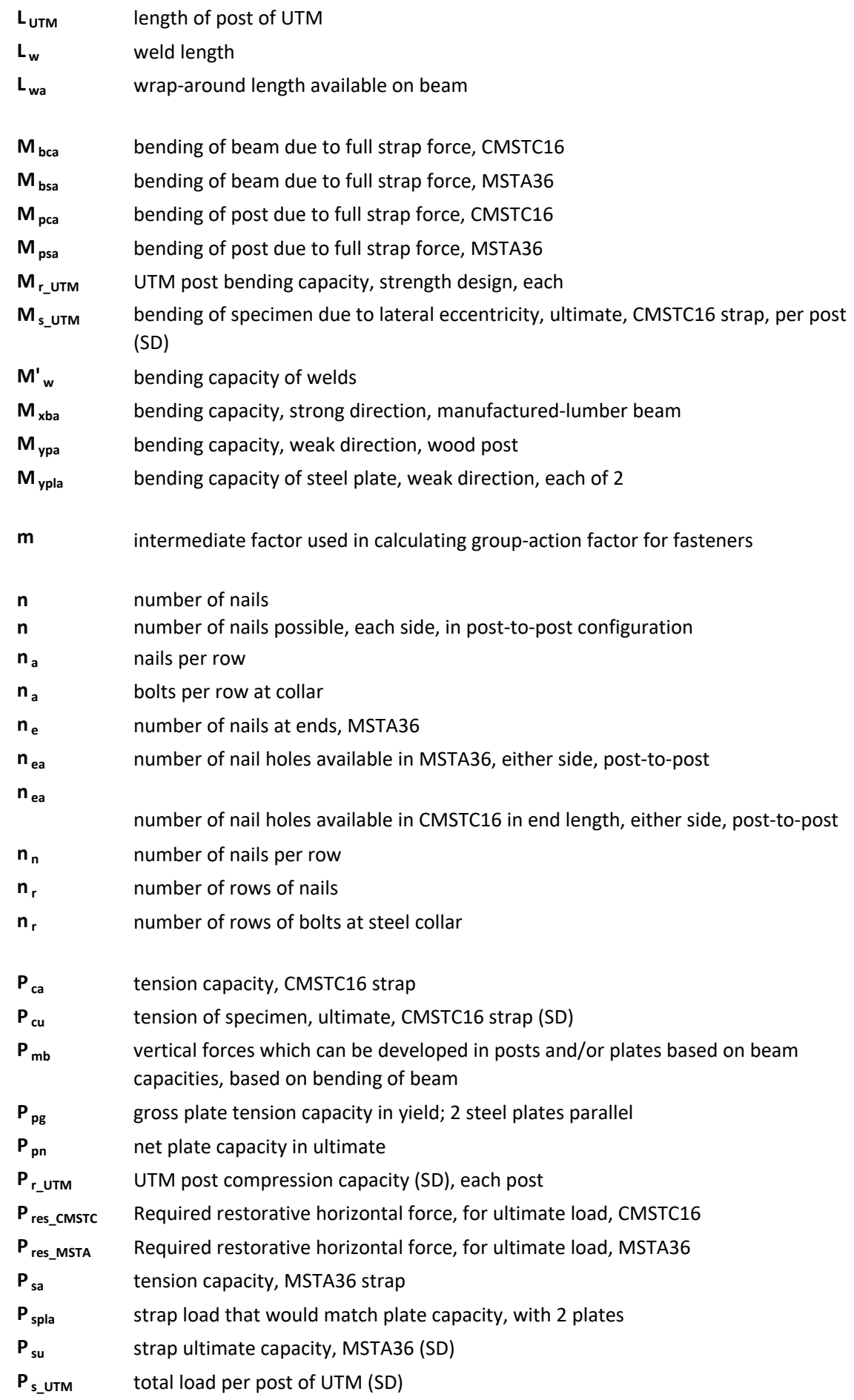




\begin{tabular}{|c|c|}
\hline $\mathbf{P}_{\text {tab }}$ & $\begin{array}{l}\text { tension capacity, post, with reduction due to bending (due to eccentricity of strap) } \\
\text { and interaction }\end{array}$ \\
\hline $\mathbf{P}_{\mathrm{tb}}$ & $\begin{array}{l}\text { Vertical forces which can be developed in posts and/or plates based on beam } \\
\text { capacities, based on torsion of beam }\end{array}$ \\
\hline $\mathbf{P}_{\mathrm{thr}}$ & tension capacity of threaded rod \\
\hline $\mathbf{P}_{\text {tpa }}$ & Tension capacity, wood post \\
\hline $\mathbf{P}_{\text {tpla }}$ & tension capacity of plate, each \\
\hline$P_{\text {UTM_u_o }}$ & UTM upper portion self-weight and weight of specimen, aprox. \\
\hline $\mathbf{P}_{\mathrm{vb}}$ & $\begin{array}{l}\text { vertical force which can be developed in posts and/or plates based on beam } \\
\text { capacities, based on shear of beam }\end{array}$ \\
\hline $\mathbf{P}_{\text {vtb }}$ & $\begin{array}{l}\text { vertical force which can be developed in posts and/or plates based on beam } \\
\text { capacities, based on shear of beam with torsion interaction }\end{array}$ \\
\hline $\mathbf{P}_{\mathrm{w}}$ & strength of weld \\
\hline $\mathbf{P}_{\text {wc }}$ & $\begin{array}{l}\text { strength of collar based on welds, given that there are } 2 \text { plates and } 2 \text { sides of welds } \\
\text { at each plate }\end{array}$ \\
\hline $\mathbf{P}_{\text {wp }}$ & $\begin{array}{l}\text { strength of steel plates at HSS beam based on welds, given that there are } 2 \text { plates } \\
\text { and } 2 \text { sides of welds at each plate }\end{array}$ \\
\hline $\mathbf{R}_{\mathrm{d}_{-} \mathbf{I}}$ & factor used in calculating bolt capacity in steel-to-wood connections, Mode I \\
\hline $\mathbf{R}_{\text {d_II }}$ & factor used in calculating bolt capacity in steel-to-wood connections, Mode II \\
\hline $\mathbf{R}_{\mathrm{d}_{-} \text {III }}$ & factor used in calculating bolt capacity in steel-to-wood connections, Mode III \\
\hline $\mathbf{R}_{\mathrm{d} \_\mathrm{IV}}$ & factor used in calculating bolt capacity in steel-to-wood connections, Mode IV \\
\hline $\mathbf{R}_{\mathrm{EA}}$ & intermediate factor used in calculating group-action factor for fasteners \\
\hline $\mathbf{r}_{\mathrm{pn}}$ & radius of gyration of post, based on reduced diameter at narrow portions \\
\hline$S_{\mathrm{pn}}$ & section modulus of post of UTM at narrows, each post \\
\hline $\mathbf{S}_{\mathrm{xb}}$ & section modulus, beam \\
\hline$S_{y p}$ & section modulus, wood post, weak direction \\
\hline$s_{n_{-}} \mathrm{c}$ & nail spacing, CMSTC16 \\
\hline$s_{n_{-} M}$ & nail spacing, MSTA36 \\
\hline $\mathbf{s}_{\mathrm{a}}$ & spacing btwn. bolts in a row at collar \\
\hline $\mathbf{s}_{\mathrm{a}}$ & spacings btwn. nails in a row \\
\hline $\mathbf{s}_{\mathrm{e}}$ & nail end distance \\
\hline $\mathbf{s}_{\mathrm{r}}$ & spacing btwn. rows of bolts at collar \\
\hline$s_{r}$ & spacings btwn. rows of nails \\
\hline$T_{\text {ba }}$ & (assumed) torsion capacity of beam \\
\hline $\mathbf{T}_{\mathrm{bc}}$ & torsion of beam, due to full strap force, CMSTC16 \\
\hline$T_{\text {bs }}$ & Torsion of beam, due to full strap force, MSTA36 \\
\hline $\mathbf{T}_{\text {pla }}$ & (assumed) torsion capacity of wood plate \\
\hline
\end{tabular}




\begin{tabular}{|c|c|}
\hline $\mathbf{t}_{\mathrm{c}}$ & thickness of steel plates at collar \\
\hline$t_{f l}$ & thickness of plywood floor \\
\hline $\mathbf{t}_{\mathrm{pl}}$ & thickness of wooden plates \\
\hline $\mathbf{t}_{\mathrm{s}}$ & strap thickness (both types of straps) \\
\hline$t_{\text {sp }}$ & thickness of steel plate connectors, wood beam to HSS beam \\
\hline $\mathbf{t}_{\mathrm{wc}}$ & weld thickness at collar \\
\hline $\mathbf{t}_{\mathrm{wp}}$ & weld thickness at steel plate to HSS \\
\hline $\mathbf{U}_{\mathrm{bc}}$ & interaction ratio in beam due to capacity force in CMSTC16 strap \\
\hline $\mathbf{U}_{\mathrm{bs}}$ & interaction ratio in beam due to capacity force in MSTA36 strap \\
\hline $\mathbf{U}_{\mathrm{pc}}$ & interaction ratio in wood post due to capacity force in CMSTC16 strap \\
\hline $\mathbf{U}_{\mathrm{ps}}$ & Interaction ratio, tension and bending in wood post, MSTA36 \\
\hline $\mathbf{U}_{\text {Uтм }}$ & Interaction ratio, tension and bending in posts of UTM, Strength Design method \\
\hline $\mathbf{U}_{\mathrm{w}}$ & $\begin{array}{l}\text { Interaction ratio, shear and bending in plate-to-HSS connection, at connection } \\
\text { capacity, defined as } 1.00\end{array}$ \\
\hline $\mathbf{V}_{\text {at }}$ & Shear capacity, beam, with torsion due to eccentricity and interaction \\
\hline $\mathbf{v}_{\mathrm{ba}}$ & Shear capacity, beam (shear only) \\
\hline $\mathbf{v}_{\mathrm{bc}}$ & Shear of beam, due to full strap force, CMSTC16 \\
\hline $\mathbf{v}_{\mathrm{bs}}$ & Shear of beam, due to full strap force, MSTA36 \\
\hline $\mathbf{V}_{\text {na }}$ & total nail shear capacity, based on solution by all of Eq'ns. 12.3 \\
\hline $\mathbf{V}^{\prime}{ }_{\mathrm{w}}$ & strength of welds at plates-to-HSS connection \\
\hline$x_{\text {ne }}$ & nail end distance (dist., nail to joint btwn. post, plate) \\
\hline $\mathbf{X}_{\mathbf{y}_{-} \text {PP_MSTA }}$ & yield stretch distance for MSTA36, Post-to-Post \\
\hline $\mathbf{X}_{\mathbf{y}_{-} \text {PP_CMSTC }}$ & yield stretch distance for CMSTC16, Post-to-Post \\
\hline $\mathbf{X}_{Y_{-} \text {PB_MSTA }}$ & yield stretch distance for MSTA36, Post-to-Beam \\
\hline $\mathbf{x}_{\mathrm{y}_{-} \text {PB_CMSTC }}$ & yield stretch distance for CMSTC16, Post-to-Beam \\
\hline \multicolumn{2}{|l|}{$\mathbf{z}_{\|}$} \\
\hline & "raw" bolt capacity, 1/2-in. dia., x $31 / 2$ in. length, double shear btwn. plates \\
\hline$Z_{1 m}$ & allowable lateral force per nail, Yield Mode 'I m' \\
\hline$Z_{1 s}$ & allowable lateral force per nail, Yield Mode 'I s' \\
\hline $\mathbf{Z}_{\text {॥I }}$ & allowable lateral force per nail, Yield Mode 'Il' \\
\hline $\mathbf{Z}_{\text {III } m}$ & allowable lateral force per nail, Yield Mode 'III m' \\
\hline $\mathbf{Z}_{\text {IIIs }}$ & allowable lateral force per nail, Yield Mode 'Ill s' \\
\hline $\mathbf{Z}_{\text {IV }}$ & allowable lateral force per nail, Yield Mode 'IV' \\
\hline $\mathbf{Z}_{\mathrm{nv}}$ & allowable lateral force per nail \\
\hline \multicolumn{2}{|r|}{ 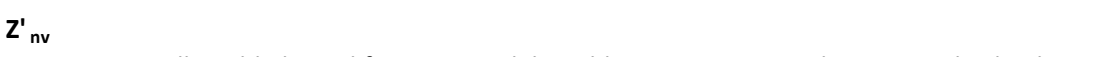 } \\
\hline & allowable lateral force per nail, by table in NDS; assumed 16-ga steel side plate \\
\hline $\mathbf{Z}_{\mathrm{vns}}$ & shear strength of steel of nails, taken independently \\
\hline
\end{tabular}




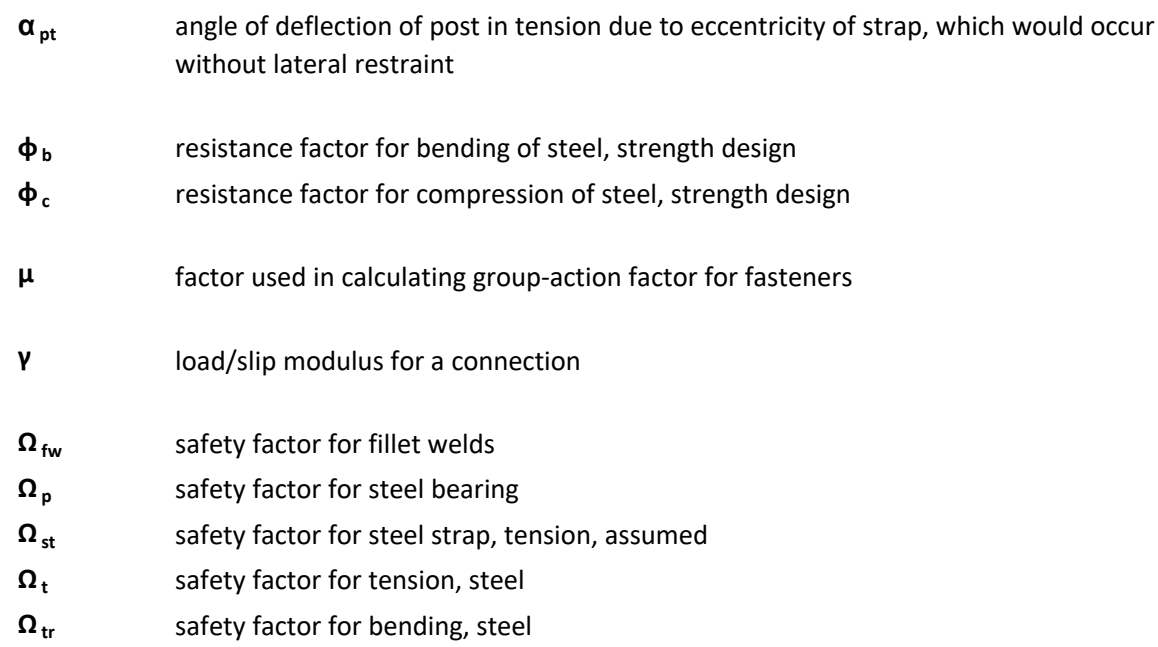

NOTE: Where colon (:) is used in equation (e.g., "b $\mathrm{p}_{\mathrm{p}}:=$ "), this indicates that the value on the left side of the equation is so stated in reference, or is so defined in these calculations. 


\section{WOOD MEMBERS}

\section{Post in tension and bending}

Member species and grade: Douglas Fir - Larch Grade \# 1

Member size: $4 \times 6$ nom.

Dimensions

\begin{tabular}{|c|c|c|c|}
\hline$b_{p}:=$ & 3.50 in. & thickness & $\begin{array}{l}\text { (American Wood Council, 2015, Supplement, } \\
\text { Table 1B) }\end{array}$ \\
\hline . & 5.50 in & width & (ibid.) \\
\hline
\end{tabular}

Allowable stresses, tension and bending

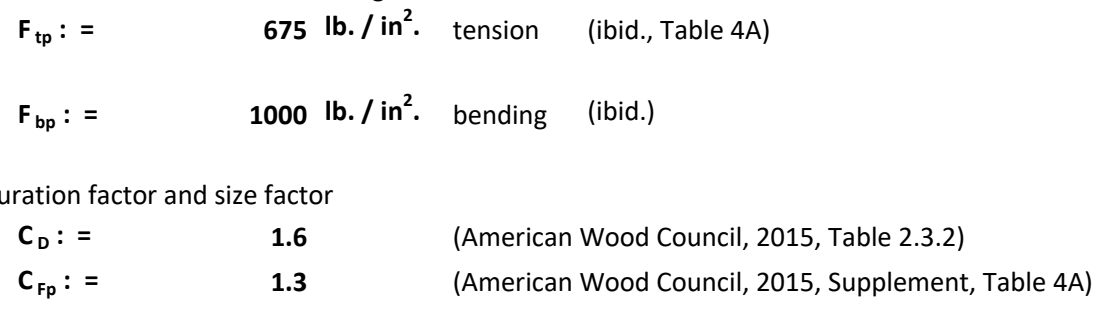

Structural section properties

$$
\begin{gathered}
A_{p}=b_{p} h_{p} \\
S_{y p}=\frac{h_{p} b_{p}^{2}}{6}
\end{gathered}
$$$$
\text { area }
$$$$
\text { section modulus, weak direction }
$$

$\begin{array}{ll}A_{p}= & 19.25 \mathrm{in}^{2} . \\ S_{\text {yp }}= & 11.23 \mathrm{in}^{3} .\end{array}$

Tension capacity, post

$$
\begin{aligned}
P_{t p a} & =A_{p} F_{t p} C_{D} C_{F p} \\
\mathbf{P}_{\mathrm{tpa}} & =\mathbf{2 7 0 2 7} \mathbf{l b} .
\end{aligned}
$$

Bending capacity, weak direction, post

$$
\begin{aligned}
M_{y p a} & =S_{y p} F_{b p} C_{D} C_{F p} \\
\mathbf{M}_{\mathbf{y p a}} & =23357 \text { lb.-in. }
\end{aligned}
$$

(American Wood Council, 2015, Sec. 3.3.2; formula rearranged algebraically) 


\section{Beam in shear and bending}

Member size and grade: "'Trus-Joist Parallam" $3 \frac{1}{2} \times 9 \frac{1}{4}$ beam

Service Level: \# 1 (dry use)

Dimensions

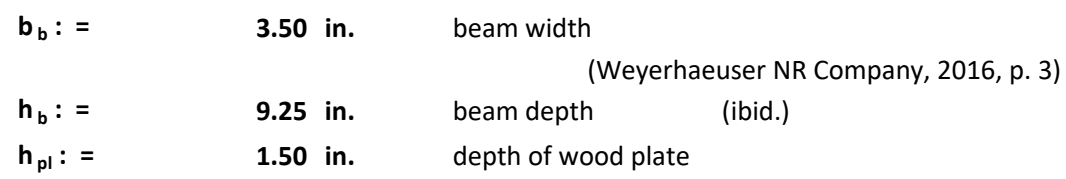

Allowable stresses, shear and bending
$\mathbf{F}_{\mathrm{vb}}:=$
$241 \mathrm{lb} . / \mathrm{in}^{2}$. shear
(ibid., p. 5)
$F_{\text {bb }}:=$
$2117 \mathrm{lb}$ / $/ \mathrm{in}^{2}$. bending

Size factor

$$
\mathrm{C}_{\mathrm{Fb}}:=
$$

Structural section properties

$$
\begin{array}{ll}
A_{b}=b_{b} h_{b} & \text { area } \\
S_{x b}=\frac{b_{b} h_{b}^{2}}{6} & \text { section modulus }
\end{array}
$$

$A_{b}=\quad 32.38 \mathrm{in}^{2}$.

$\mathrm{S}_{\mathrm{xb}}=\quad 49.91 \mathrm{in}^{3}$.

Shear capacity, beam

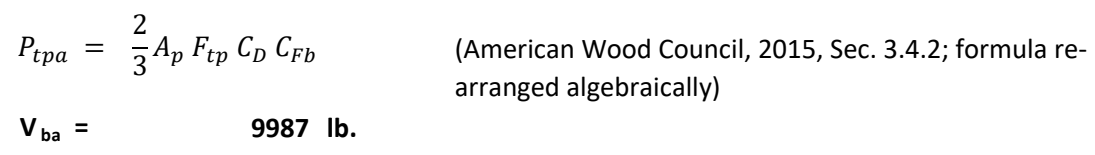

Bending capacity, strong direction, beam

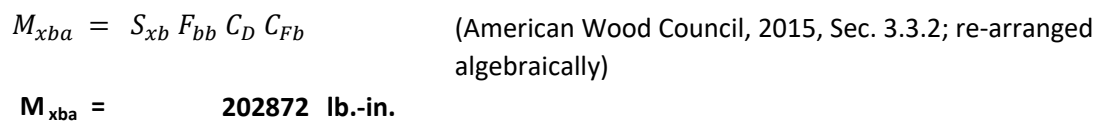

(assumed) allowable torsion strength of beam, being same as ordinary shear strength
$\mathbf{F}_{\mathrm{vt}}:=$
$241 \mathrm{lb} . / \mathrm{in}^{2}$. 
(assumed) torsion capacity of beam

$$
\begin{array}{r}
\tau_{\max }=\frac{3 T_{a}}{8 a b^{2}}\left[1+0.6095 \frac{b}{a}+0.8865\left[\frac{b}{a}\right]^{2}-1.8023\left[\frac{b}{a}\right]^{3}+0.9100\left[\frac{b}{a}\right]^{4}\right] \\
\text { (Young \& Budynas, 2002, p. 401) }
\end{array}
$$

$T_{b a}=\quad 7120$ lb.-in.

beam-plus-wood plate capacity; joined through one line of nails only

$T_{\text {pla }}=\quad 482 \mathrm{lb}$.-in.

$T_{\text {ba }}+T_{\text {pla }}=7601 \mathrm{lb}$.-in. 


\section{STEEL STRAPS}

\section{Capacities of steel straps}

Tension capacity, MSTA36

$\mathbf{P}_{\mathrm{sa}}:=\quad 2050 \mathrm{lb} . \quad$ (Simpson Strong-Tie Company, 2017, p. 302)

Tension capacity, CMSTC16
$\mathbf{P}_{\mathrm{ca}}:=$
$4585 \mathrm{lb}$.
(ibid., p. 305)

\section{Dimensions}

eccentricities of loading, beam and post

$$
\begin{aligned}
e_{a a} & =\frac{b_{p}}{2} \\
\mathbf{e}_{\mathrm{aa}} & =\quad \mathbf{1 . 7 5} \text { in. } \quad \text { same for both straps }
\end{aligned}
$$

strap thickness (both types of straps)

$\begin{array}{lll}\mathbf{t}_{\mathrm{s}}:= & \mathbf{0 . 0 6 3 5} \text { in. } & \text { (American Institute of Steel Construction, 2003. Manual of } \\ & \text { Steel Construction, Table 17-10) }\end{array}$

eccentricities of loading, beam and post (both types of straps)

$$
\begin{array}{ll}
e_{s t}=e_{a a}+\frac{t_{s}}{2} & \\
\mathbf{e}_{\text {st }}= & 1.78 \mathrm{in} .
\end{array}
$$

Bending of posts based on strap capacity and eccentricity, MSTA36

Tension capacity, post, with reduction due to bending (due to eccentricity) and interaction

$$
\begin{aligned}
P_{\text {tab }} & =\frac{1}{\frac{1}{P_{t p a}}+\frac{e_{s t}}{M_{y p a}}} \\
\mathbf{P}_{\text {tab }} & =\quad \mathbf{8 8 2 7} \mathbf{~ l b .}
\end{aligned}
$$

bending of post due to full strap force, MSTA36

$$
\begin{array}{ll}
M_{p s a} & =e_{s t} P_{s a} \\
\mathbf{M}_{\text {psa }} & =\quad 3653 \text { lb.-in. }
\end{array}
$$


Interaction, tension and bending in post, MSTA36

$$
\begin{aligned}
& U_{p}=\frac{P_{s a}}{P_{t p a}}+\frac{M_{p s a}}{M_{y p a}} \\
& \mathbf{u}_{\mathrm{ps}}=
\end{aligned}
$$

This value is less than unity, thus, elastic behavior is predicted.

Bending, shear and torsion in beam based on strap capacity and eccentricity, MSTA36

span length of beam, between steel plates

$$
L_{b}:=\quad 24.0 \text { in. }
$$

bending of beam due to full strap force, MSTA36

$$
\begin{array}{ll}
M_{b s a}=\frac{L_{b} P_{s a}}{4} & \\
\mathbf{M}_{\text {bsa }}= & 12300 \text { lb.-in. } \quad \text { MSTA36 }
\end{array}
$$

Shear capacity, beam, with torsion due to eccentricity and interaction

$$
\begin{aligned}
& V_{a t s}=\frac{\frac{1}{\frac{1}{V_{b a}}+\frac{e_{s t}}{T_{b a}}}}{\mathbf{v}_{\text {at }}=} \quad \mathbf{2 8 5 4} \mathbf{l b} .
\end{aligned}
$$

Shear of beam, due to full strap force, MSTA36

$$
\begin{aligned}
V_{b s} & =\frac{P_{s a}}{2} \\
\mathbf{v}_{\mathrm{bs}} & =\quad 1025 \mathrm{lb} .
\end{aligned}
$$

Torsion of beam, due to full strap force, MSTA36

$$
\begin{array}{ll}
T_{b s}=V_{b s} e_{s t} & \\
\mathbf{T}_{\text {bs }}= & 1826 \text { lb.-in. }
\end{array}
$$

Interaction, shear and torsion in beam

(assumed) shear and torsion interaction in beam: $\left[\mathbf{f}_{v} / \mathbf{F}_{v}\right]+\left[\mathbf{f}_{t} / \mathbf{F}_{t}\right]:<=\mathbf{1 . 0 0}$, for MSTA36

$$
\begin{aligned}
& U_{b s}=\frac{V_{b s}}{V_{b a}}+\frac{T_{b s}}{T_{b a}} \\
& \mathrm{U}_{\mathrm{bs}}=\quad 0.359
\end{aligned}
$$

This value is less than unity, thus, elastic behavior is predicted. 
Bending of posts based on strap capacity and eccentricity, CMSTC16

bending of post due to full strap force, CMSTC16

$$
\begin{array}{ll}
M_{p c a} & =e_{s t} * P_{c a} \\
\mathbf{M}_{\text {pca }}= & \mathbf{8 1 6 9} \text { lb.-in. }
\end{array}
$$

bending of beam due to full strap force, CMSTC16

$$
\begin{array}{ll}
M_{b c a} & =\frac{L_{b} P_{c a}}{4} \\
\mathbf{M}_{\text {bca }} & =27510 \mathrm{lb} . \text {-in. }
\end{array}
$$

interaction in post, CMSTC16

$$
\begin{array}{ll}
U_{p c}= & \frac{P_{c a}}{P_{t p a}}+\frac{M_{p c a}}{M_{y p a}} \\
\mathbf{U}_{\mathrm{pc}}= & \mathbf{0 . 5 1 9}
\end{array}
$$

This value is less than unity, thus, elastic behavior is predicted.

Bending, shear and torsion in beam based on strap capacity and eccentricity, CMSTC16

Shear of beam, due to full strap force, CMSTC16

$$
\mathrm{V}_{\mathrm{bc}}=\quad 2293 \mathrm{lb} \text {. }
$$

Torsion of beam, due to full strap force, CMSTC16

$$
T_{b c}=\quad 4085 \text { lb.-in. }
$$

interaction in beam, CMSTC16

$$
\mathrm{U}_{\mathrm{bc}}=\quad 0.803
$$

This value is less than unity, thus, elastic behavior is predicted.

Vertical forces which can be developed in posts and/or plates based on beam capacities based on shear of beam, 2 ends

$$
\begin{array}{ll}
P_{v b}=2 V_{b} & \\
\mathbf{P}_{\mathbf{v b}}= & 19974 \mathbf{l b} .
\end{array}
$$

based on bending of beam, 2 ends

$$
\begin{array}{ll}
P_{m b}=\frac{2 M_{x b a}}{L_{b} / 2} & \\
\mathbf{P}_{\mathbf{m b}}= & \mathbf{3 3 8 1 2} \mathbf{l b} .
\end{array}
$$


based on torsion of beam, 2 ends

$$
\begin{aligned}
& P_{t b}=\frac{2 T_{b a}}{e_{s t}} \\
& \mathbf{P}_{\mathrm{tb}}=
\end{aligned}
$$

$7992 \mathrm{lb}$.

based on shear of beam with torsion interaction, 2 ends

$$
P_{\text {vtb }}=\quad 5708 \mathrm{lb} \text {. }
$$

thickness, width of steel plate connectors, wood beam to HSS beam

$$
\begin{array}{ll}
t_{\text {sp }}:= & 0.50 \mathrm{in} . \\
b_{p 1}:= & 4.00 \mathrm{in} .
\end{array}
$$

eccentricity of plate connectors, wood beam to HSS beam, relative to applied force

$$
\begin{array}{ll}
e_{p l}=e_{a a}+\frac{t_{s p}}{2} & \\
\mathbf{e}_{p l}= & 2.00 \mathrm{in} .
\end{array}
$$




\section{NAILS, STEEL-STRAPS-TO-WOOD}

\section{Capacities of nails in shear}

Nail size: 10d. common; with "MSTA36" strap

Number of nails possible, each side, in post-to-post configuration

$\begin{array}{lll}\mathbf{n}:= & \mathbf{8} & \text { (Simpson Strong-Tie Company, 2017. Wood Construction } \\ & \begin{array}{l}\text { Connectors - HRS ... MSTA .., p. 302); also made geometry } \\ \text { calculation }\end{array}\end{array}$

Allowable lateral force per nail, by table in NDS; assumed 16-ga steel side plate

$$
\begin{aligned}
& \mathrm{Z}^{\prime}{ }_{\mathrm{nv}} \text { : }=\quad 116 \mathrm{lb} . \quad \text { (American Wood Council, 2015, Table 12P; used values for } \\
& \mathrm{G}:=0.50)
\end{aligned}
$$

diameter of nails
$d_{n}=$
0.148 in.

strength of nails; ; assumed: low- to medium-carbon steel, not hardened
$F_{\text {yn }}:=$
90000 lb. / in ${ }^{2}$. (ibid., Table I.1)

Allowable lateral force per nail by Eq'ns. 12.3-1 thru 12.3-6, NDS; assumed: 16-ga steel side plate

Steel bearing factor of safety
$\Omega_{\mathrm{p}}:=$
2.00
(ANSI/AISC 360-10, Sec. J7)

wood dowel bearing strength
$\mathbf{F}_{\mathrm{em}}:=$
4650 lb. / in ${ }^{2}$.
(American Wood Council, 2015, Table 12.3.3)

steel dowel bearing strength;

$$
\begin{aligned}
& F_{e s}=\frac{1.8 F_{y n}}{\Omega_{p}} \\
& F_{\text {es }}:=\quad 81000 \mathrm{lb} . / \mathrm{in}^{2} . \quad \text { (ANSI/AISC 360-10, Sec. J7) }
\end{aligned}
$$

length of nail in wood, aprox.

$$
\begin{aligned}
& \mathrm{L}_{\mathrm{m}}:= \\
& 2.8 \mathrm{in.} \\
& k_{1}=\frac{\sqrt{R_{e}+2 R_{e}^{2}\left[1+R_{t}+R_{t}^{2}\right]+R_{t}^{2} R_{e}^{3}}-R_{e}\left[1+R_{t}\right]}{1+R_{e}} \\
& \begin{array}{ll}
\mathrm{k}_{1}= & 1.03
\end{array} \\
& k_{2}=-1+\sqrt{2\left[1+R_{e}\right]+\frac{2 F_{y n}\left[1+2 R_{e}\right] d_{n}^{2}}{3 F_{e m} L_{m}^{2}}} \\
& \begin{array}{ll}
k_{2}= & 0.47
\end{array}
\end{aligned}
$$




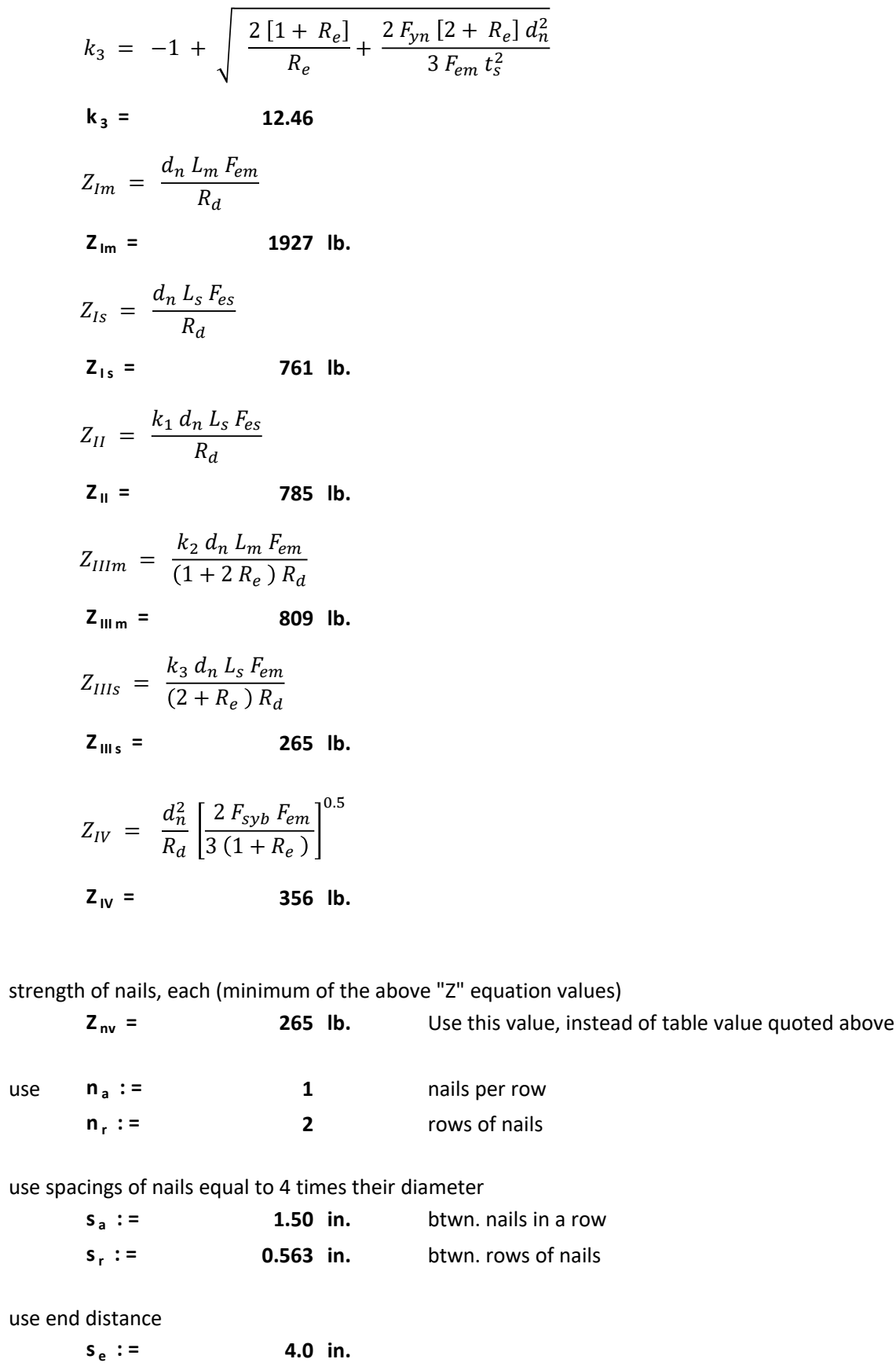




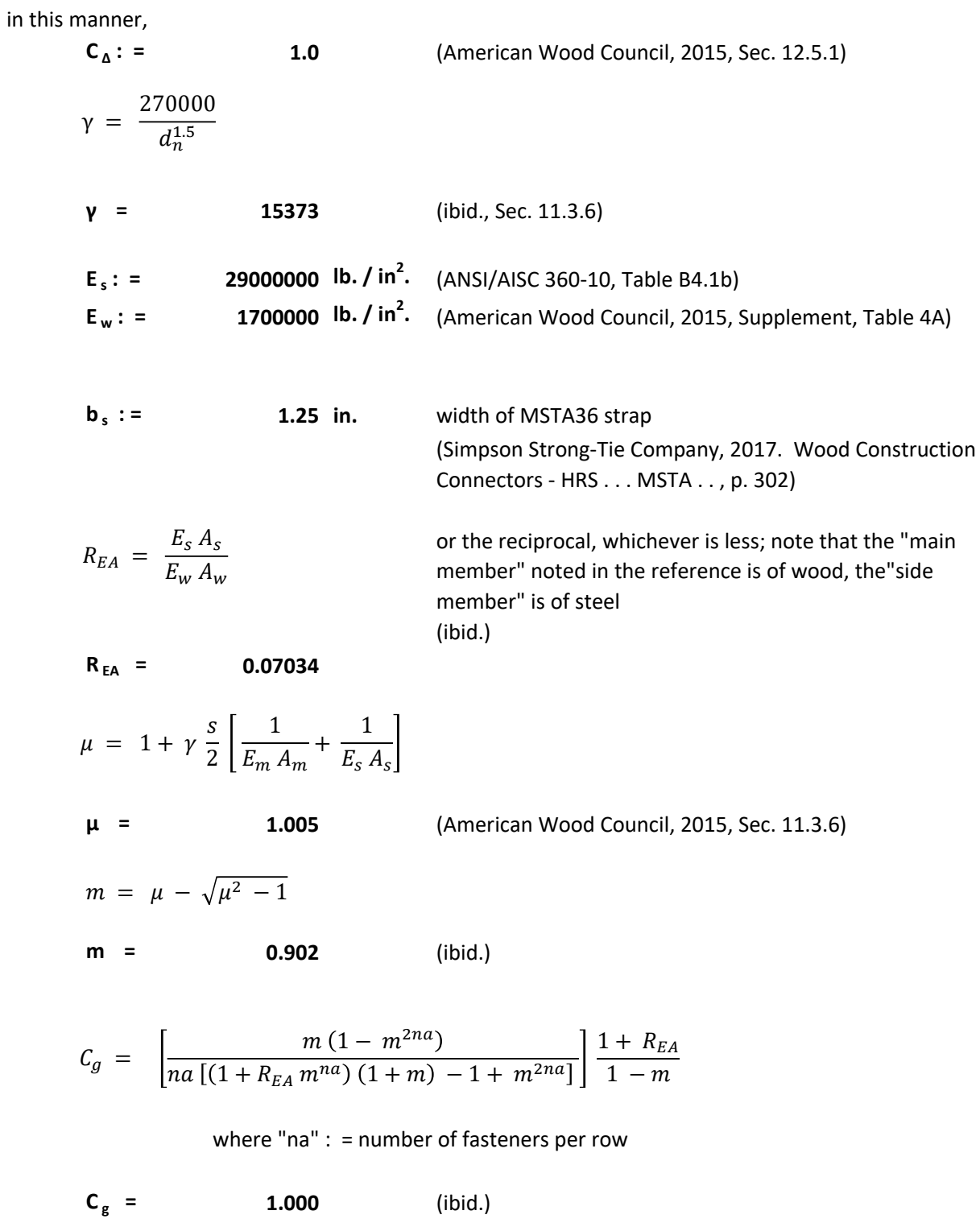

$$
\begin{array}{ll}
V_{\text {na }}= & n Z_{v} C_{D} C_{\Delta} C_{g} \\
\mathbf{v}_{\text {na }}= & \mathbf{3 3 8 6} \mathbf{l b} .
\end{array}
$$


Nail size: $16 \mathrm{~d}$. sinker; with "CSMTC16" strap

Number of nails

$$
\mathrm{n}:=
$$

25
(Simpson Strong-Tie Company, 2017. Wood Construction Connectors - CS/CMST, p. 305); also made geometry calculation

Allowable lateral force per nail; assumed 16-ga steel side plate

$$
\mathbf{Z}_{\text {nvs }} \text { : = }
$$

$116 \mathrm{lb}$.

(American Wood Council, 2015, Table 12P)

diameter of nails, sinker nails

$$
d_{n c}=0.148 \text { in. }
$$

length of nail in wood, aprox.

$\begin{array}{lc}\mathrm{L}_{\mathrm{m}}:= & 3.1 \mathrm{in} . \\ \mathrm{k}_{1}= & 1.14 \\ \mathrm{k}_{2}= & 0.47 \\ \mathrm{k}_{3}= & 12.46 \\ \mathrm{Z}_{\mathrm{Im}}= & 2133 \mathrm{lb} . \\ \mathrm{Z}_{\text {Is }}= & 761 \mathrm{lb} . \\ \mathrm{Z}_{\mathrm{II}}= & 869 \mathrm{lb} . \\ \mathrm{Z}_{\mathrm{III} \mathrm{m}}= & 896 \mathrm{lb} . \\ \mathrm{Z}_{\mathrm{III}}= & 265 \mathrm{lb} . \\ \mathrm{Z}_{\mathrm{IV}}= & 356 \mathrm{lb} .\end{array}$

strength of nails, each

$\mathbf{Z}_{\text {min }}=$

$265 \mathrm{lb}$.

see calculations for nails, above

\section{2}

2

nails per row

$\mathrm{n}_{\mathrm{r}}:=$

rows of nails

use spacings of nails equal to 4 times their diameter
$s_{\mathrm{a}}:=$
1.50 in.
btwn. nails in a row
$s_{\mathrm{r}}:=$
0.563 in.
btwn. rows of nails

use end distance

$\begin{array}{lr}S_{e}:= & 4.0 \text { in. } \\ \gamma= & 15373\end{array}$

see for "MSTA36" straps above, typ. 


\begin{tabular}{|c|c|c|}
\hline$b_{\mathrm{s}}:=$ & 3.00 in. & $\begin{array}{l}\text { width of CMSTA16 strap } \\
\text { (Simpson Strong-Tie Company, 2017. Wood Construction } \\
\text { Connectors - CS/CMST, p. 305) }\end{array}$ \\
\hline$t_{\mathrm{s}}:=$ & 0.0635 in. & $\begin{array}{l}\text { (American Institute of Steel Construction, 2003. Manual of } \\
\text { Steel Construction, Table 17-10) }\end{array}$ \\
\hline $\mathbf{R}_{\mathrm{EA}}=$ & 0.169 & \\
\hline$\mu=$ & 1.002 & \\
\hline$m=$ & 0.933 & \\
\hline$C_{g}=$ & 0.998 & (American Wood Council, 2015, Sec. 11.3.6) \\
\hline \multicolumn{3}{|c|}{ Total nail shear capacity } \\
\hline $\mathrm{V}_{\mathrm{na}}=$ & $10564 \mathrm{lb}$. & \\
\hline [If table values $\mathrm{c}$ & city were $\iota$ & 4632 lb. ] \\
\hline
\end{tabular}




\section{STEEL MEMBERS}

\section{Capacities of steel plates at "collar"}

Dimensions of plates at collar
$b_{c}:=$
4.00 in
$\mathbf{t}_{\mathrm{c}}:=$
0.25 in.

Yield and ultimate stress, steel; assumed: ASTM A36
$F_{\mathrm{y}}:=$
$36000 \mathrm{lb} . / \mathrm{in}^{2}$.
$F_{\mathrm{u}}:=$
$58000 \mathrm{lb} . / \mathrm{in}^{2}$.

Effective bolt hole diameter

$\mathbf{d}_{\mathrm{bh}}=$

0.625 in.

Net width of plates
$\mathbf{b}_{\mathrm{pn}}=$
2.75 in.

Safety factors for tension and bending

$\begin{array}{lll}\Omega_{\mathrm{t}}:= & 1.67 & \text { (ANSI/AISC 360-10, Sec. D2) } \\ \Omega_{\mathrm{tr}}:= & 2.00 & \text { (ibid.) } \\ \Omega_{\mathrm{t}}:= & 1.67 & \text { (ibid., Sec. F1) }\end{array}$

Gross plate tension capacity in yield; 2 plates parallel Assumed: $10 \%$ eccentricity of load

$$
\begin{aligned}
& P_{p g}=\frac{2 b_{c} t_{c} F_{y}}{1.1 \Omega_{t}} \\
& P_{p g}=\quad 39194 \text { lb. } \quad \text { (ibid., Sec. D2) }
\end{aligned}
$$

net plate capacity in ultimate

$$
\begin{aligned}
& P_{p g}=\frac{2\left(b_{c}-2 d_{b h}\right) t_{c} F_{u}}{1.1 \Omega_{t r}} \\
& P_{\mathrm{pn}}=\quad 36250 \mathrm{lb} . \quad \text { (ibid., Sec's. D2, D3) }
\end{aligned}
$$

\section{Capacities of plates connecting wood beam to HSS beam}

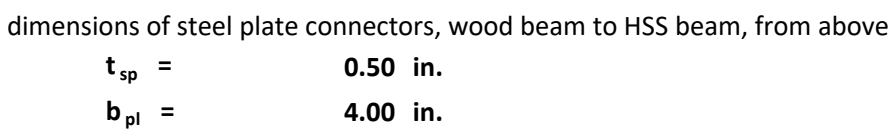

tension capacity of plate, each of 2

$$
\begin{aligned}
P_{\text {tpla }} & =\frac{F_{y} t_{p l} b_{p l}}{\Omega_{t}} \\
\mathbf{P}_{\text {tpla }} & =\quad \mathbf{4 3 1 1 4} \mathbf{l b} . \quad \text { See above for plate cross-section dimensions. }
\end{aligned}
$$


bending capacity of plate, weak direction, each of 2

$$
\begin{aligned}
M_{y p l a} & =\frac{F_{y} t_{p l}^{2} b_{p l}}{6 \Omega_{f}} \\
\mathbf{M}_{\text {ypla }} & =\quad 3593 \text { lb.-in. }
\end{aligned}
$$

strap load that would match plate capacity, with 2 plates

$$
\begin{aligned}
& U_{p l}=\frac{P_{\text {spla }}}{2 P_{\text {tpla }}}+\frac{P_{\text {spla }} e_{p l}}{2 M_{y p l a}}:=1.000 \\
& P_{\text {spla }}=\frac{2}{\frac{1}{P_{t p l a}}+\frac{e_{p l}}{M_{y p l a}}} \\
& \mathbf{P}_{\text {spla }}=\quad 3449 \mathrm{lb} \text {. }
\end{aligned}
$$

\section{Capacities of welds at steel plates at "collar"}

Weld stress capacity, steel; assumed: E70

$$
F_{w}:=\quad 70000 \mathrm{lb} . / \mathrm{in}^{2} \text {. }
$$

use weld thickness

$$
t_{w c}:=\quad 0.188 \text { in. }
$$

use weld length

$\mathrm{L}_{\mathrm{w}}:=\quad 3.500 \mathrm{in}$.

Safety factor for fillet welds

$$
\Omega_{\mathrm{fw}}:=\quad \mathbf{2 . 0 0} \quad \text { (ANSI/AISC 360-10, Sec. D2) }
$$

Strength of collar based on welds, given that there are 2 plates and 2 sides of welds at each plate

$$
\begin{array}{rlrl}
P_{w c} & =2 * \frac{2}{\sqrt{2}} * 1.5 t_{w c} L_{w} \frac{0.60 F_{w}}{\Omega_{f w}} & \text { for load perpendicular to axis of weld } \\
\mathbf{P}_{\mathbf{w c}} & = & \mathbf{5 8 4 6 9} \mathbf{l b} . & \text { (ibid., Sec J2.4) }
\end{array}
$$

\section{Capacities of welds at steel plates to HSS beam}

Since a shim plate was used in middle of weld, consider gap, and resulting bending

Since overlap distance of steel plate on HSS beam is 3.5 inches (measured to corner of beam), conservatively use effective weld length:
$\mathrm{L}_{\mathrm{w}}:=$
2.500 in. 
weld is approximately $3 / 8$ inch thick, but part of thickness is $1 / 4$-in. shim plate; assume effective weld thickness as follows:
$\mathbf{t}_{\mathrm{wp}}:=$
0.125 in.

Strength of connection based on welds, given that there are 2 plates and 2 sides of welds at each plate

$$
\begin{array}{rlr}
P_{w p} & =2 * \frac{2}{\sqrt{2}} t_{w p} L_{w} \frac{0.60 F_{w}}{\Omega_{f w}} & \text { for load parallel to axis of weld } \\
\mathbf{V}^{\prime}{ }_{\mathbf{w}}= & 18562 \mathrm{lb} . & \begin{array}{l}
\text { shear capacity; (ANSI/AISC 360-10, Sec J2.4) } \\
\text { neglecting bending }
\end{array}
\end{array}
$$

Note that bending of welds involves tension and compression parallel to weld axes. According to

ANSI/AISC 360-10, Table J2.5, these axial forces need not be considered separately in design of welds.

\section{Capacities of steel threaded rods used to attach specimen to Universal Test Machine}

Diameter of steel rods

$$
d_{r}:=\quad 1.25 \text { in. }
$$

Yield and ultimate stress, steel; assumed: ASTM A449

$$
F_{\mathrm{ub}}:=105000 \mathrm{lb} . / \mathrm{in}^{2} \text {. (American Institute of Steel Construction, 2003. Manual of }
$$
Steel Construction , Table 2-3)

Effective rod cross-section area

$$
A_{t s}:=\quad 0.969 \text { in }^{2} . \quad \text { (ibid., Table 7-4) }
$$

Safety factor for tension

$$
\Omega_{\mathrm{t}}:=
$$

(ANSI/AISC 360-10, Sec. J3.6)

Rod tension capacity

$$
\begin{array}{rlr}
P_{\text {thr }} & =\frac{0.75 \emptyset_{t b} A_{t s} F_{u b}}{\Omega_{t b}} \\
\mathbf{P}_{\mathrm{thr}} & =\mathbf{3 8 1 5 4} \mathrm{lb.} & \text { (ibid., Table J3.2) }
\end{array}
$$


Capacities of welds at steel nuts at threaded rods to HSS beam or "collar"

width of nut; equals twice edge length

$\mathrm{C}_{\mathrm{n}}:=\quad \mathbf{1 . 8 7 5}$ in.

(American Institute of Steel Construction, 2003. Manual of Steel Construction , Table 7-6)

weld length

$\mathrm{L}_{\mathrm{w}}:=\quad 5.625$ in.

see section on "collar" weld for items not shown here

Strength of weld
$P_{w}=1.5 \frac{0.60 F_{w}}{\Omega_{f w}} t_{w} L_{w}$
for load perpendicular to axis of weld
$\mathbf{P}_{\mathrm{w}}=$
$33223 \mathrm{lb}$.
(ANSI/AISC 360-10, Sec J2.4) 


\section{BOLTS, STEEL-MEMBERS-TO-WOOD}

\section{Capacities of steel-to-wood bolts in shear at "collar"}

use bolt diameter

$$
d_{b}:=\quad 0.500 \text { in. }
$$

"raw" bolt capacity, 1/2-in. dia., x $31 / 2$ in. length, double shear btwn. plates

$$
\mathbf{Z}_{\text {III }}:=\quad \mathbf{1 6 5 0} \mathrm{lb} . \quad \text { (American Wood Council, 2015, Table 12G) }
$$

use $\quad \mathrm{n}_{\mathrm{a}}:=\quad \mathbf{2} \quad$ bolts per row

$\mathrm{n}_{\mathrm{r}}:=\quad \mathbf{2}$ rows of bolts

use spacings of bolts equal to 4 times their diameter
$\mathrm{s}_{\mathrm{a}}:=$
2.0 in.
btwn. bolts in a row
$s_{\mathrm{r}}:=$
2.0 in.
btwn. rows of bolts

use end distance
$s_{\mathrm{e}}:=$
4.0 in.

in this manner,

$\mathrm{C}_{\Delta}:=\quad \mathbf{1 . 0}$

$\gamma=$

95459 lb. / in. see calculations for nails, above; substitute "bolt" for "nail", typ.

$\begin{array}{lll}\mathrm{R}_{\text {EA }}= & 0.886 & \\ \mu= & 1.005 & \text { see calculations for nails, above } \\ \mathrm{m}= & 0.907 & \text { see calculations for nails, above } \\ \mathrm{C}_{\mathrm{g}}= & 1.000 & \text { see calculations for nails, above }\end{array}$

Total bolt shear capacity

$$
\mathrm{z}_{\mathrm{t}}=
$$

$10557 \mathrm{lb}$.

\section{Capacities of steel-to-wood bolts in shear, steel plates at wood beam}

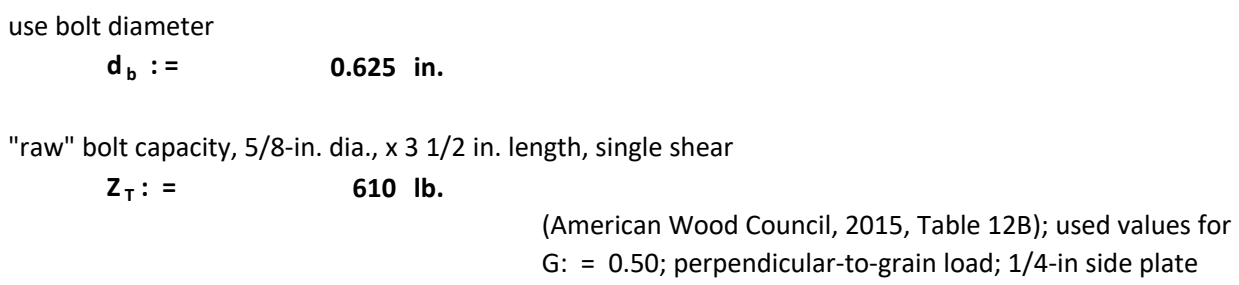


Allowable lateral force per bolt by Eq'ns. 12.3-1 thru 12.3-6, NDS; assumed 16-ga steel side plate

\begin{tabular}{|c|c|c|}
\hline$F_{\mathrm{emb}}:=$ & 2800 lb. $/ \mathrm{in}^{2}$ & $\begin{array}{l}\text { (American Wood Council, 2015, Table 12.3.3); used values } \\
\text { for G: }=0.50\end{array}$ \\
\hline $\mathrm{K}_{\theta}:=$ & 1.25 & \\
\hline $\mathbf{R}_{\mathrm{d}_{1} \mid}:=$ & 5.00 & \\
\hline $\mathbf{R}_{\mathrm{d}_{-} \|}:=$ & 4.50 & \\
\hline $\mathbf{R}_{\mathrm{d}_{\text {_IIII }}:}:=$ & 4.00 & \\
\hline $\mathbf{R}_{\mathrm{d} \_I V}:=$ & 4.00 & \\
\hline
\end{tabular}

length of bolt in wood, aprox.

$\mathbf{k}_{1}$

$\mathbf{k}_{2}=$

$\mathbf{k}_{3}=$

$\mathrm{Z}_{\mathrm{Im}}=$

$\mathrm{Z}_{1 \mathrm{~s}}=$

$\mathrm{Z}_{11}=$

$\mathrm{Z}_{\text {III } \mathrm{m}}=$

$\mathbf{Z}_{\text {III s }}=$

$\mathrm{Z}_{\mathrm{IV}}=$

0.13

0.58

9.04

$1225 \mathrm{lb}$.

$5063 \mathrm{lb}$.

$757 \mathrm{lb}$.

$802 \mathrm{lb}$.

$962 \mathrm{lb}$.

1231 lb.
3.5 in.

see calculations for nails, above

strength of bolts, each

$\mathbf{Z}_{\text {min }}=$

$757 \mathrm{lb}$.

use

$\mathrm{n}_{\mathrm{a}}:=$

2

bolts per row

use spacings of bolts equal to 4 times their diameter

$\begin{array}{lrl}S_{\mathrm{a}}:= & 2.0 \text { in. } & \text { btwn. bolts in a row } \\ \nu= & 133409 & \text { see calculations for nails, above } \\ \mathrm{R}_{\mathrm{EA}}= & 0.886 & \\ \mu= & 1.007 & \text { see calculations for nails, above } \\ \mathrm{m}= & 0.891 & \\ \mathrm{C}_{\mathrm{g}}= & 1.000 & \end{array}$

Total bolt shear capacity; one row of bolts only; not loaded toward, nor near, end of member

$\mathrm{z}_{\mathrm{t}}=$ $2420 \mathrm{lb}$.

based on loading of beam, 2 ends

$\mathbf{v}_{\mathrm{bb}}=$

$4841 \mathrm{lb}$. 


\section{SUMMARY - VERTICAL FORCE CAPACITIES}

NOTE: These capacities are allowable values. Safety factors are presumed to have been incorporated into these results (and may differ from one type of load to another). Therefore, actual strengths may be much greater.

based on tension capacity, MSTA36 strap

$2050 \mathrm{lb}$.

based on tension capacity, CMSTC16 strap

$4585 \mathrm{lb}$.

based on shear capacity of beam with torsion

$5708 \mathrm{lb}$.

based on tension capacity of posts with bending

8827 lb.

based on shear of beam

$19974 \mathrm{lb}$.

based on bending of beam

$33812 \mathrm{lb}$.

based on shear capacity of nails, MSTA36 strap

$3386 \mathrm{lb}$.

based on shear capacity of nails, CMSTC16 strap

$10564 \mathrm{lb}$.

based on tension and bending in steel plates, P-to-B only

$3449 \mathrm{lb}$.

based on wood-to-steel bolts at HSS beam, P-to-B only

based on shear capacity of bolts at "collar"

$4841 \mathrm{lb}$.

$10557 \mathrm{lb}$.

based on tension capacity of plates, net

$36250 \mathrm{lb}$.

based on tension capacity of threaded rods

$38154 \mathrm{lb}$.

based on tension capacity of plates, gross

$39194 \mathrm{lb}$.

based on welds at HSS beam, P-to-B only

$18562 \mathrm{lb}$.

based on welds at nuts at threaded rods

$33223 \mathrm{lb}$.

based on welds at "collar"

$58469 \mathrm{lb}$.

\section{MSTA36 Post-to-Post}

strap

nails to strap

wood-to-steel bolts at beam

tension of post with bending

bolts at "collar"

welds at HSS beam

welds at nuts at threaded rods

threaded rods

welds at "collar"

$2050 \mathrm{lb}$.

$3386 \mathrm{lb}$.

$4841 \mathrm{lb}$.

$8827 \mathrm{lb}$.

$10557 \mathrm{lb}$.

$18562 \mathrm{lb}$.

$33223 \mathrm{lb}$.

$38154 \mathrm{lb}$.

$58469 \mathrm{lb}$. 
MSTA36 Post-to-Beam

strap

$2050 \mathrm{lb}$.

nails to strap

$3386 \mathrm{lb}$.

tension and bending in steel plates at P-to-B

$3449 \mathrm{lb}$.

wood-to-steel bolts at beam

$4841 \mathrm{lb}$.

shear of beam with torsion

$5708 \mathrm{lb}$.

tension of post with bending

$8827 \mathrm{lb}$.

bolts at "collar"

welds at HSS beam

$10557 \mathrm{lb}$.

welds at nuts at threaded rods

$18562 \mathrm{lb}$.

bending of beam

threaded rods

$33223 \mathrm{lb}$.

$33812 \mathrm{lb}$.

welds at "collar"

$38154 \mathrm{lb}$.

$58469 \mathrm{lb}$.

\section{CSMTC16 Post-to-Post}

strap

wood-to-steel bolts at beam

$4585 \mathrm{lb}$.

tension of post with bending

bolts at "collar"

nails to strap

welds at HSS beam

welds at nuts at threaded rods

threaded rods

welds at "collar"

4841 lb.

$8827 \mathrm{lb}$.

$10557 \mathrm{lb}$.

$10564 \mathrm{lb}$.

$18562 \mathrm{lb}$.

$33223 \mathrm{lb}$.

$38154 \mathrm{lb}$.

$58469 \mathrm{lb}$.

\section{CSMTC16 Post-to-Beam}

tension and bending in steel plates at P-to-B

$3449 \mathrm{lb}$.

strap

$4585 \mathrm{lb}$.

wood-to-steel bolts at beam

shear of beam with torsion

$4841 \mathrm{lb}$.

$5708 \mathrm{lb}$.

tension of post with bending

$8827 \mathrm{lb}$.

bolts at "collar"

$10557 \mathrm{lb}$.

nails to strap

welds at HSS beam

$10564 \mathrm{lb}$.

$18562 \mathrm{lb}$.

welds at nuts at threaded rods

$33223 \mathrm{lb}$.

bending of beam

$33812 \mathrm{lb}$.

threaded rods

welds at "collar"

$38154 \mathrm{lb}$.

$58469 \mathrm{lb}$. 


\section{DESIGN OF LATERAL RESTRAINT}

\section{Effect of eccentricity of strap on strap load, MSTA36 strap}

length of post

$$
L_{p}=\quad 36.00 \text { in. }
$$

\section{Bending and torsion loads based on strap capacities, MSTA36 strap}

bending of post and torsion of beam, MSTA36

$$
M_{s a}=e_{s t} P_{s u}
$$

assumed: strap ultimate breaking capacity is

$$
\mathbf{\Omega}_{\text {st }}:=
$$

3.00 times rated capacity

Then, strap ultimate capacity is:

$$
\begin{array}{ll}
P_{s u}=\Omega_{s t} P_{s a} & \\
\mathbf{P}_{\text {su }}= & \mathbf{6 1 5 0} \mathbf{l b} \text {.-in. }
\end{array}
$$

angle of deflection of post in tension due to eccentricity of strap, without lateral restraint

$$
\begin{array}{lr}
\alpha_{p t}=\operatorname{atan}\left[\frac{e_{s t}}{L_{p}}\right] & \\
\boldsymbol{\alpha}_{\mathrm{pt}}= & 0.0495 \mathrm{rad} . \\
2.8 \mathrm{deg} .
\end{array}
$$

Required restorative horizontal force, for ultimate load

$$
\begin{array}{lr}
P_{\text {res_MSTA }}= & 2 P_{s u} \tan \left(\alpha_{p t}\right) \\
\mathbf{P}_{\text {res_MSTA }}= & \mathbf{6 0 9} \mathbf{l b .} .
\end{array}
$$


Effect of eccentricity of strap on strap load, CMSTC16 strap

eccentricities of loading, beam and post, from above
$\mathbf{e}_{\text {sct }}=$
1.78 in.

Bending and torsion loads based on strap capacities, CMSTC16 strap

strap ultimate breaking capacity, assumed, given safety factor stated above:

$P_{\text {cu }}=\quad 13755 \mathrm{lb}$.-in.

angle of deflection of post in tension due to eccentricity of strap

$\alpha_{\mathrm{pt}}=\quad 0.0495 \mathrm{rad}$.

$=\quad 2.8 \mathrm{deg}$.

Required restorative horizontal force, for ultimate load

$P_{\text {res_cmstc }}=1362 \mathrm{lb}$. 


\section{BENDING CAPACITY OF POSTS OF UNIVERSAL TEST MACHINE (UTM)}

NOTE:

All calculations in this Section, only, are based upon Strength Design (SD) capacities, equations and values.

\section{Dimensions of posts}

post is cylindrical, with narrow points; diameter at narrows:

$$
D_{p n}:=\quad 3.125 \text { in. }
$$

cross-section area of post at narrows, each

$$
\begin{array}{ll}
A_{p n}=\frac{\pi D_{p n}^{2}}{4} & \\
\mathbf{A}_{\mathrm{pn}}= & 7.67 \mathrm{in}^{2} .
\end{array}
$$

section modulus of post at narrows, each

$$
\begin{array}{ll}
S_{p n} & =\frac{\pi D_{p n}^{3}}{32} \\
S_{\text {pn }} & = \\
& 2.996 \mathrm{in}^{3} .
\end{array}
$$

effective length of post of UTM, with specimen installed; conservatively assume:

$$
\mathrm{L}_{\text {UTM }}:=\quad 120.00 \text { in. }
$$

Bending and compression loads on posts of UTM based on strap capacities, CMSTC16 strap

assumed: maximum-loaded post takes one-half of total load

tension of specimen, ultimate, CMSTC16 strap

$$
\mathbf{P}_{\mathrm{cu}}=\quad \mathbf{1 3 7 5 5 \mathrm { lb } . \quad \text { from above }}
$$

add, estimated, for UTM upper portion self-weight and weight of specimen

$$
P_{\text {UtM_u_o }}:=1400 \mathrm{lb} \text {. }
$$

total load per post, of 2 (Load Factor: = 1.0, typ.)

$$
\begin{aligned}
& P_{S_{-} U T M}=\frac{P_{c u}+P_{U T M \_} u_{-} o}{2} \\
& P_{\text {s_UTM }_{-}}=\quad \mathbf{7 5 7 8} \mathbf{l b} .
\end{aligned}
$$

bending of specimen due to lateral eccentricity, ultimate, CMSTC16 strap, per post, of 2 assumed: lateral restraint at mid-height

$$
\begin{aligned}
& M_{S_{-} U T M}=\frac{P_{\text {res_CMSTC }} L_{U T M}}{4} * \frac{1}{2} \\
& \mathbf{M}_{\text {s_UTM }_{\text {UT }}}=\mathbf{2 0 4 2 3} \mathrm{lb} . \text {-in. }
\end{aligned}
$$




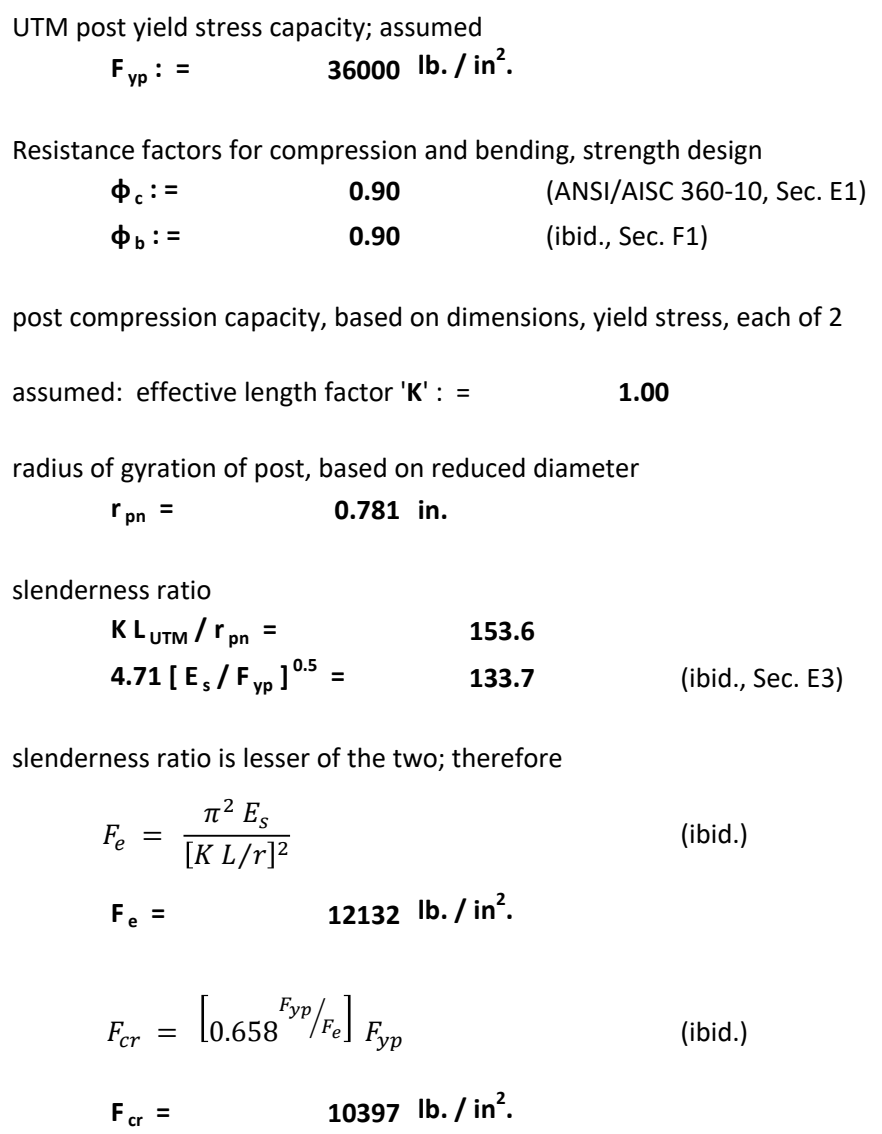

UTM post compression capacity, strength design, based on dimensions at narrows, each

$$
P_{r_{-} U T M}=\phi_{c} A_{p n} F_{c r} \quad \text { (ibid.) }
$$$$
P_{r_{-} U T M}=71767 \mathrm{lb} \text {. }
$$

post bending capacity, strength design, each

$$
\begin{aligned}
& M_{r_{-} \text {UTM }}=\phi_{b} S_{p n} F_{y p} \\
& \mathbf{M}_{r_{-} \text {UTM }}=\quad 97072 \quad \mathrm{lb} . \text {-in. }
\end{aligned}
$$

interaction in demand-vs.-capacity, 2 posts of UTM, CMSTC16 strap 
demand-capacity ratio of compression
$\mathbf{P}_{\text {S_UTM }_{-} / \mathbf{P}_{r_{-} \text {UTM }}=} \mathbf{0 . 1 0 6}$

compr. D/C ratio is less than $\quad 0.20 ;$ therefore

$$
\begin{gathered}
U_{U T M}=\frac{P_{S_{-} U T M}}{2 P_{r_{-} U T M}}+\frac{M_{S_{-} U T M}}{M_{r_{-} U T M}} \\
\mathbf{U}_{\text {UTM }}=\quad 0.263
\end{gathered}
$$

This value is less than unity, thus, no yielding is predicted. 


\section{GEOMETRIC CONSIDERATIONS}

\section{"Critical zone"}

Dimensions of beam, from above

$\begin{array}{lll}b_{b}= & 3.50 \text { in. } & \text { width } \\ h_{b}= & 9.25 \text { in. } & \text { depth }\end{array}$

thickness of wooden plates

$t_{p l}=\quad 1.50$ in. depth; width of plates is same as that of beam

thickness of plywood floor

$\mathbf{t}_{\mathrm{fl}}=\quad \mathbf{0 . 7 5}$ in. depth

nail end distance (dist., nail to joint btwn. post, plate)
$x_{\mathrm{ne}}:=$
1.00 in.

Length of "critical zone" at floor: beam with plates and plywd., Post-to-Post, in specimen

$$
\begin{aligned}
& L_{c r_{-} P P}=h_{b}+3 t_{p l}+t_{f l}+2 x_{n e} \\
& \mathrm{~L}_{\mathrm{cz} \_\mathrm{PP}}= \\
& 16.50 \text { in }
\end{aligned}
$$

Length of floor "critical zone": plates and plywd., Post-to-Beam, in specimen

$$
\begin{array}{ll}
L_{c r_{-} P B}= & t_{p l}+t_{f l}+2 x_{n e} \\
\mathbf{L}_{\mathrm{cz}_{-} \mathrm{PB}}= & 4.25 \mathrm{in} .
\end{array}
$$

wrap-around length available on beam

$$
\begin{aligned}
& L_{w a}=b_{b}+2 h_{b} \\
& \mathbf{L}_{\text {wa }}=\quad \mathbf{2 2 . 0 0 ~ i n .}
\end{aligned}
$$

\section{Nailing length, MSTA36}

length of strap, MSTA36

$$
\begin{array}{ll}
\mathrm{L}_{\text {MSTA }}=\quad 36.00 \text { in. } \quad & \text { (Simpson Strong-Tie Company, 2017. Wood Construction } \\
& \text { Connectors - HRS ... MSTA .., p. 302) }
\end{array}
$$

length of MSTA36 strap available for nailing, each side of floor, in Post-to-Post situation

$$
\begin{aligned}
& L_{n_{-} M S T A}=\frac{L_{M S T A}-L_{c r_{-} P P}}{2} \\
& \mathbf{L}_{n_{n} \text { MSTA }}=\quad 9.75 \mathrm{in.}
\end{aligned}
$$


nail spacing, MSTA36

$$
S_{n_{-} M}:=\quad 1.50 \text { in. }
$$

Number of nails per row, MSTA36

$$
\mathrm{n}_{\mathrm{n}}:=\quad \mathbf{1}
$$

Number of nails at ends, MSTA36

$$
\mathrm{n}_{\mathrm{e}}: \mathbf{3}
$$

Number of nail holes available in MSTA36, either side, post-to-post

$$
n_{e a}=\operatorname{int}\left(\frac{L_{n \_} M S T A}{s_{n \_} M}-2 x_{n e}\right) n_{n}+n_{e}
$$

$\mathrm{n}_{\text {ea }}=\mathbf{7}$

\section{Nailing length and cutting length, CMSTC16}

end length of strap, CMSTC16

$$
\begin{array}{ll}
\mathrm{L}_{\mathrm{e}_{-} \text {смSTс }}=20.00 \text { in. } & \text { (Simpson Strong-Tie Company, 2017. Wood Construction } \\
& \text { Connectors - CS/CMST, p. 305) }
\end{array}
$$

nail spacing, CMSTC16

$$
s_{n_{-} C}:=\quad 1.50 \text { in. }
$$

Number of nails per row, CMSTC16

$$
\mathbf{n}_{\mathrm{n}}:=
$$

Number of nail holes available in CMSTC16 in end length, either side, post-to-post

$$
\mathrm{n}_{\mathrm{e}}=
$$

nailing length, CMSTC16

$$
\begin{array}{lr}
L_{n \_ \text {_MSTC }}=\left(n_{e}-n_{n}\right) \frac{s_{n_{-} C}}{n_{n}} \\
\mathbf{L}_{n_{-} \text {СMSTC }}= & 18.00 \text { in. }
\end{array}
$$

minmum total strap length required in Post-to-Post

$$
\begin{array}{ccc}
L_{t_{-} C M S T C} & =L_{C r_{-} P P}+2\left(L_{n_{-} C M S T C}+x_{n e}\right) & \\
\mathbf{L}_{\mathbf{t}_{-} \mathrm{CMSTC}}= & \mathbf{5 4 . 5 0} \text { in. } \quad \text {, but use } & \mathbf{6 0 . 0 0} \text { in. } \\
\text { minmum total strap length required in Post-to-Beam } & =
\end{array}
$$

$L_{t_{-} \text {CMSTC }}=\quad 42.25$ in. $\quad$, but use $L_{t_{-} \text {CMSTC }}:=\quad 48.00$ in.




\section{Elongations and strains}

strap stress capacity, steel; given: ASTM A653, SS designation, for both MSTA36 and CMSTC16 (ICC Evaluation Service, 2017, p.3):

see also Assumption \# 8

$$
\begin{aligned}
& \mathbf{F}_{\text {yst }}:=\quad \mathbf{5 0 0 0 0} \mathbf{l b} . / \mathrm{in}^{2} \text {. yield } \quad \text { (ICC Evaluation Service, 2017, Table } 3 \text { for } \\
& F_{\text {ust }}:=\quad 65000 \mathrm{lb} . / \mathrm{in}^{2} \text {. ultimate (ibid.) }
\end{aligned}
$$

stretch length assumed: critical zone, plus 2/4 times nailing length, Post-to-Post

$$
\begin{aligned}
& L_{S_{-} P P_{-} M S T A}=L_{c r_{-} P P}+2 / 4 L_{n \_M S T A}
\end{aligned}
$$

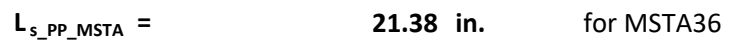

$$
\begin{aligned}
& \mathrm{L}_{\mathrm{s}_{-} \mathrm{PP} \mathrm{C}_{-} \mathrm{CMSTC}}=\mathbf{2 5 . 5 0} \text { in. } \quad \text { for CMSTC16 }
\end{aligned}
$$

stretch length: critical zone, plus 2/4 times nailing length, Post-to-Beam

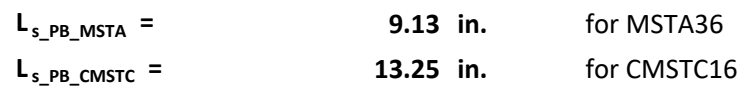

predicted strain at yield

$$
\begin{aligned}
& \epsilon_{y}=\frac{F_{y s t}}{E_{s}} \\
& \epsilon_{\mathbf{y}}=
\end{aligned}
$$$$
0.0017
$$

yield elongation distances

$\begin{array}{lll}x_{y_{-} P P \_M S T A}=\epsilon_{y} L_{S_{-} P P_{-} M S T A} & & \\ \mathbf{x}_{\mathbf{y}_{-} \text {PP_MSTA }}= & 0.037 \text { in. } & \text { for MSTA36, Post-to-Post } \\ \mathbf{x}_{\mathbf{y}_{-} \text {PB_MSTA }}= & 0.016 \text { in. } & \text { for MSTA36, Post-to-Beam } \\ \mathbf{x}_{\mathbf{y}_{-} \text {PP_CMSTC }}= & 0.044 \text { in. } & \text { for CMSTC16, Post-to-Post } \\ \mathbf{x}_{\mathbf{y}_{-} \text {PB_CMSTC }}= & 0.023 \text { in. } & \text { for CMSTC16, Post-to-Beam }\end{array}$




\section{ASSUMPTIONS MADE}

1. Strength of wood in torsion (shear stress) is equal to that of wood in ordinary shear.

2 Wood will be fully dried, and in dry use only.

3. Shear and torsion interaction in beam follows relation: $\left[f_{v} / F_{v}\right]+\left[f_{t} / F_{t}\right]:<=1.00$

4. Grade of steel plates is ASTM A36.

5. Grade of steel brackets is ASTM A36.

6. Grade of steel bolts is ASTM A307.

7. Grade of steel threaded rods is ASTM A449. 


\section{Appendix C. Photographs of Test Specimens}

\section{Appendix Contents}

Figure C-1. Upper collar and upper head of UTM and load cell ............. C-3

Figure C-2. Nut at threaded rod at upper head of UTM.................. C-3

Figure C-3. Lateral restraint attached to UTM, side view.................. C-4

Figure C-4. Lateral restraint attached to UTM, from above............... C-4

Figure C-5. Lateral restraint attached to UTM, from below............... C-5

Figure C-6. Lower collar ................................................. C-5

Figure C-7. Lower collar and lower head of UTM..................... C-6

Figure C-8. Nut at threaded rod at lower head of UTM................... C-6

Figure C-9. TSM1 - Strap nailed, ready to lift into place................... C-7

Figure C-10. TSM1 - Specimen mounted in UTM....................... C-7

Figure C-11. TSM1 - Specimen mounted in UTM, with wire pot.............. C-8

Figure C-12. TSM1 - Specimen mounted in UTM, side view............... C-8

Figure C-13. TSM1 - Specimen mounted in UTM, front view, lower portion... C-9

Figure C-14. TSM1 - Specimen mounted in UTM, front view, upper portion ... C-9

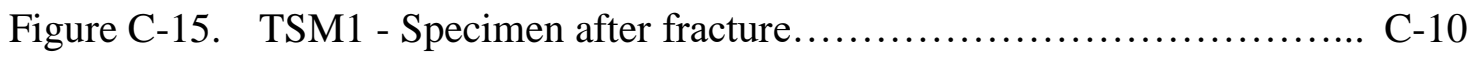

Figure C-16. TSM1 - Specimen after fracture, detail..................... C-10

Figure C-17. TSM1 - Specimen taken down and wood returned to original configuration after fracture, showing elongation............... C-11

Figure C-18. TSM2 - Specimen mounted in UTM, front and side view.......... C-11 
Figure C-19. TSM2 - Specimen mounted in UTM, front view from below...... C-12

Figure C-20. TSM2 - Specimen mounted in UTM, front view, detail showing

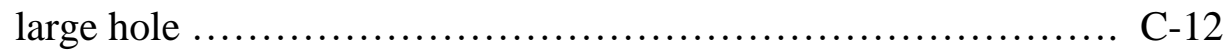

Figure C-21. TSM2 - Specimen mounted in UTM, rear view with lateral restraint.................................................. C-13

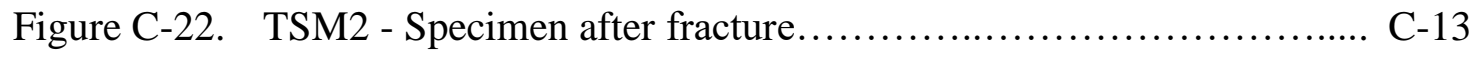

Figure C-23. TSM2 - Piece of strap removed after fracture................... C-14

Figure C-24. TSC1 - Specimen mounted in UTM, front view............... C-14

Figure C-25. TSC1 - Specimen mounted in UTM, front view, wire pot detail... C-15

Figure C-26. TSC1 - Specimen after fracture............................ C-15

Figure C-27. TSC2 - Specimen partly mounted in UTM, front view............. C-16

Figure C-28. TSC2 - Specimen mounted in UTM, front view with wire pot, upper collar, and load cell.............................. C-16

Figure C-29. TSC2 - Specimen mounted in UTM, front view................ C-17

Figure C-30. TSC2 - Specimen mounted in UTM, front and side view......... C-17

Figure C-31. TSC2 - Specimen mounted in UTM, rear view with lateral restraint............................................... 18

Figure C-32. TSC2 - Specimen mounted in UTM, rear view with lateral restraint.............................................. 18

Figure C-33. TSC2 - Specimen after fracture, disassembled.................. C-19

NOTE: The symbols "TSM1", “TSM2", "TSC1" and "TSC2" refer to the tests performed. See Table 3.B in text. "UTM" refers to Universal Test Machine. See Page 10 of text. 


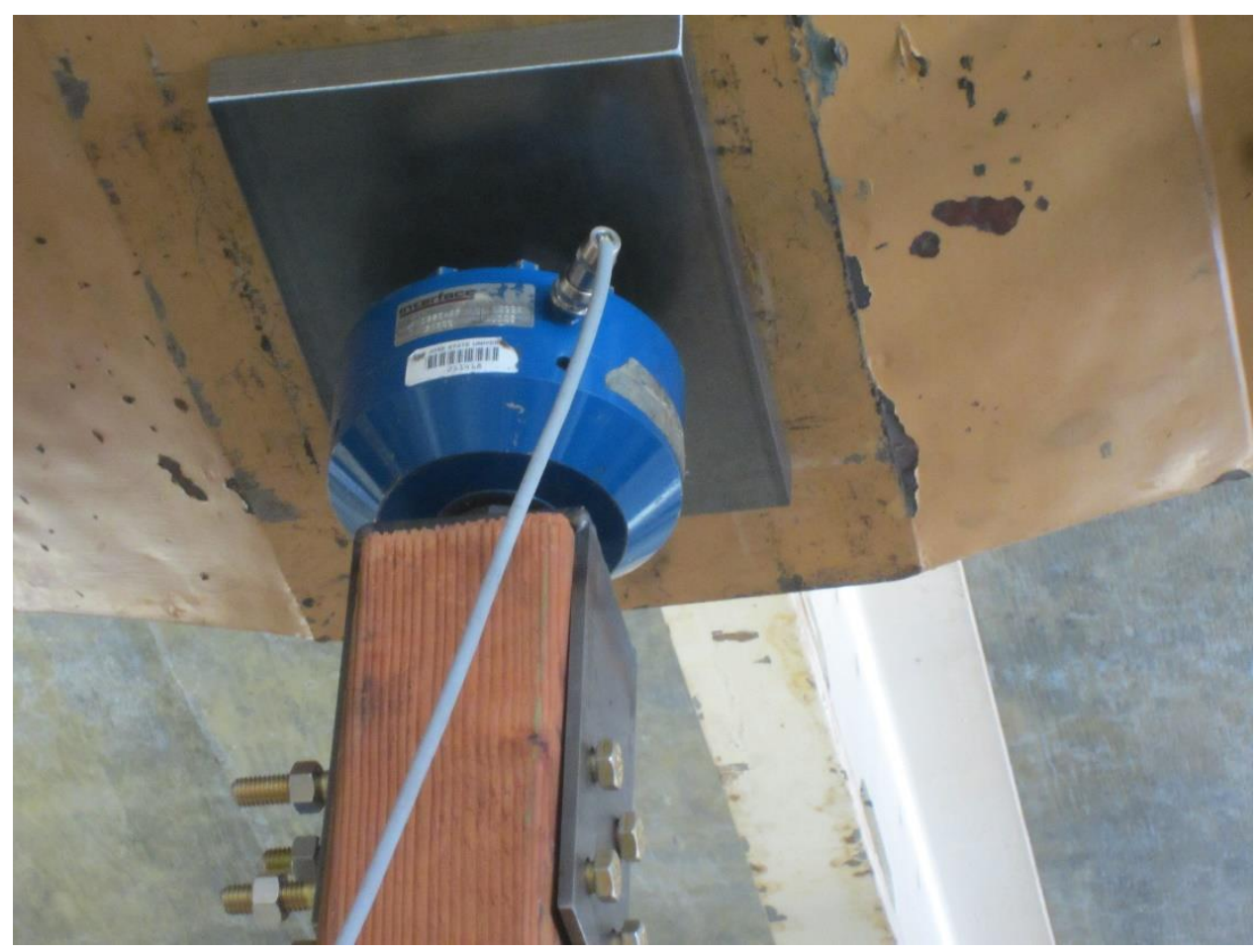

Figure C-1. Upper collar and upper head of UTM and load cell.

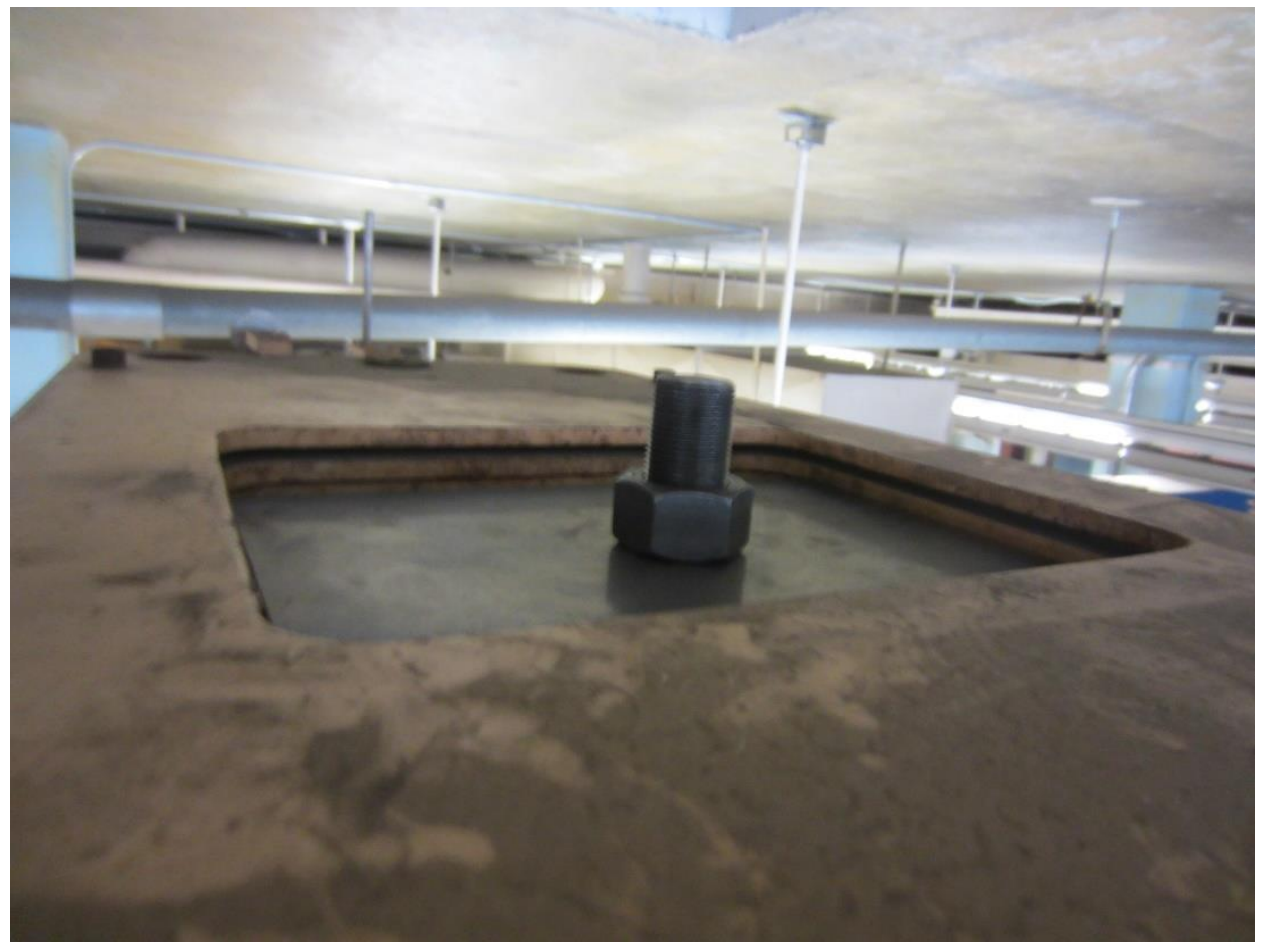

Figure C-2. Nut at threaded rod at upper head of UTM. 


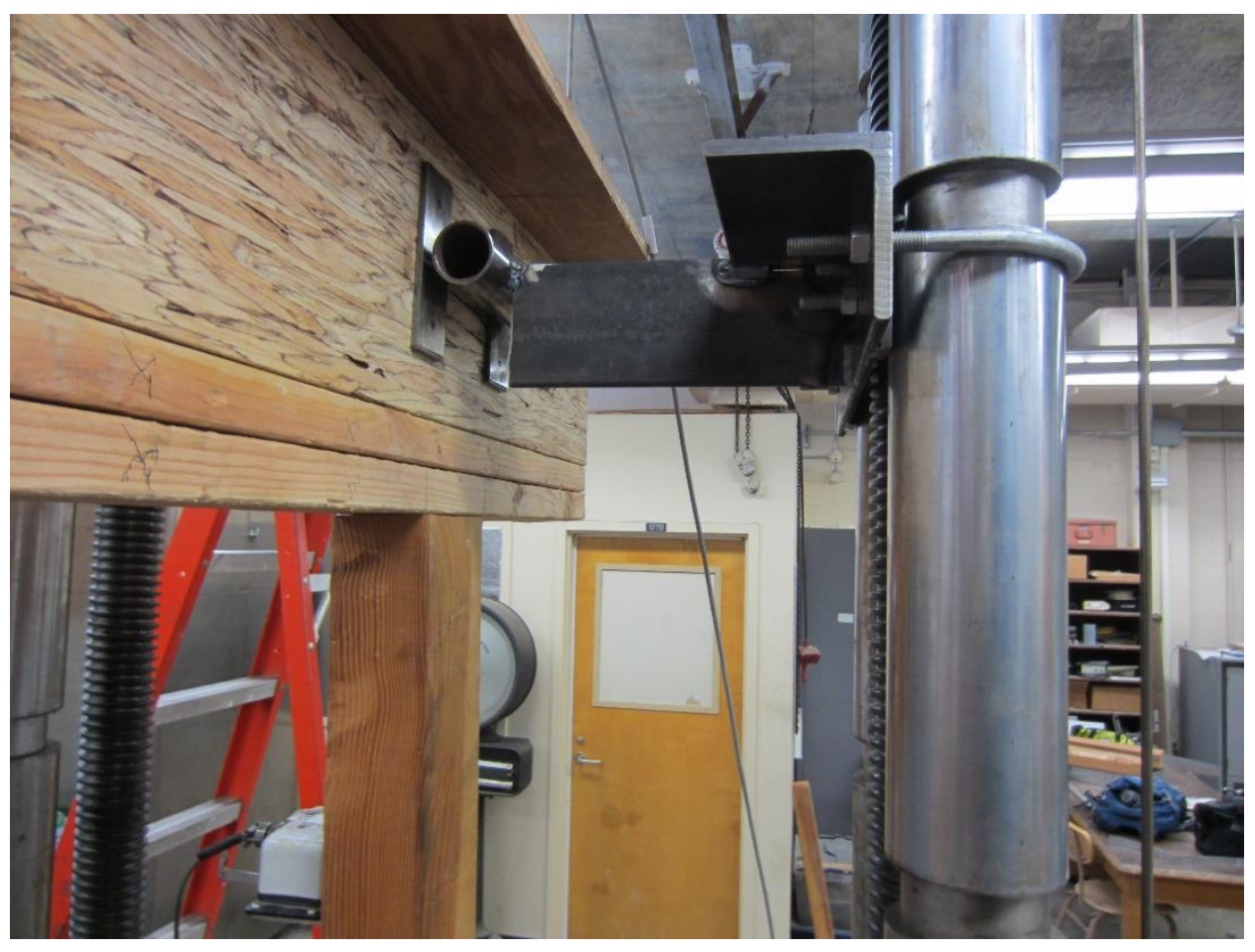

Figure C-3. Lateral restraint attached to UTM, side view.

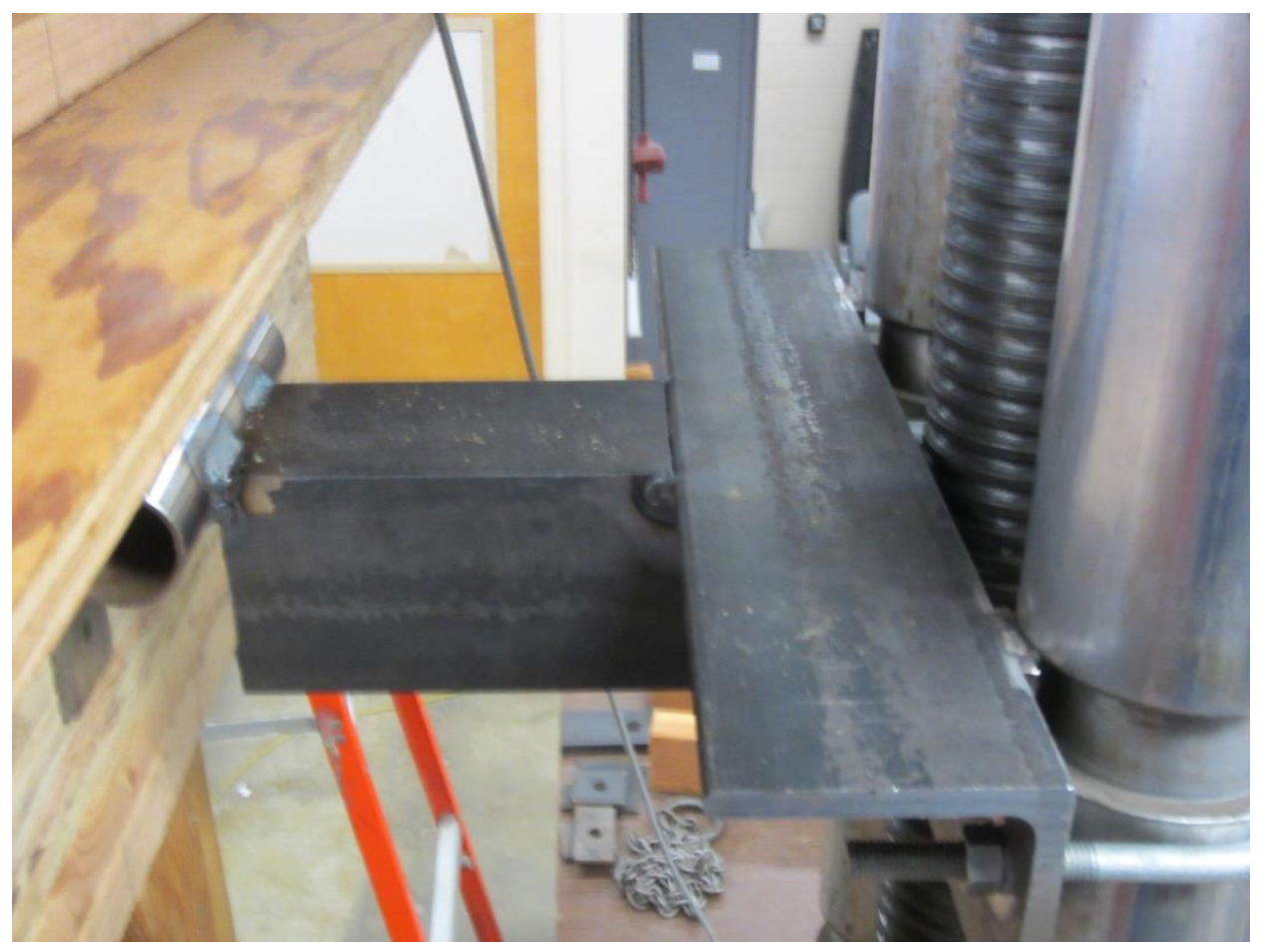

Figure $C$-4. Lateral restraint attached to UTM, from above. 


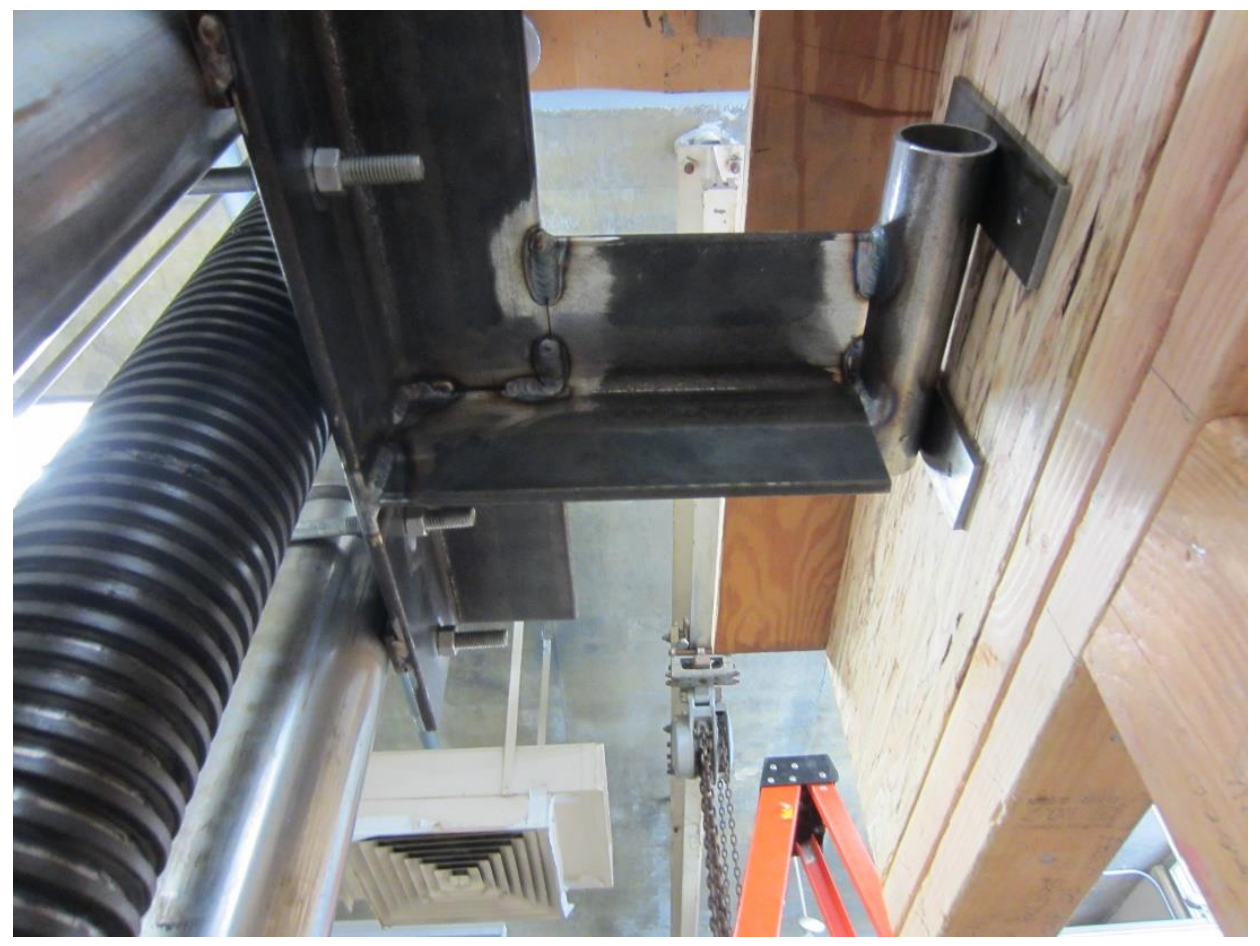

Figure C-5. Lateral restraint attached to UTM, from below.

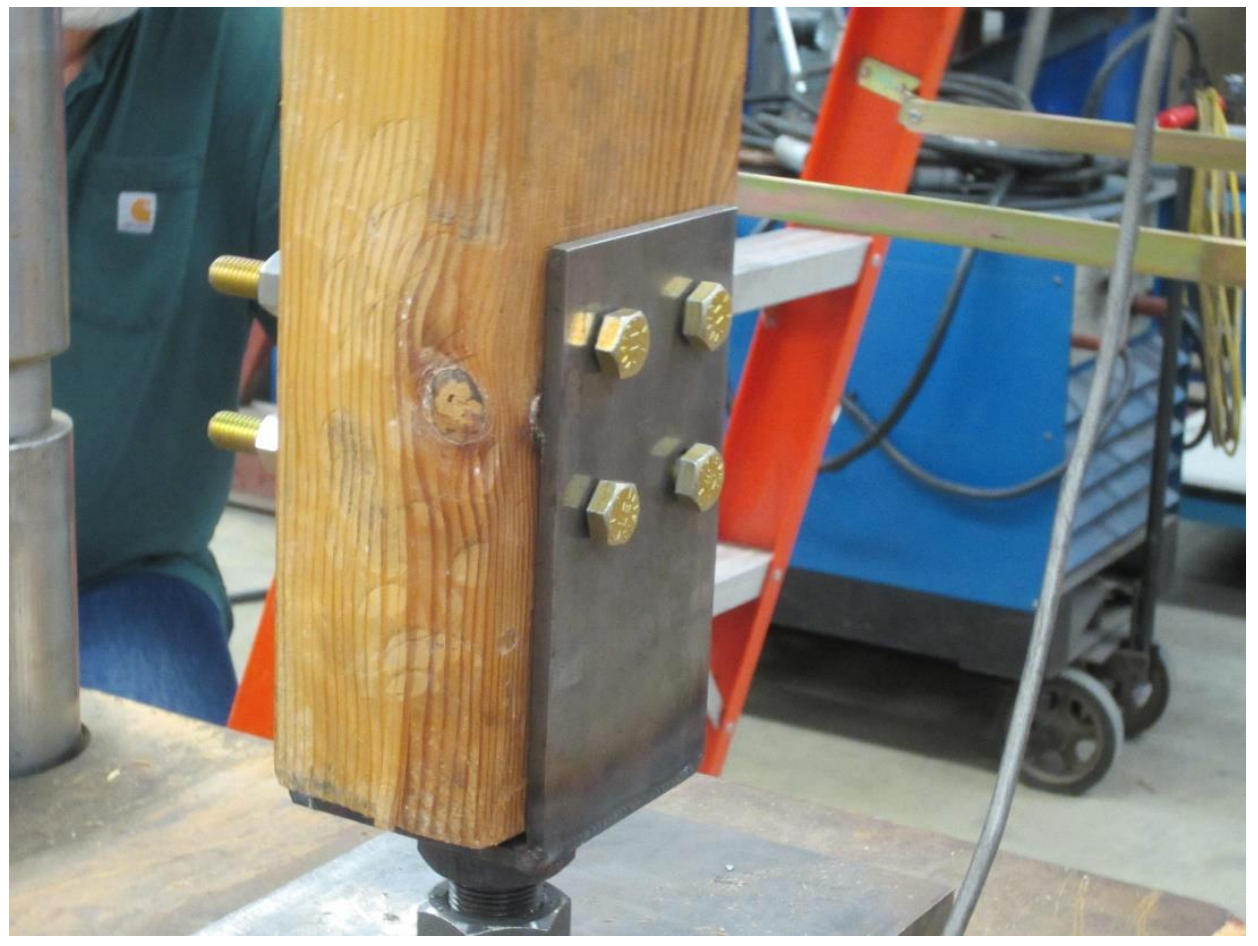

Figure C-6. Lower collar. 


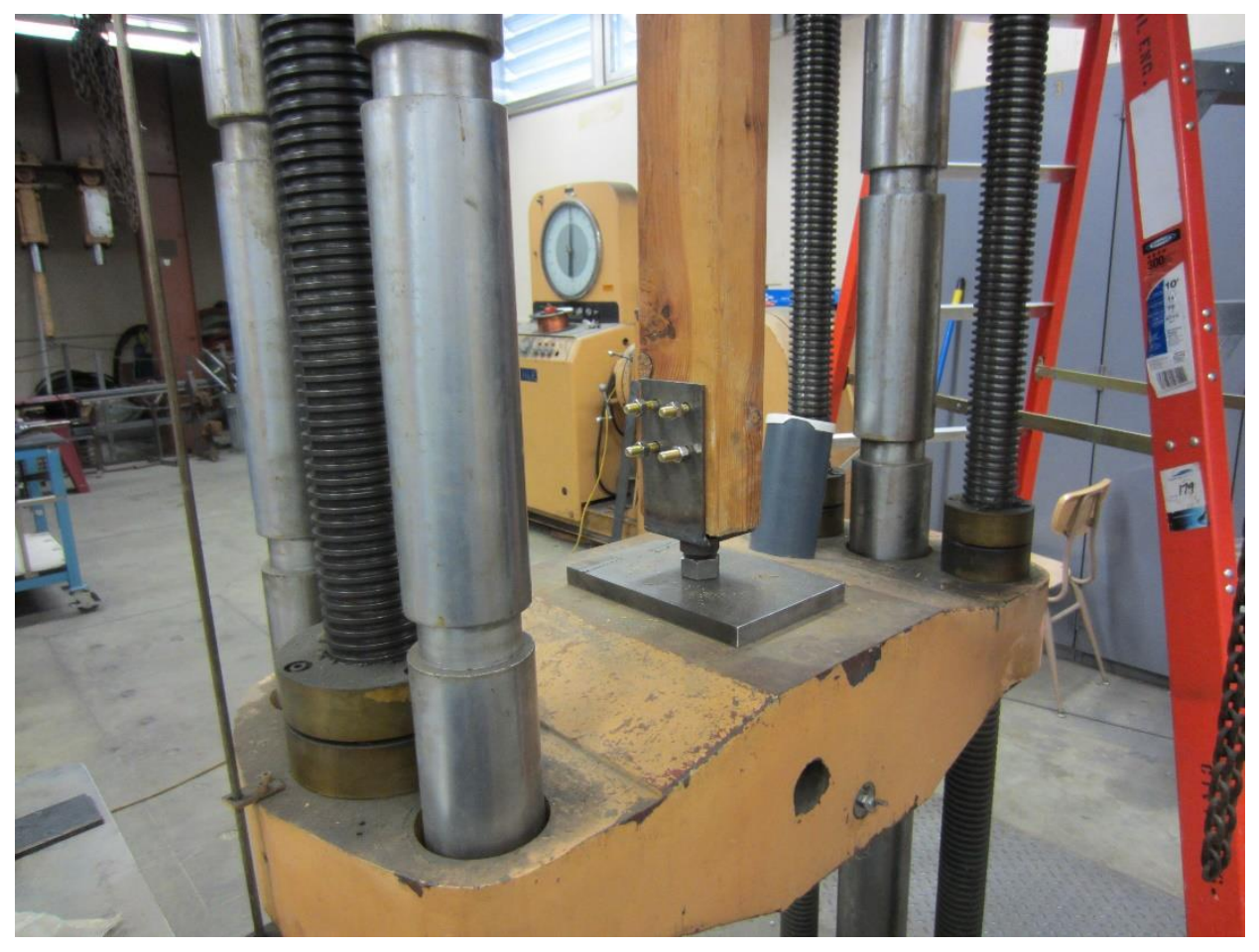

Figure C-7. Lower collar and lower head of UTM.

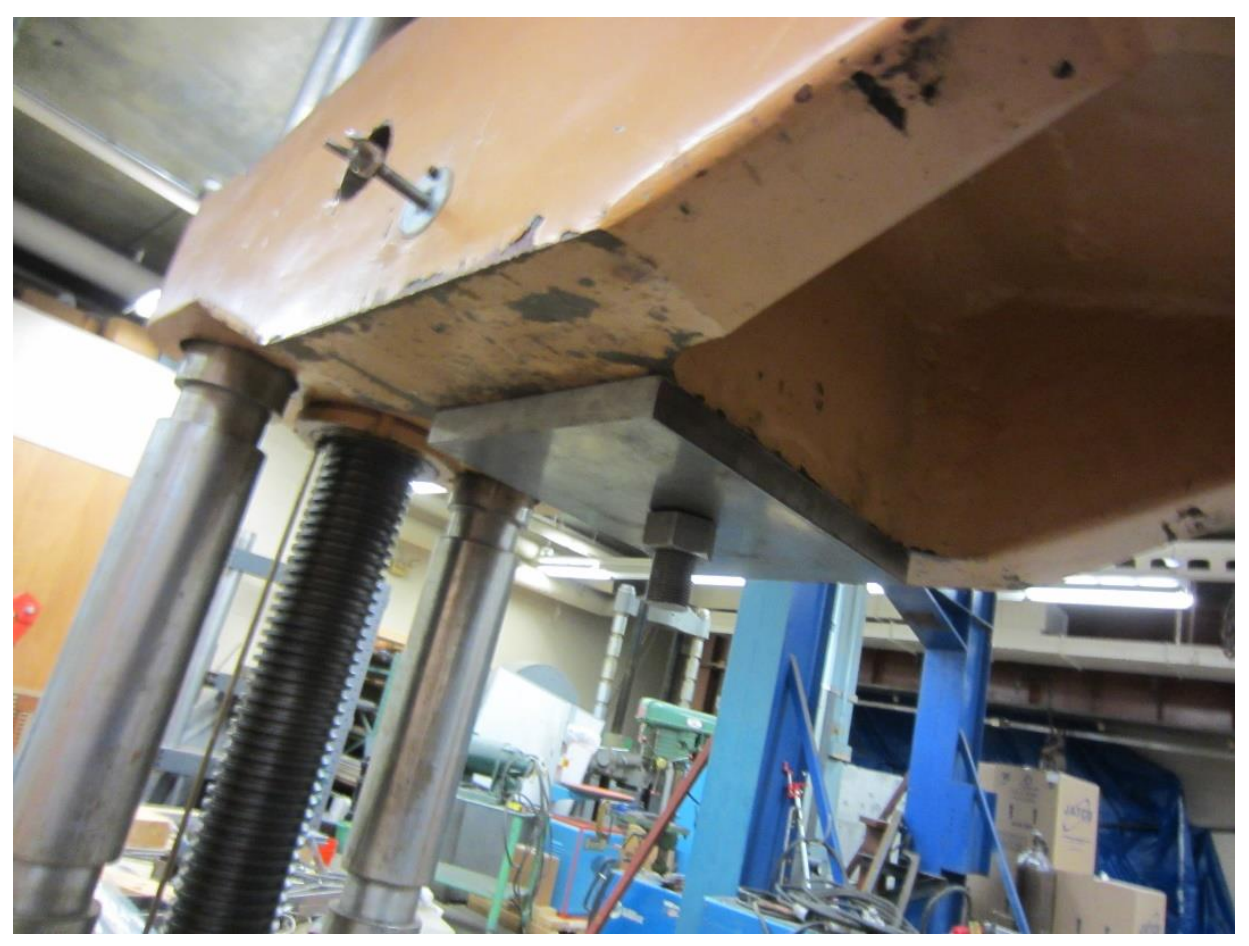

Figure C-8. Nut at threaded rod at lower head of UTM. 


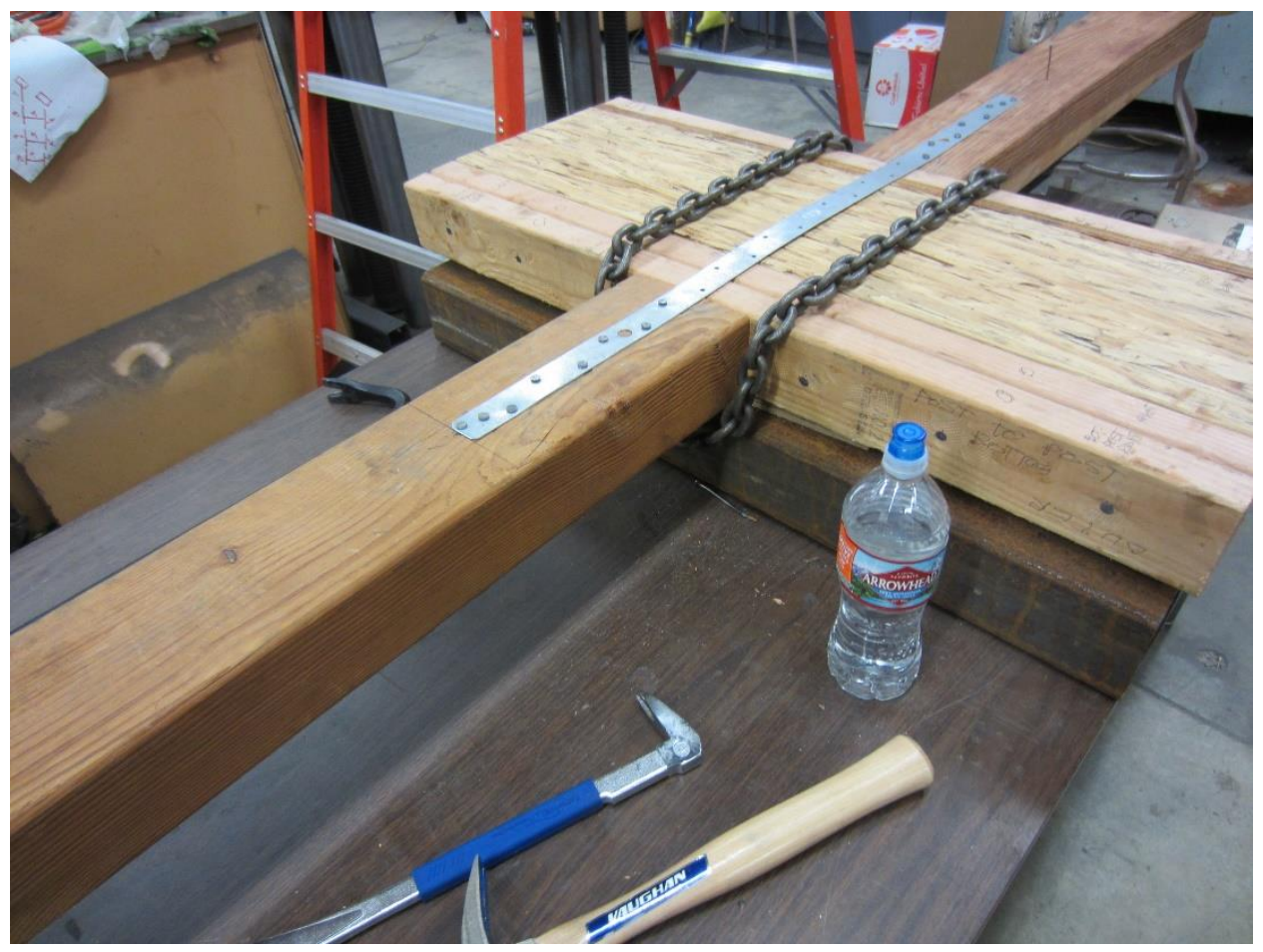

Figure C-9. TSM1 - Strap nailed, ready to lift into place.

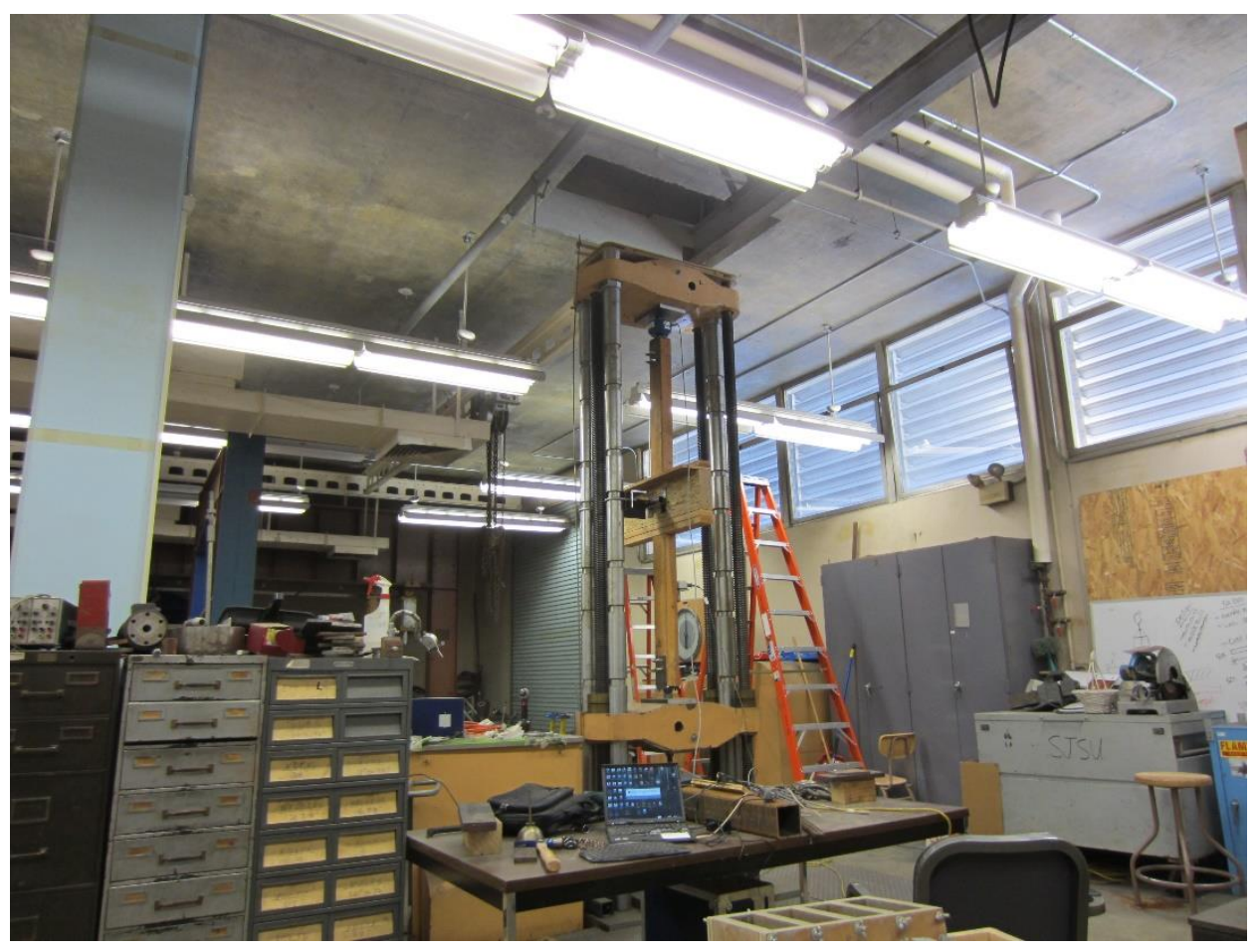

Figure C-10. TSM1 - Specimen mounted in UTM. 


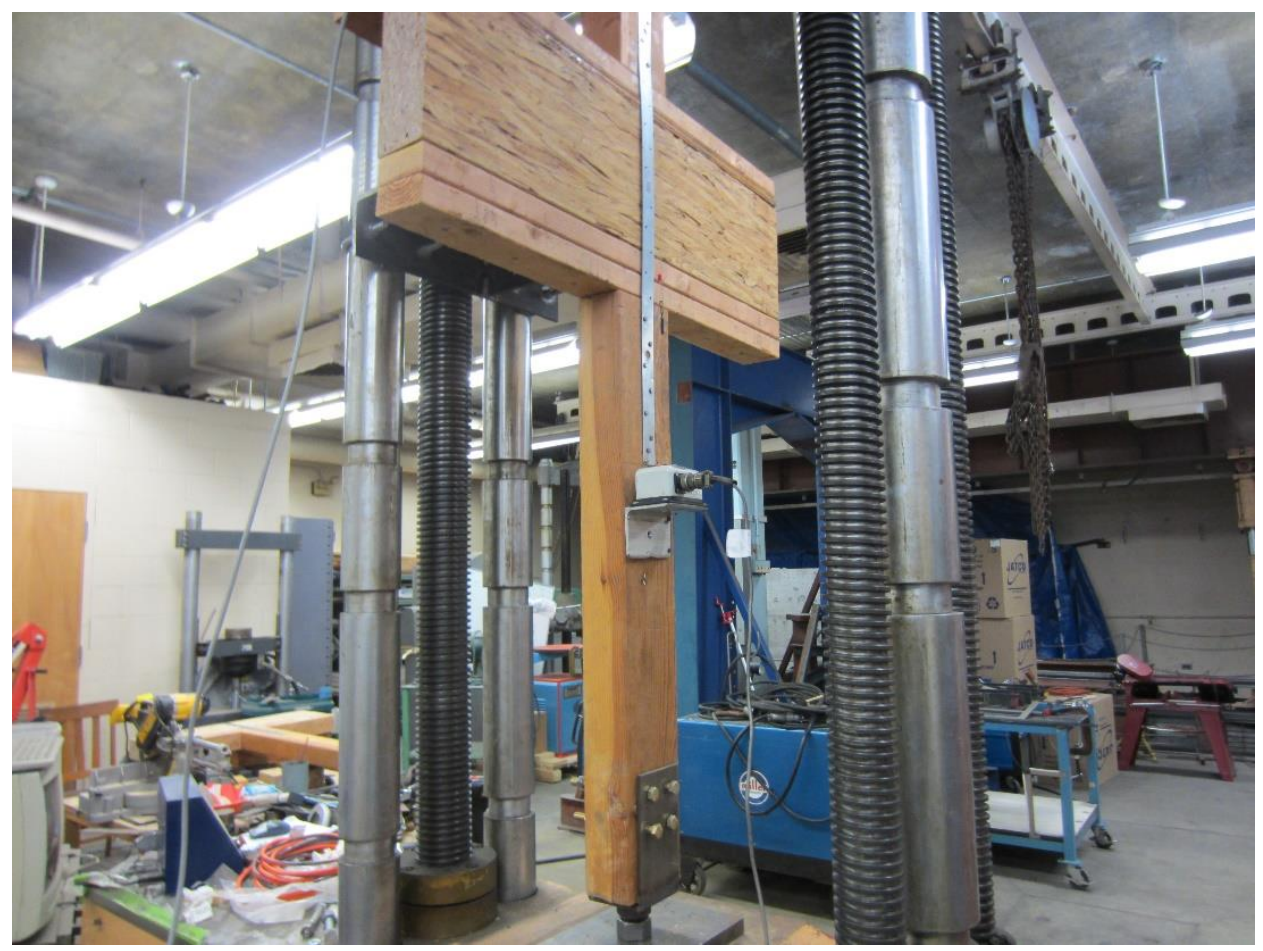

Figure C-11. TSM1 - Specimen mounted in UTM, with wire pot.

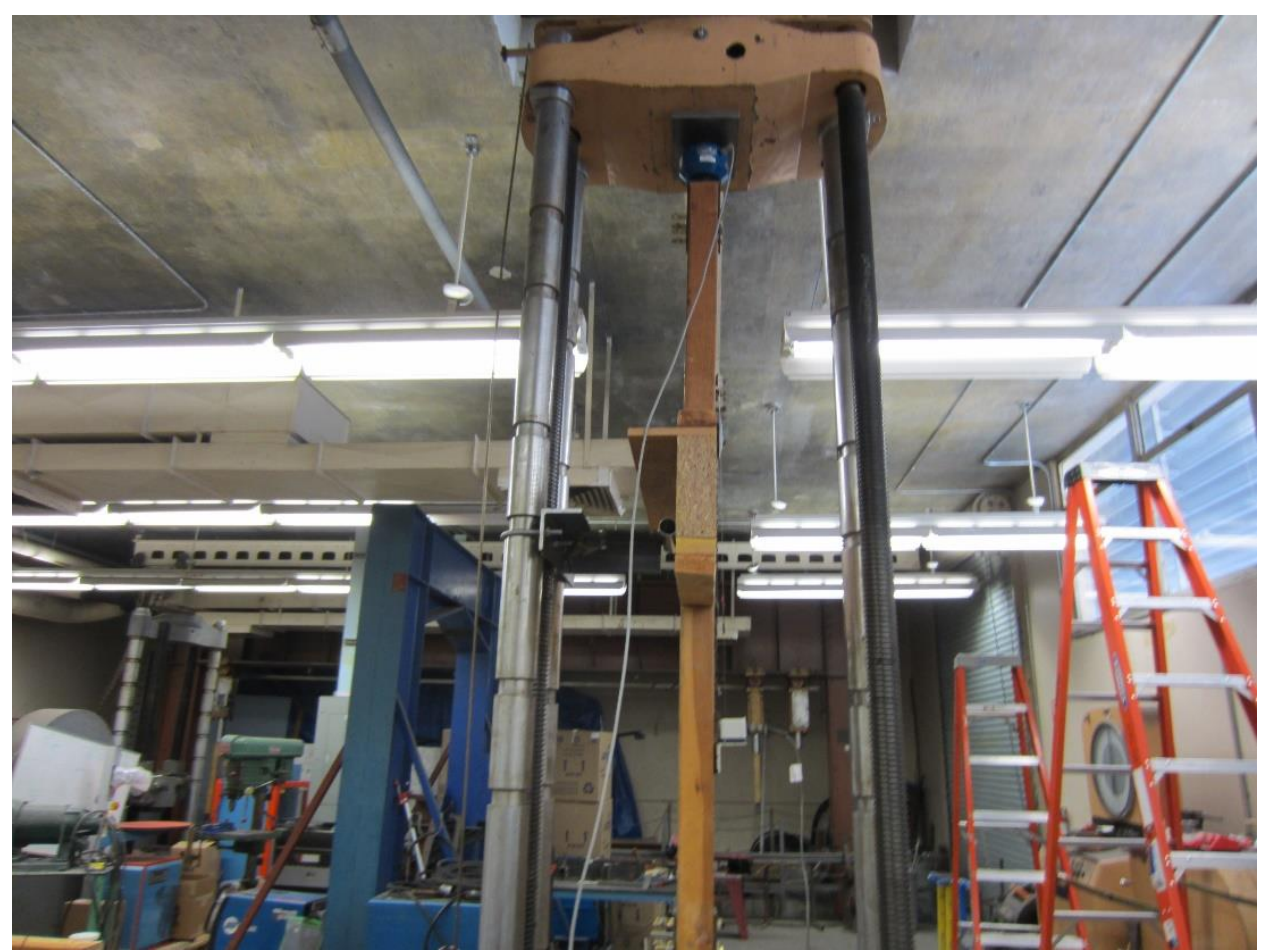

Figure C-12. TSM1 - Specimen mounted in UTM, side view. 


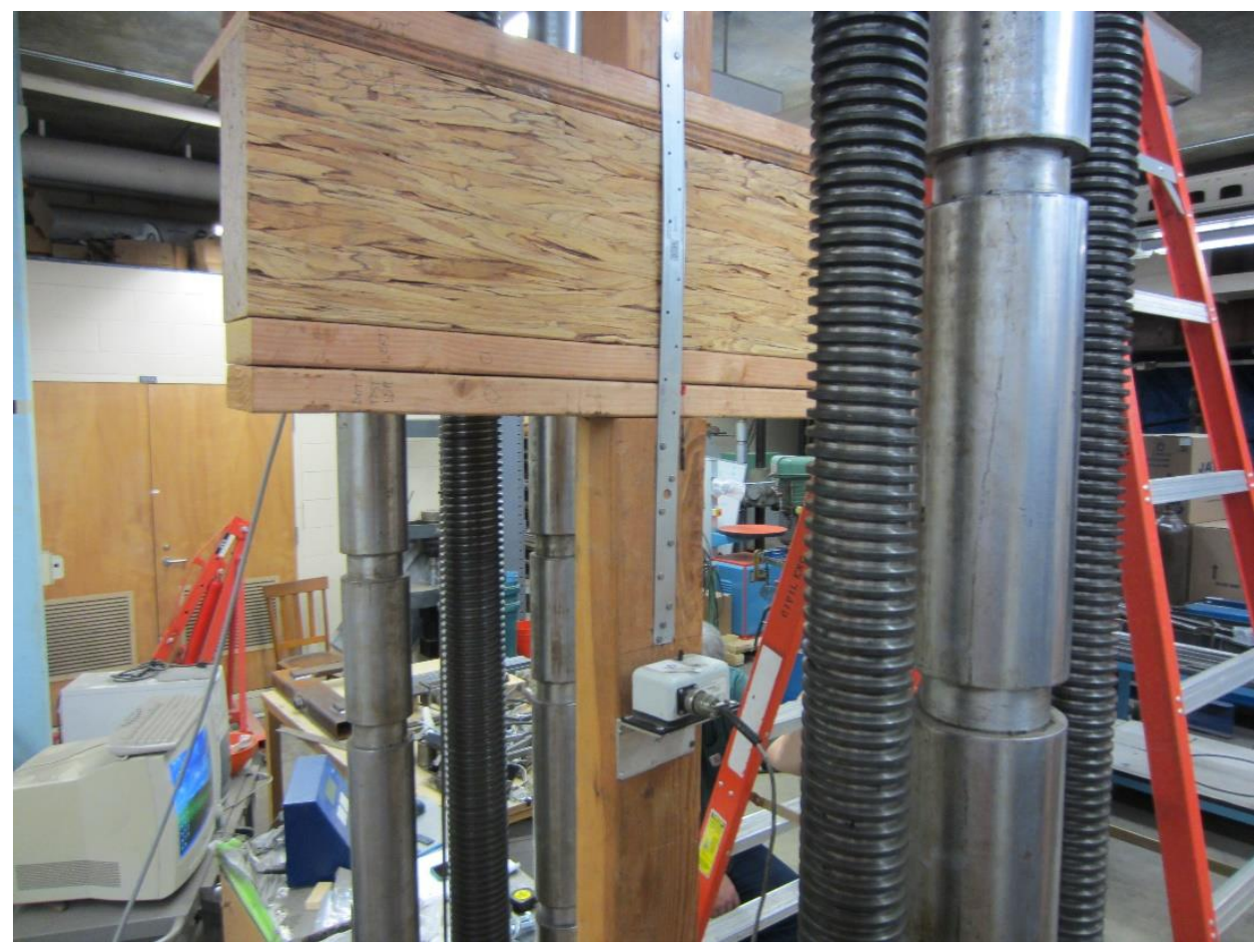

Figure $C$-13. TSM1 - Specimen mounted in UTM, front view, lower portion.

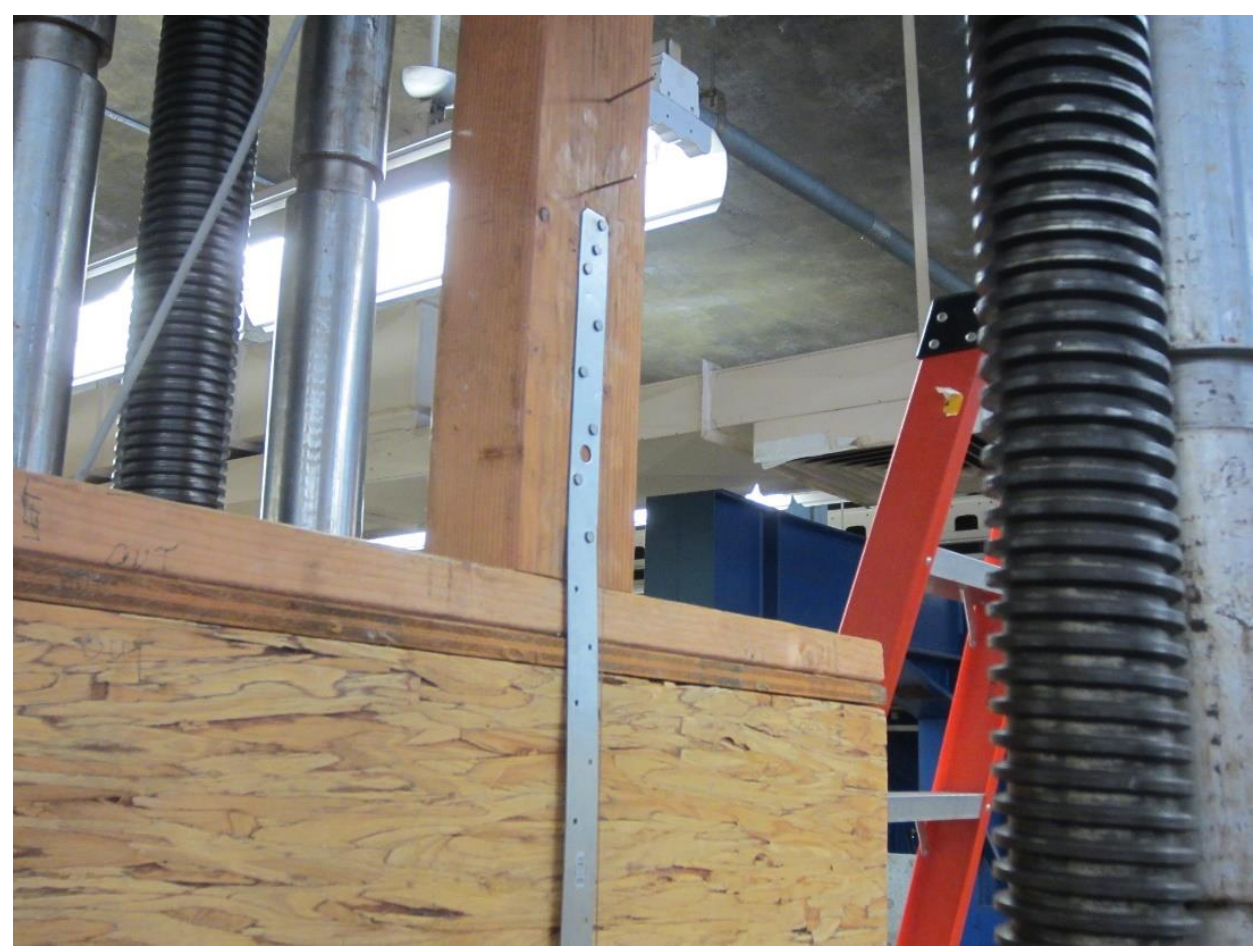

Figure C-14. TSM1 - Specimen mounted in UTM, front view, upper portion. 


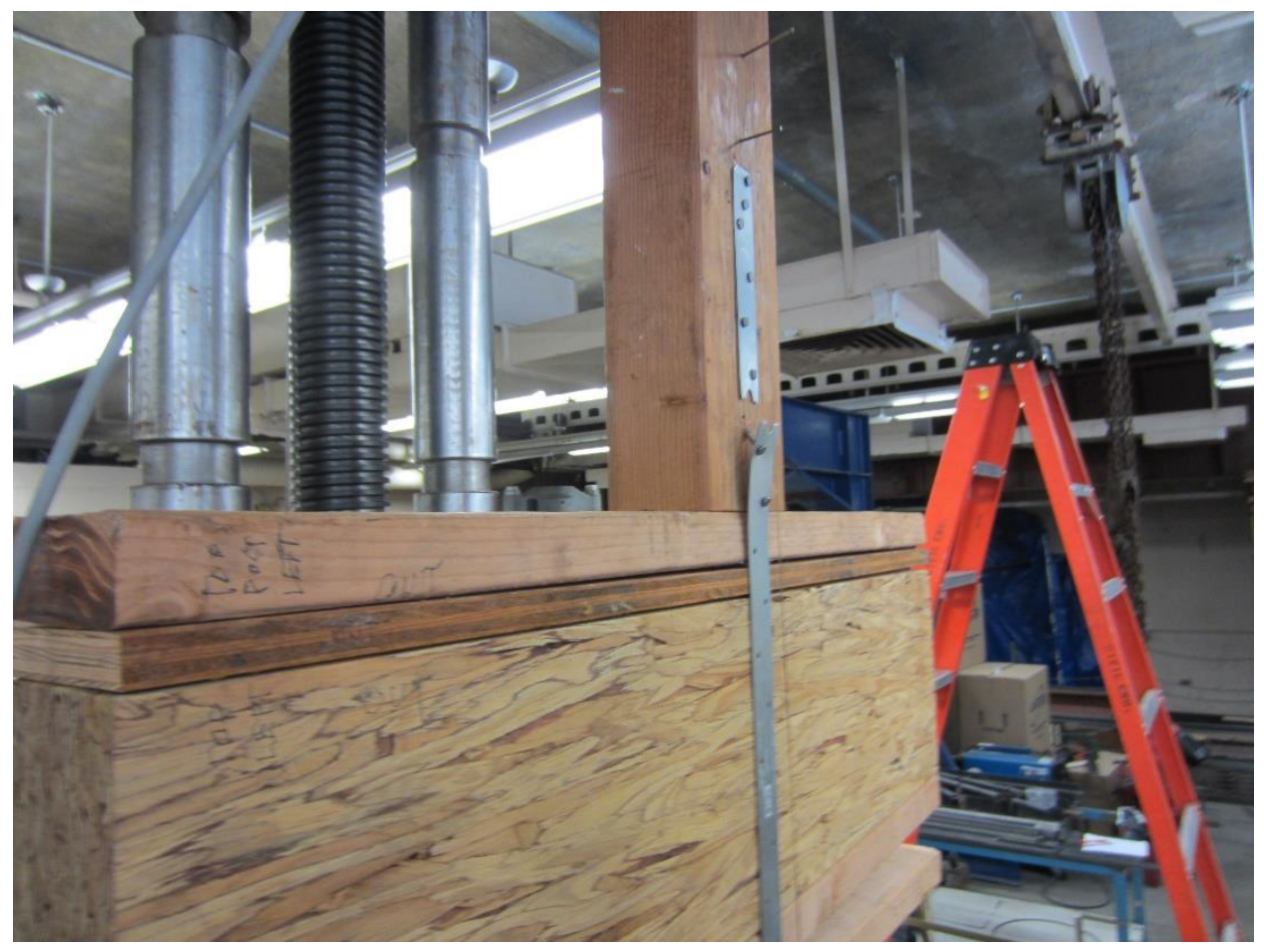

Figure C-15. TSM1 - Specimen after fracture.

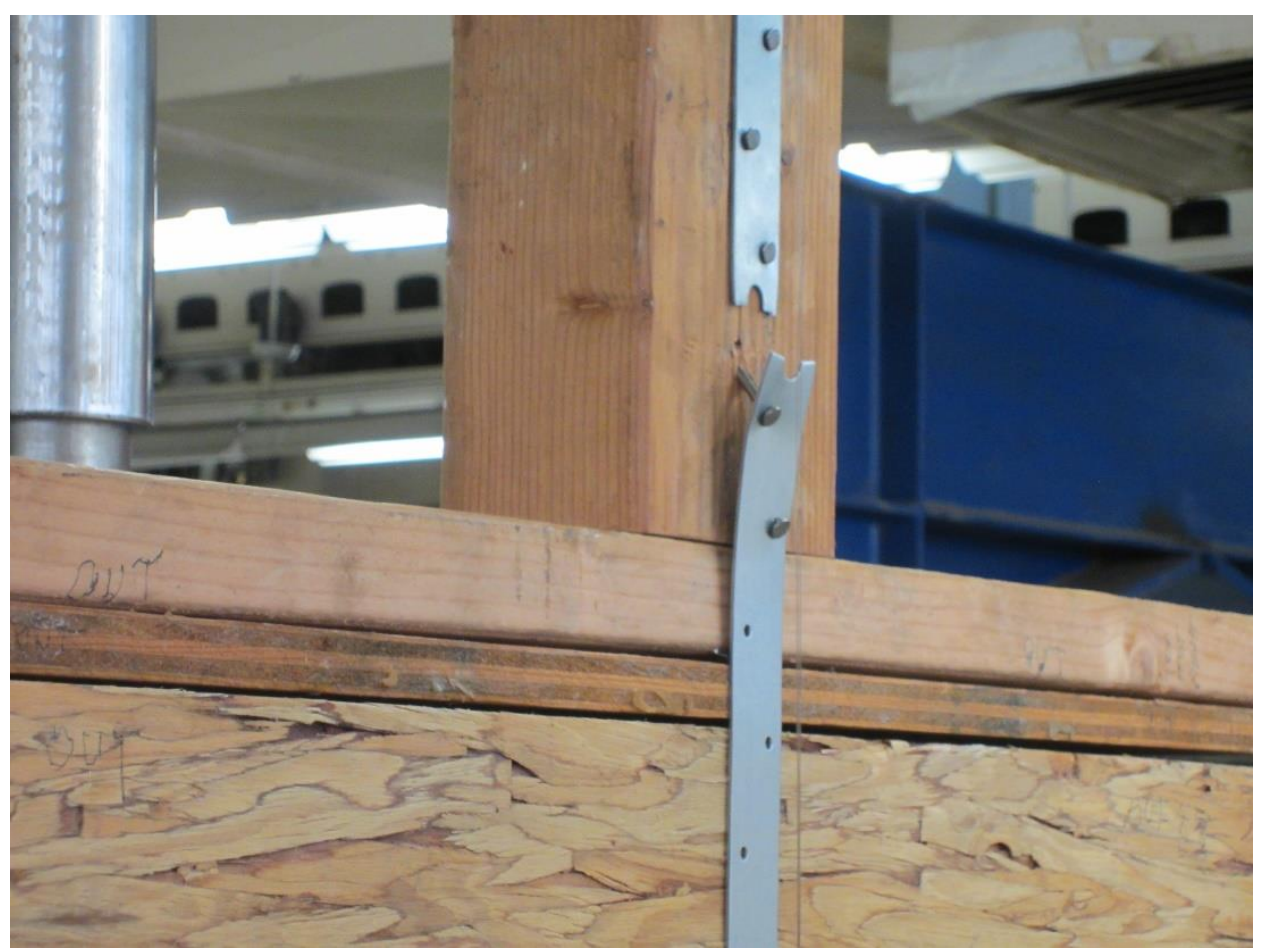

Figure C-16. TSM1 - Specimen after fracture, detail. 


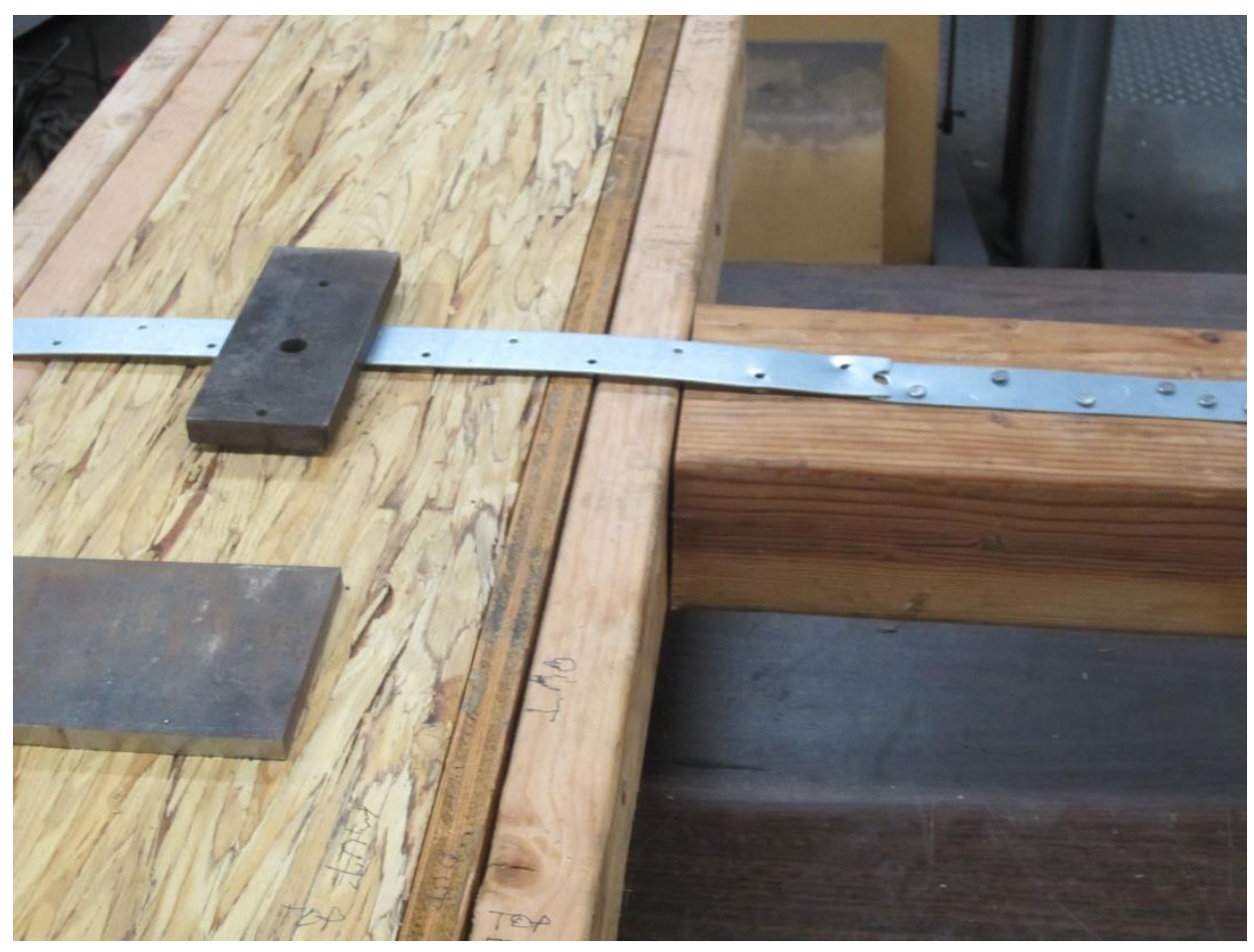

Figure C-17. TSM1 - Specimen taken down and wood returned to original configuration after fracture, showing elongation.

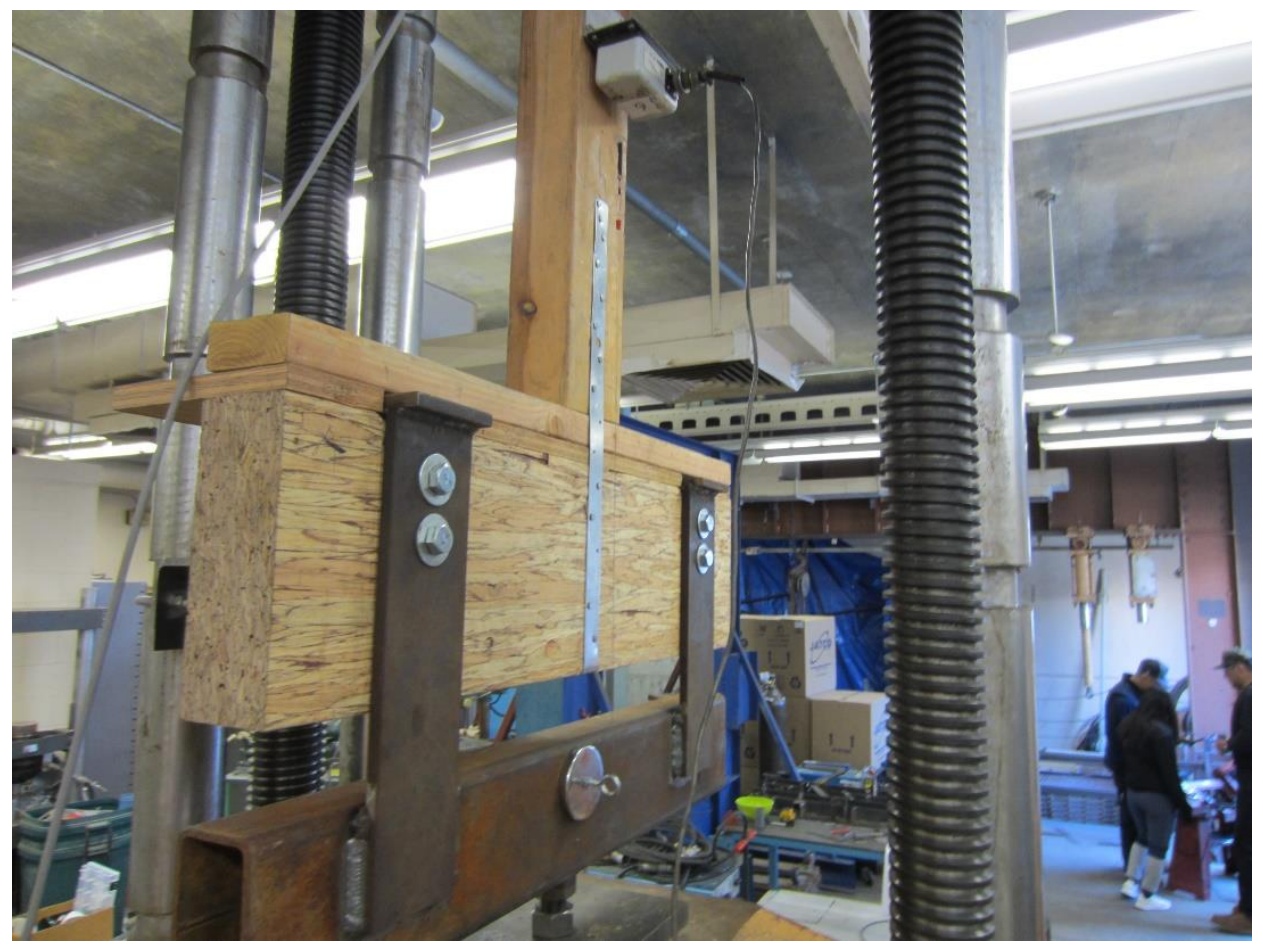

Figure C-18. TSM2 - Specimen mounted in UTM, front and side view. 


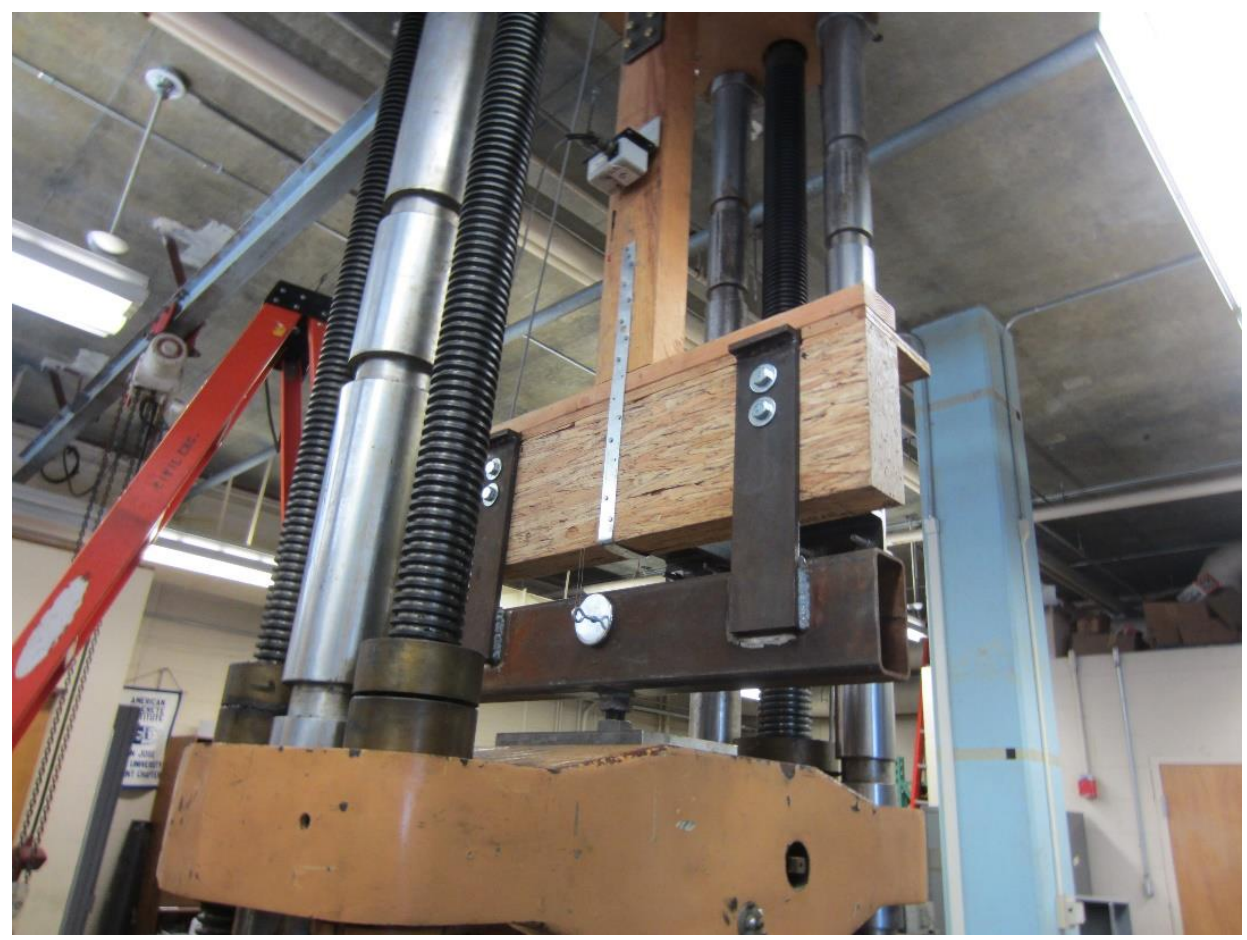

Figure C-19. TSM2 - Specimen mounted in UTM, front view from below.

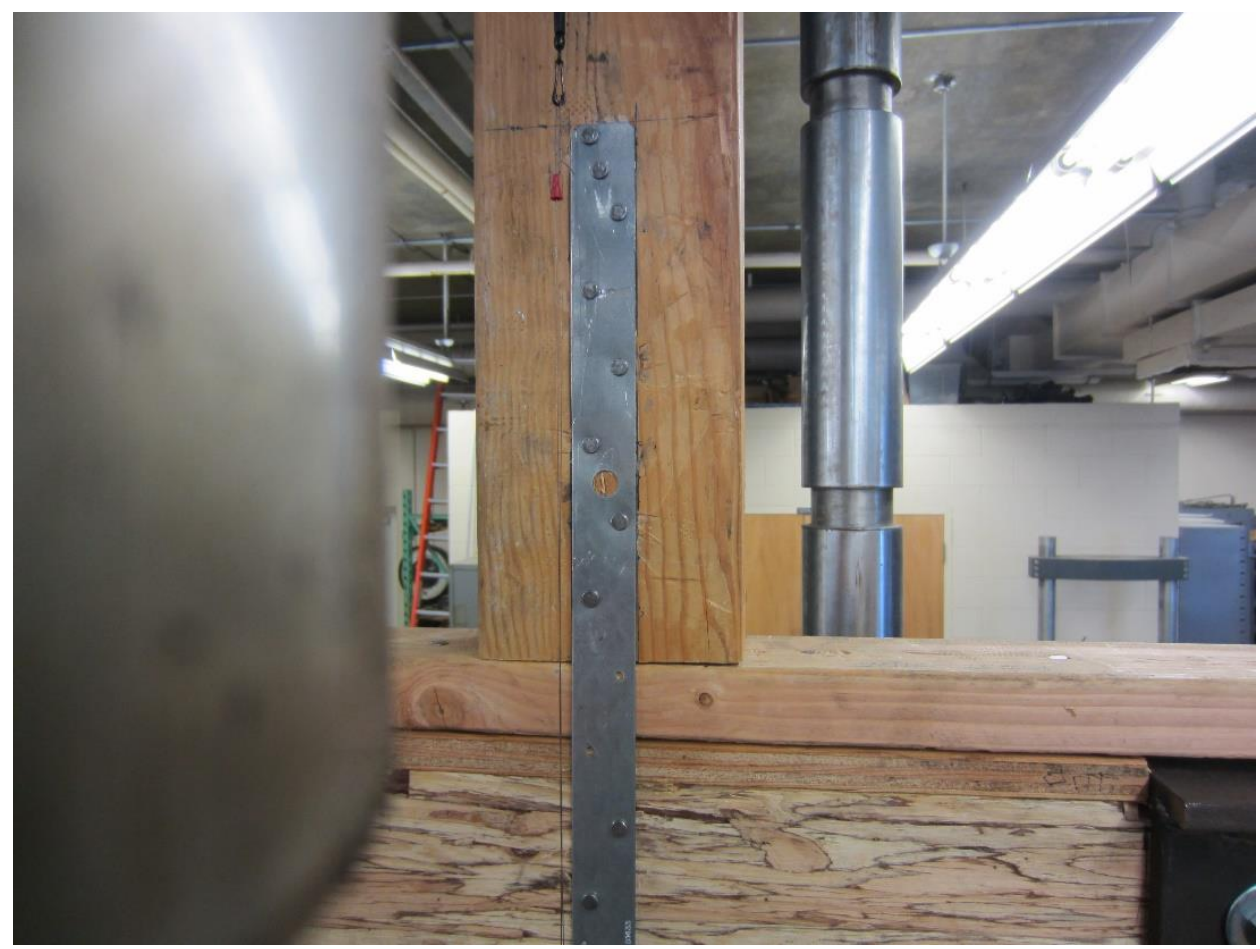

Figure C-20. TSM2 - Specimen mounted in UTM, front view, detail showing large hole. 


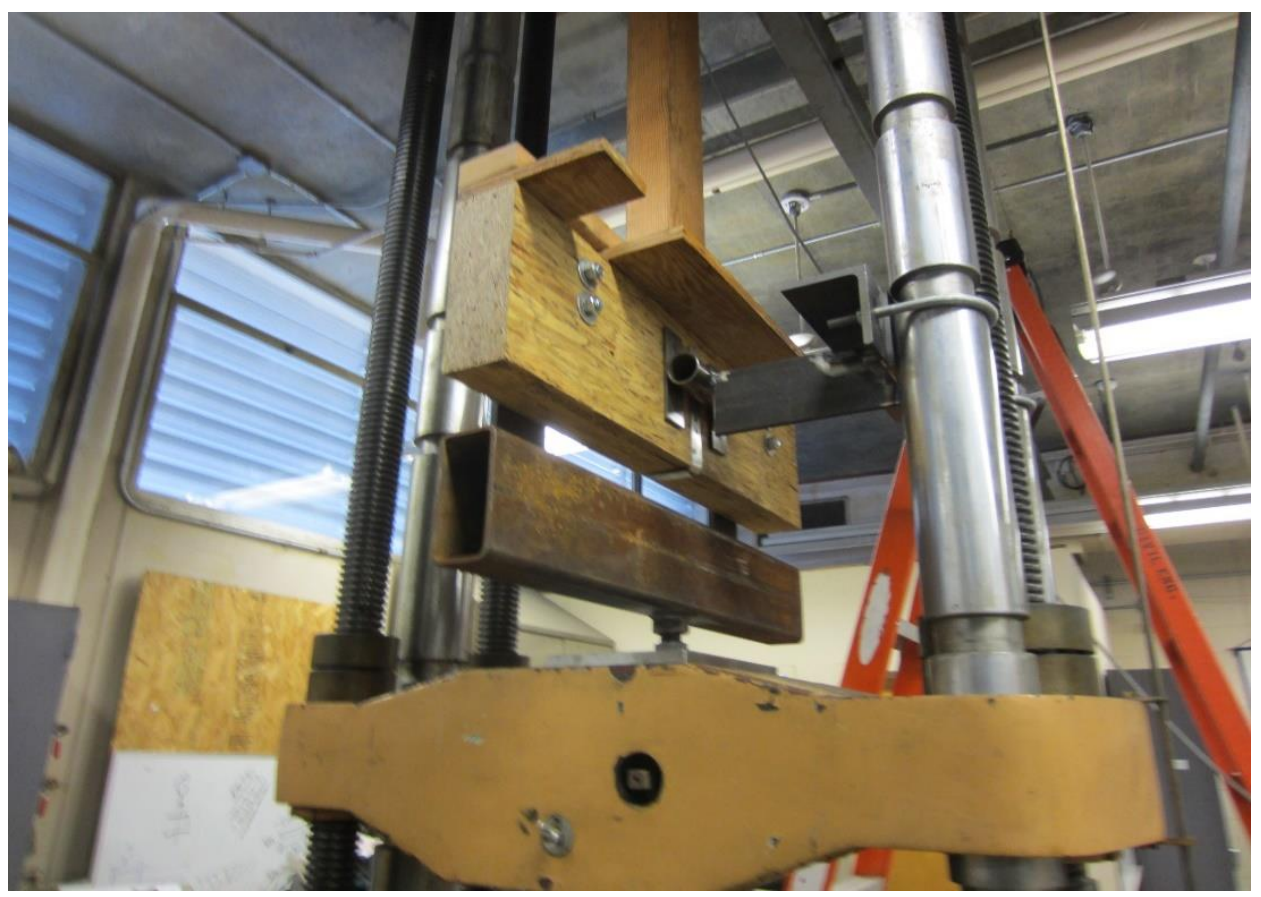

Figure C-21. TSM2 - Specimen mounted in UTM, rear view with lateral restraint.

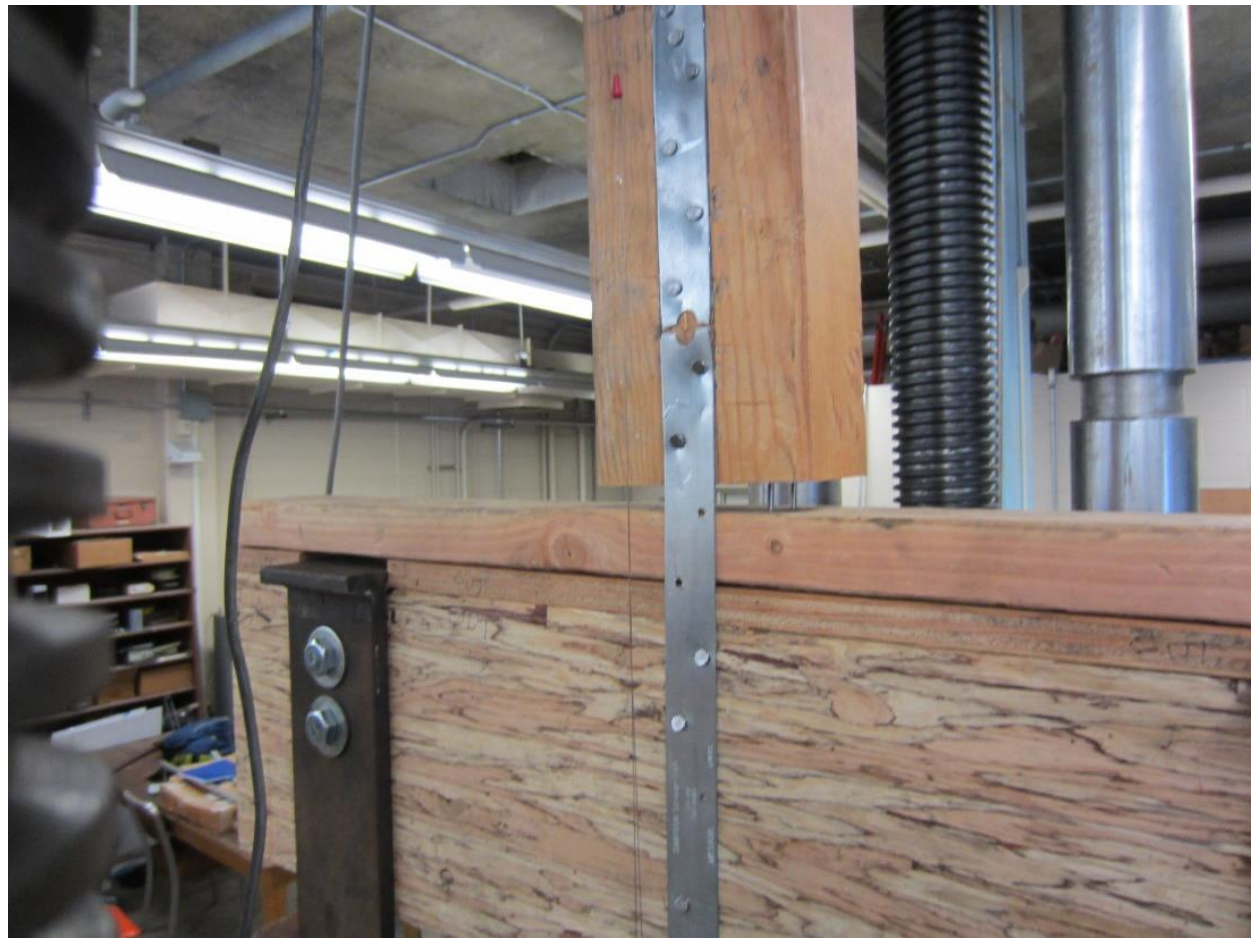

Figure $C$-22. TSM2 - Specimen after fracture. 


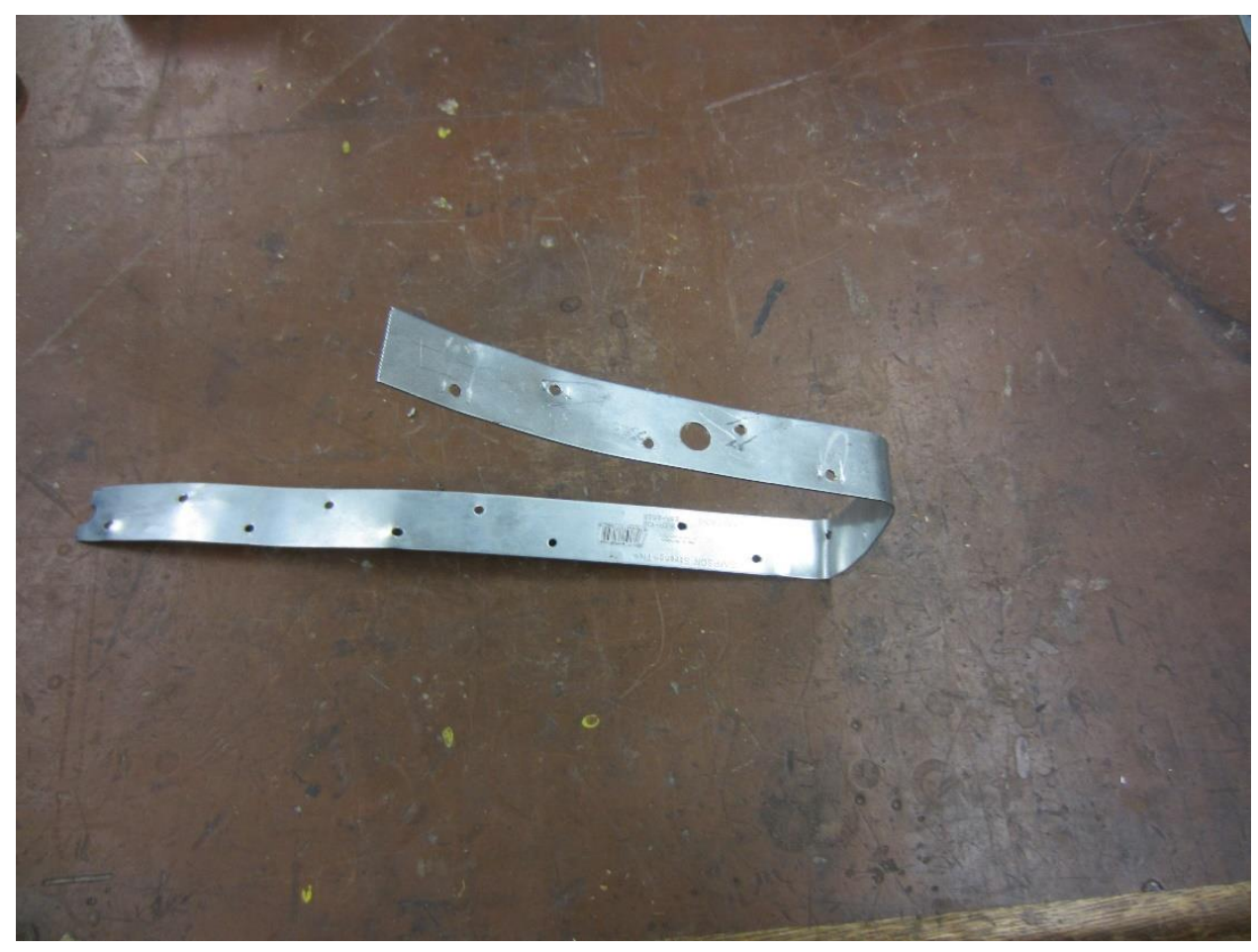

Figure $C$-23. TSM2 - Piece of strap removed after fracture.

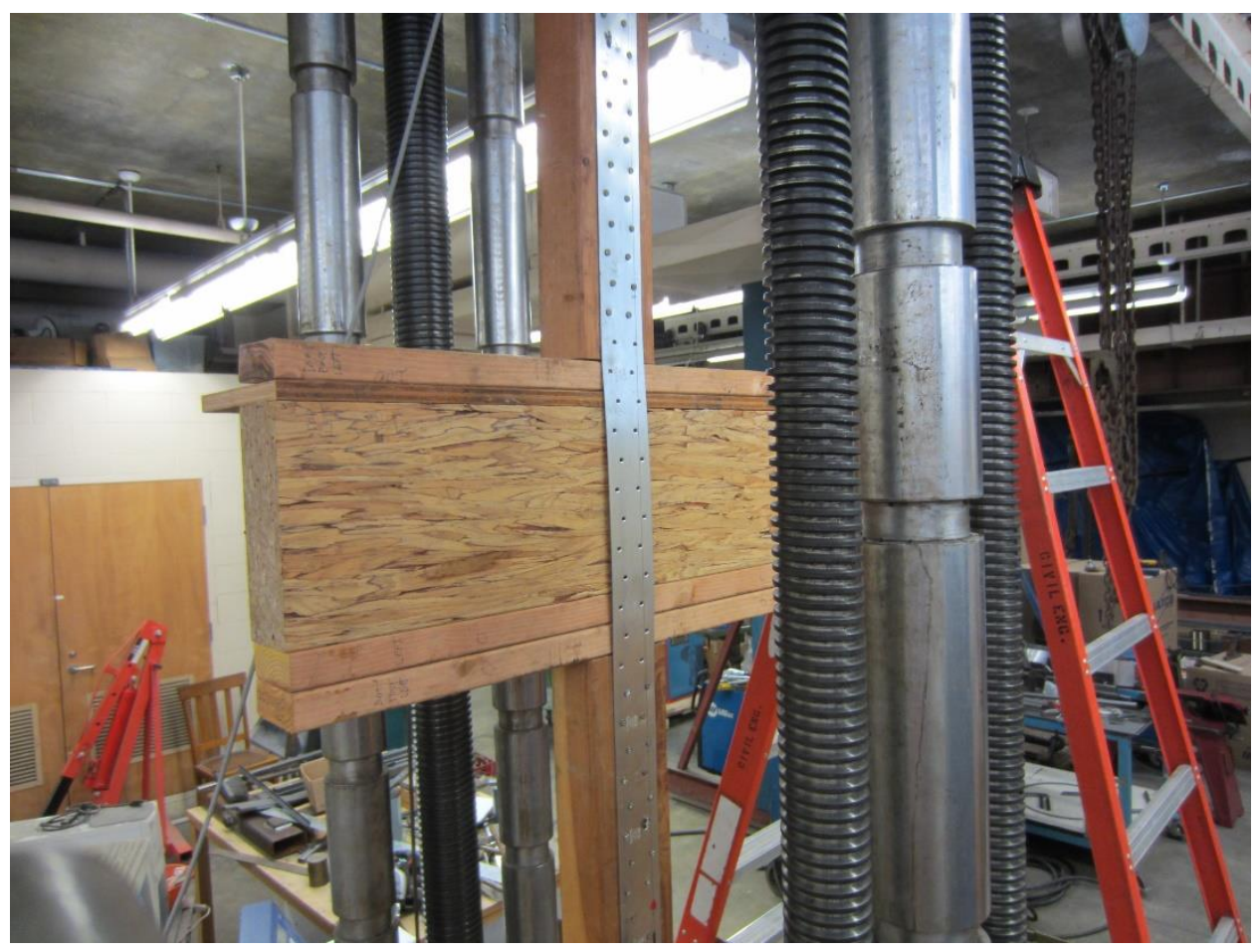

Figure $C$-24. TSC1 - Specimen mounted in UTM, front view. 


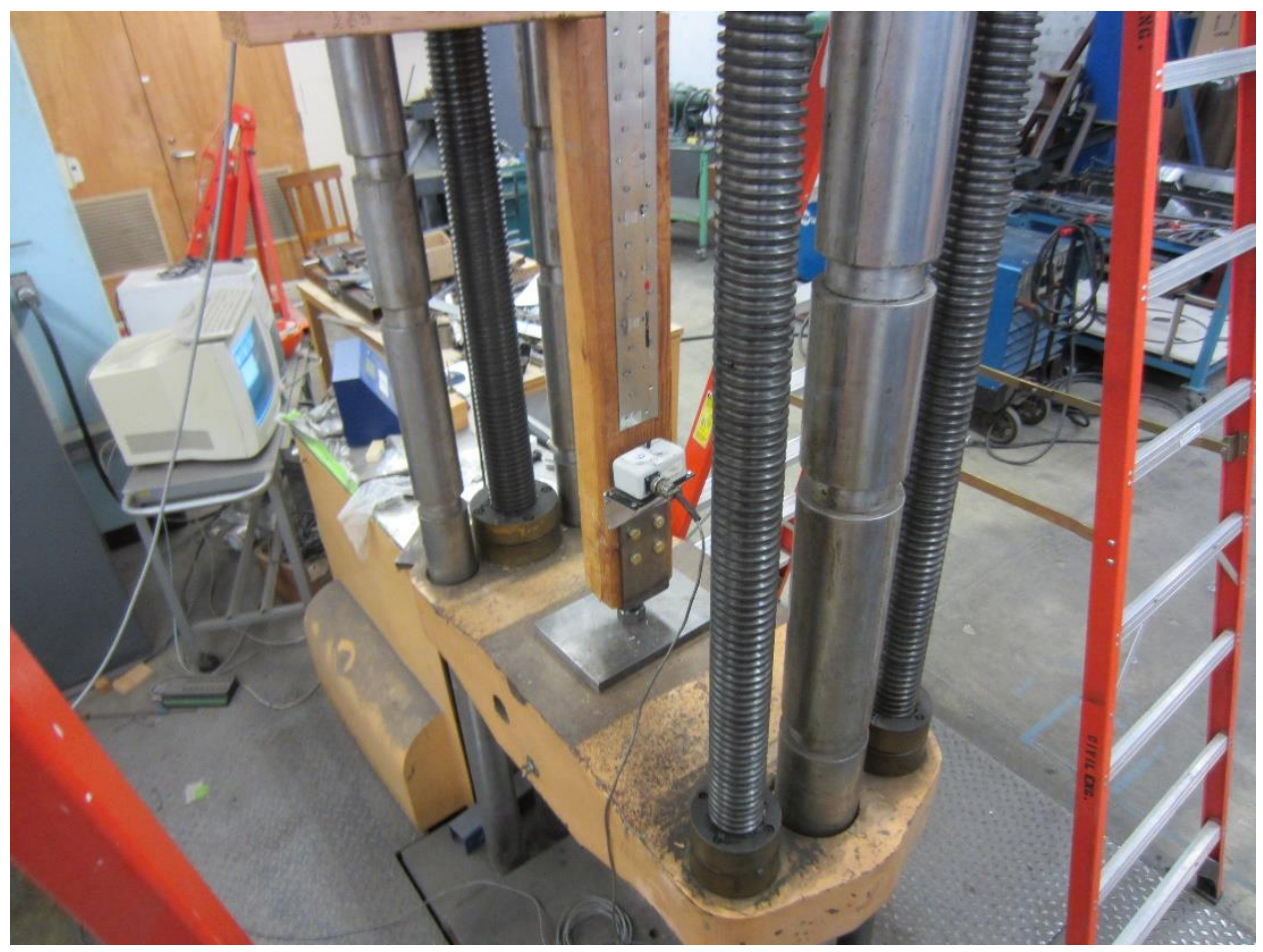

Figure C-25. TSC1 - Specimen mounted in UTM, front view, wire pot detail.

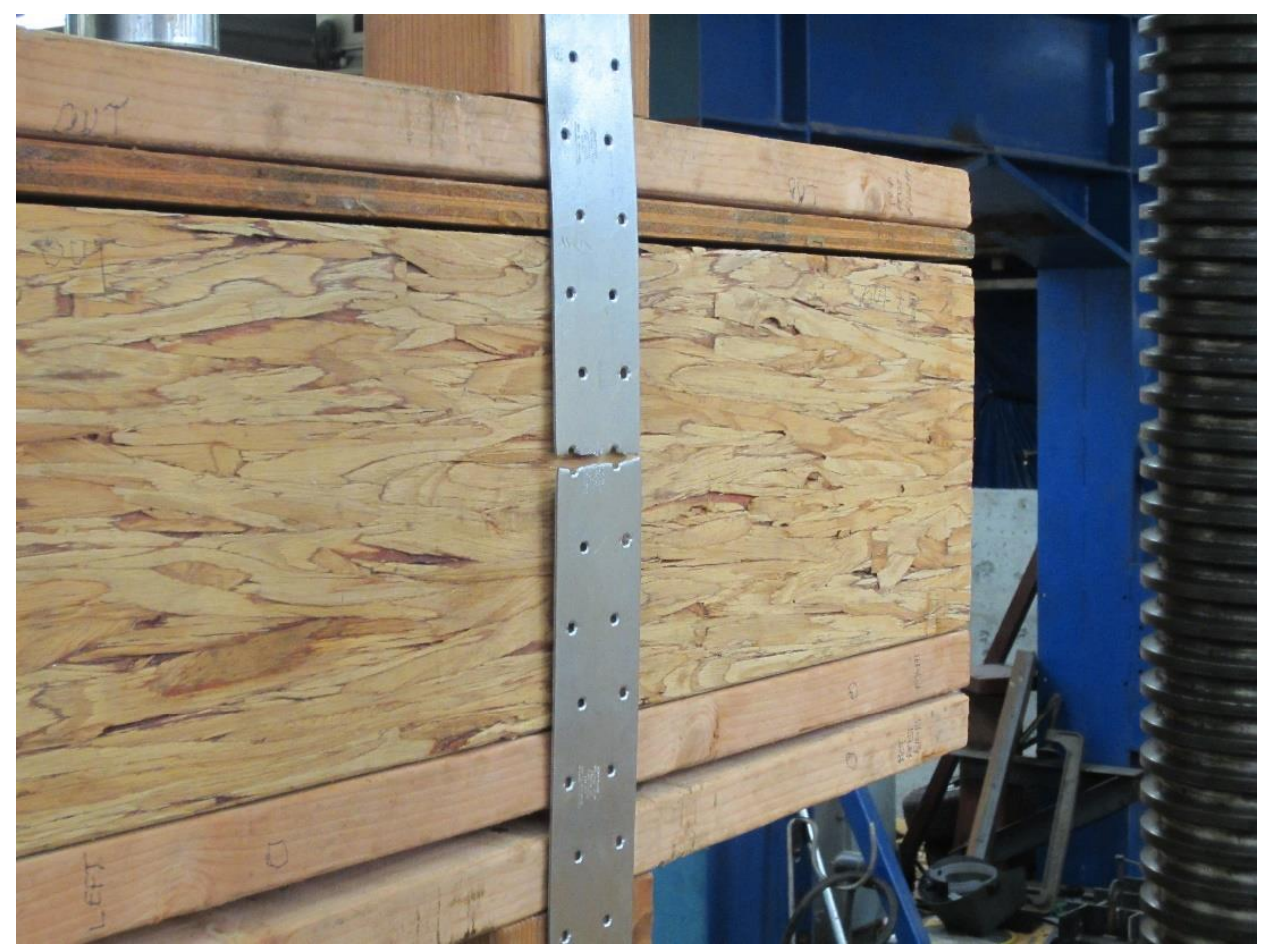

Figure C-26. TSC1 - Specimen after fracture. 


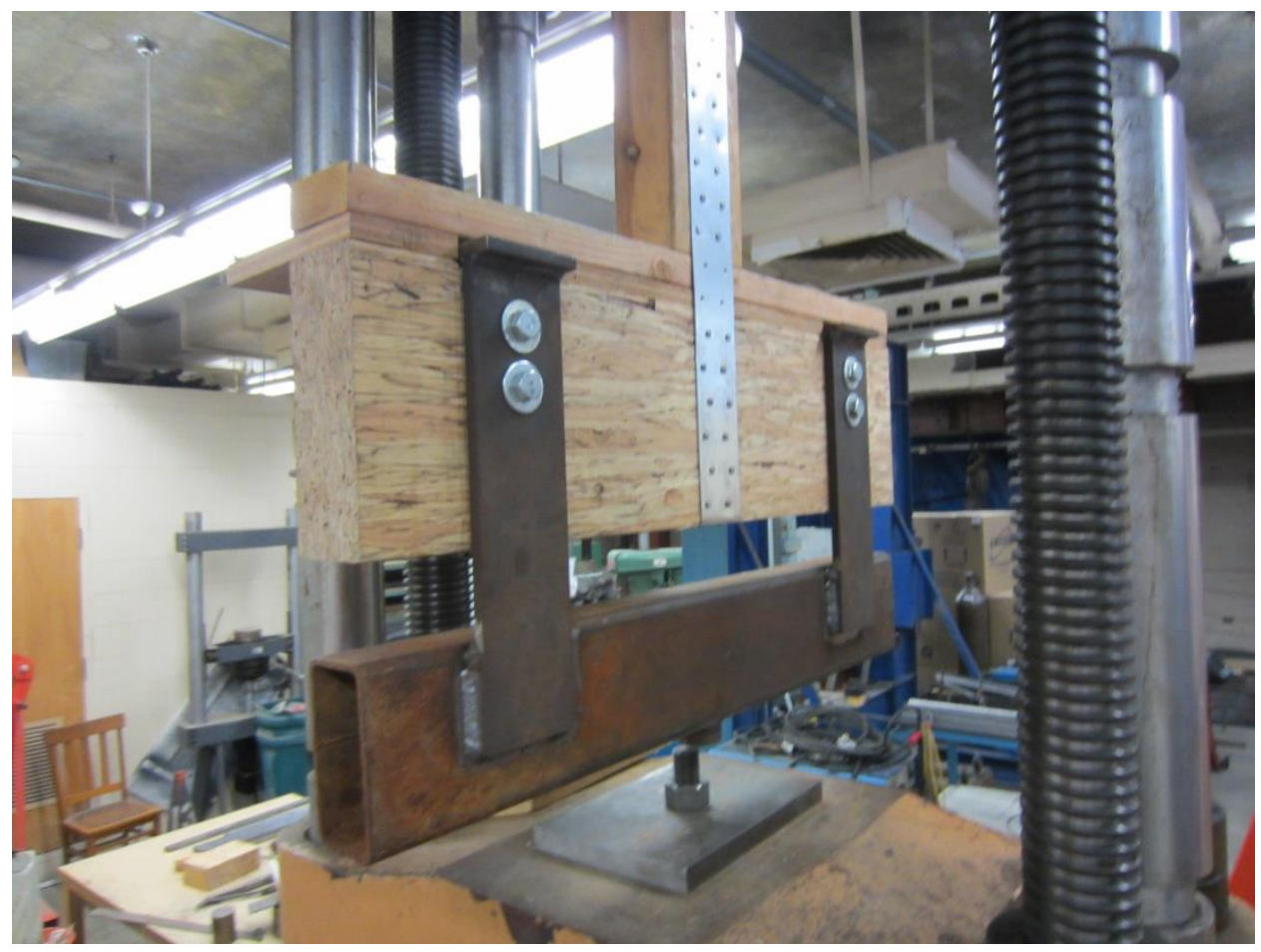

Figure C-27. TSC2 - Specimen partly mounted in UTM, front view.

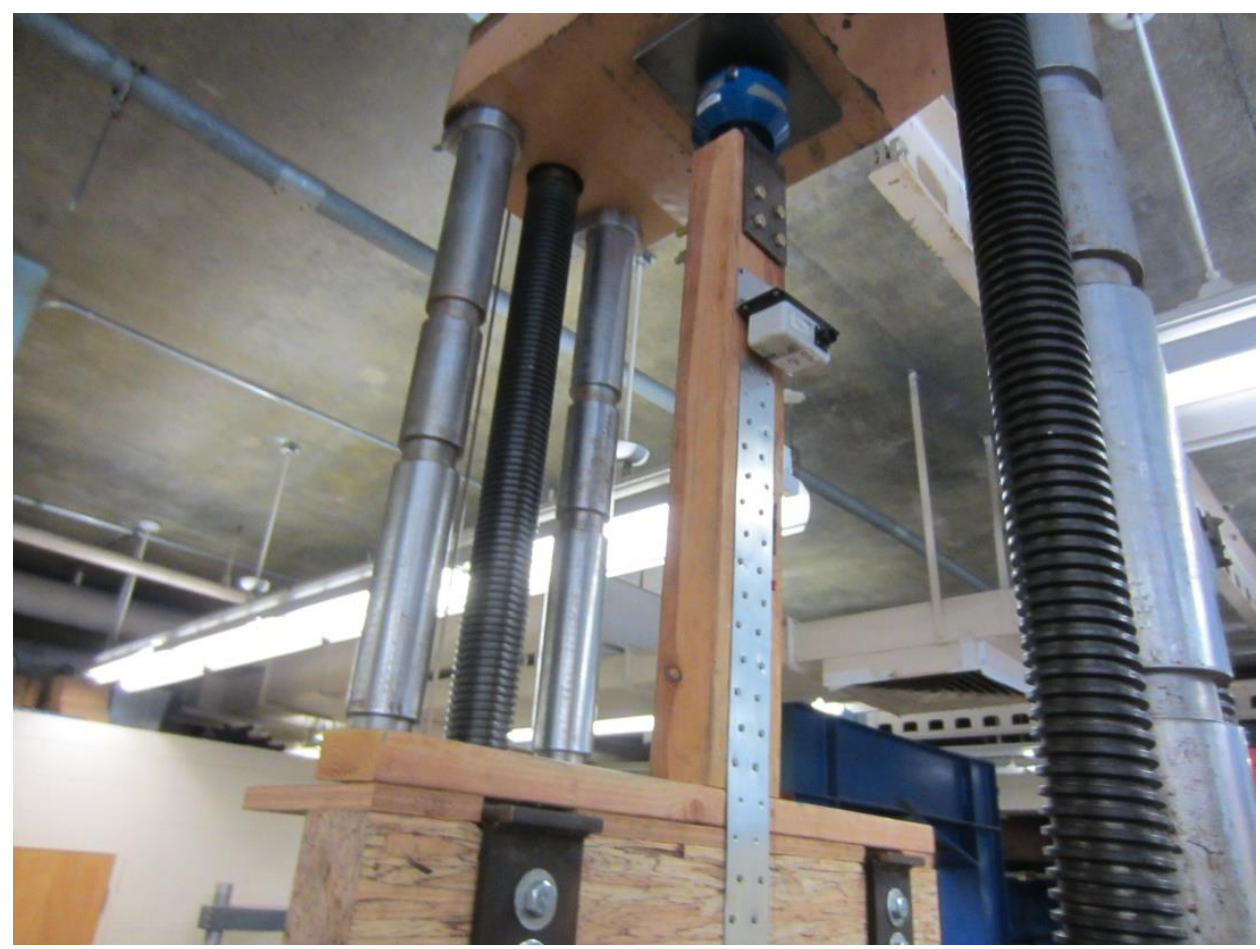

Figure C-28. TSC2 - Specimen mounted in UTM, front view with wire pot, upper collar, and load cell. 


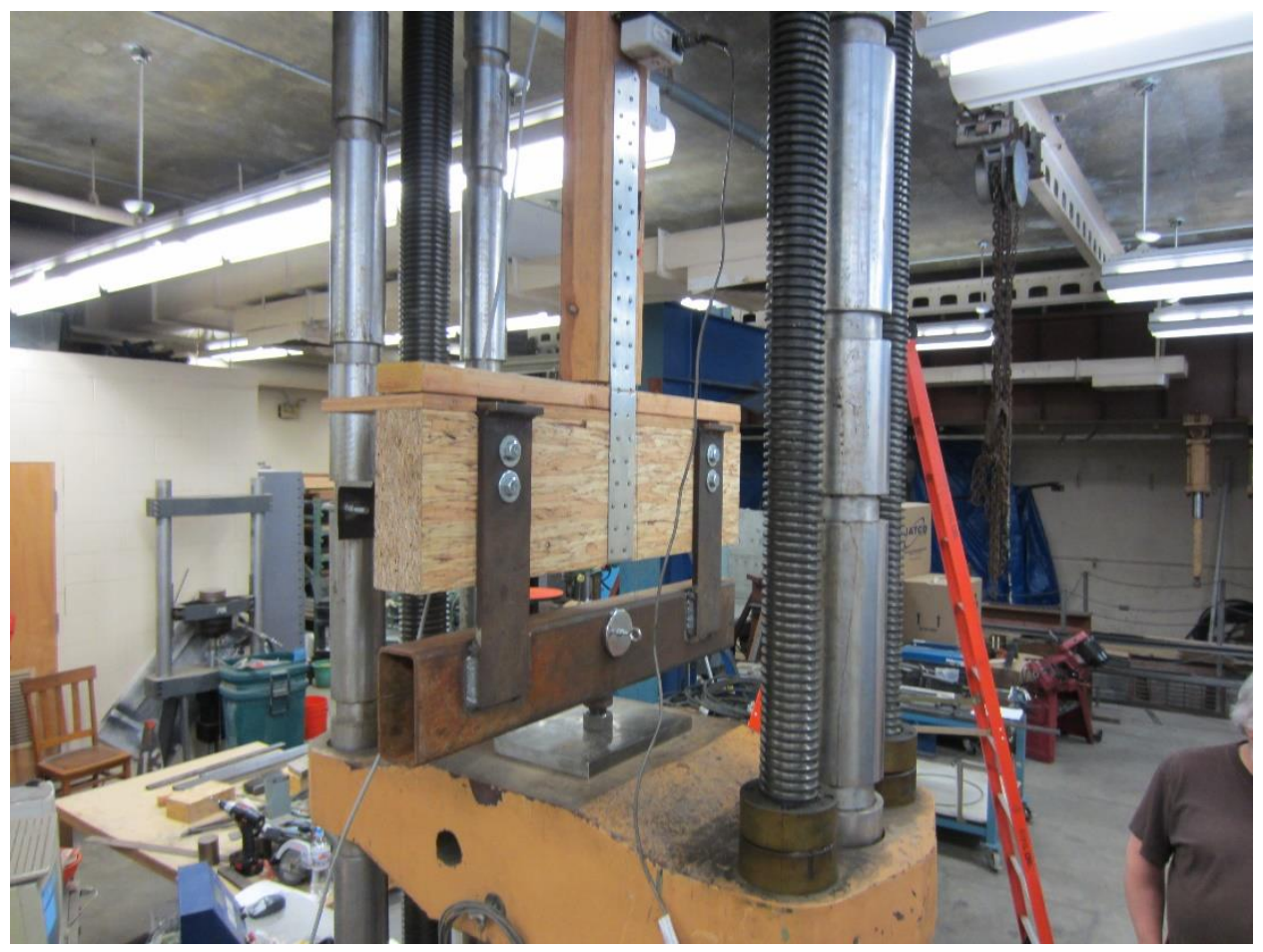

Figure C-29. TSC2 - Specimen mounted in UTM, front view.

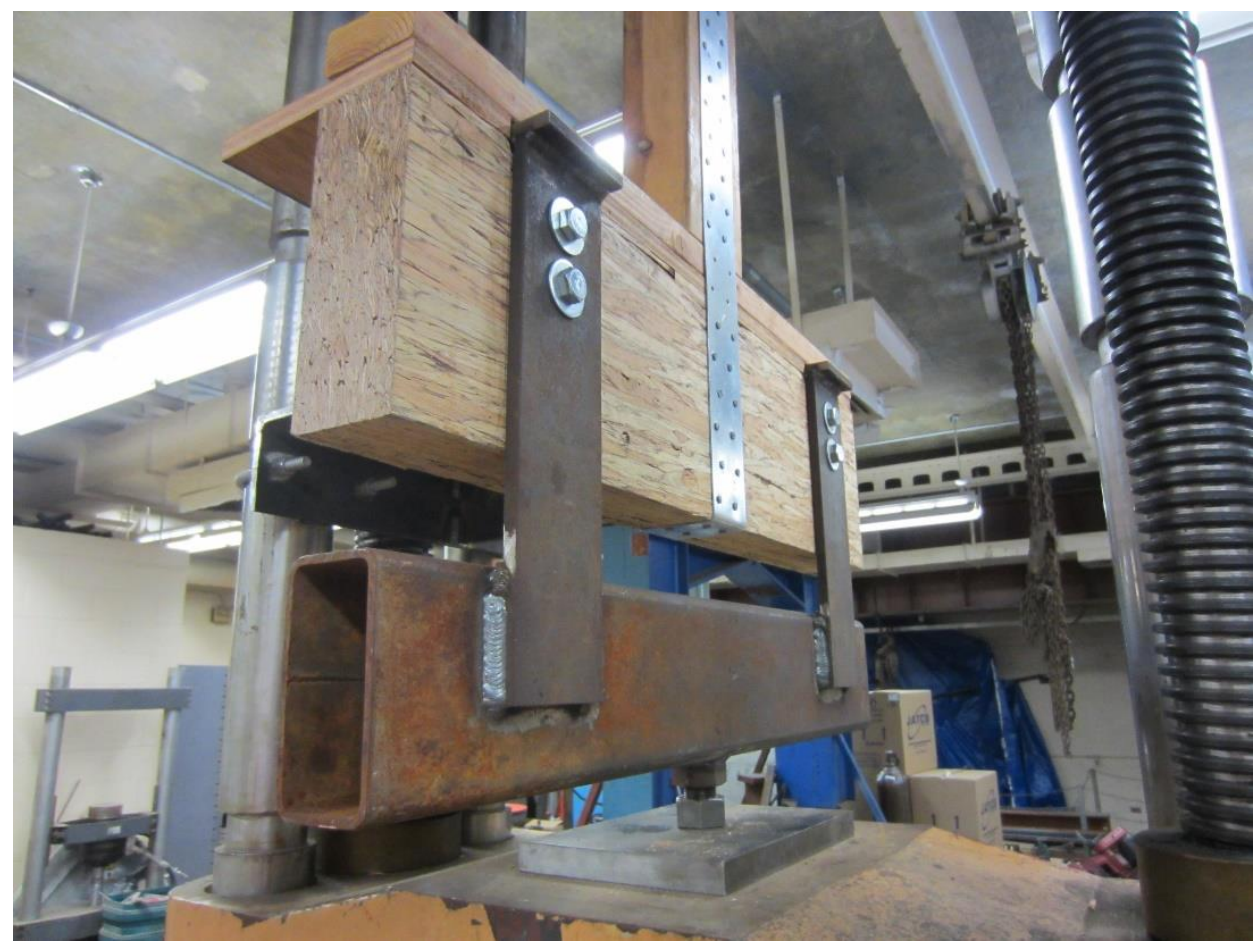

Figure $C$-30. TSC2 - Specimen mounted in UTM, front and side view. 


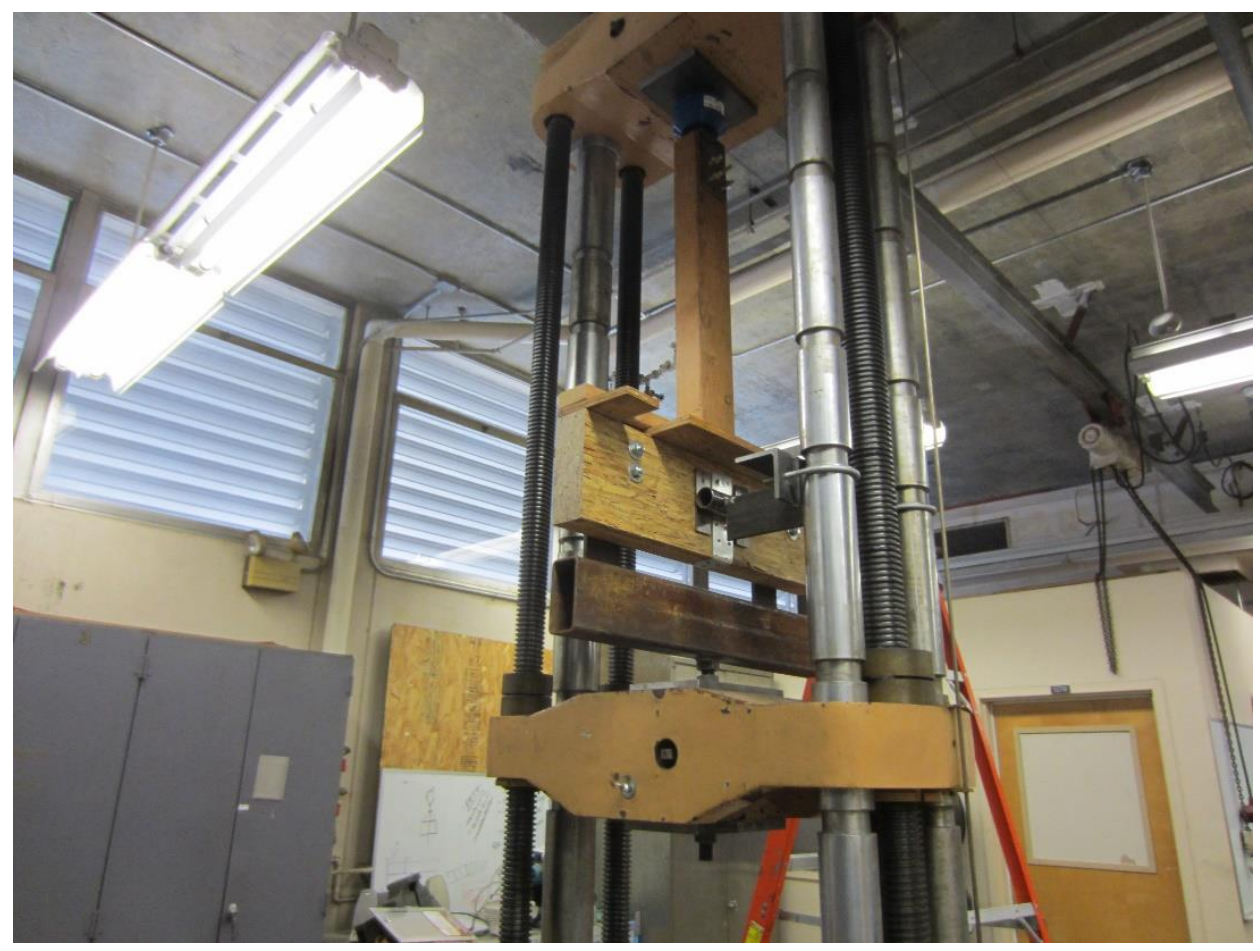

Figure C-31. TSC2 - Specimen mounted in UTM, rear view with lateral restraint.

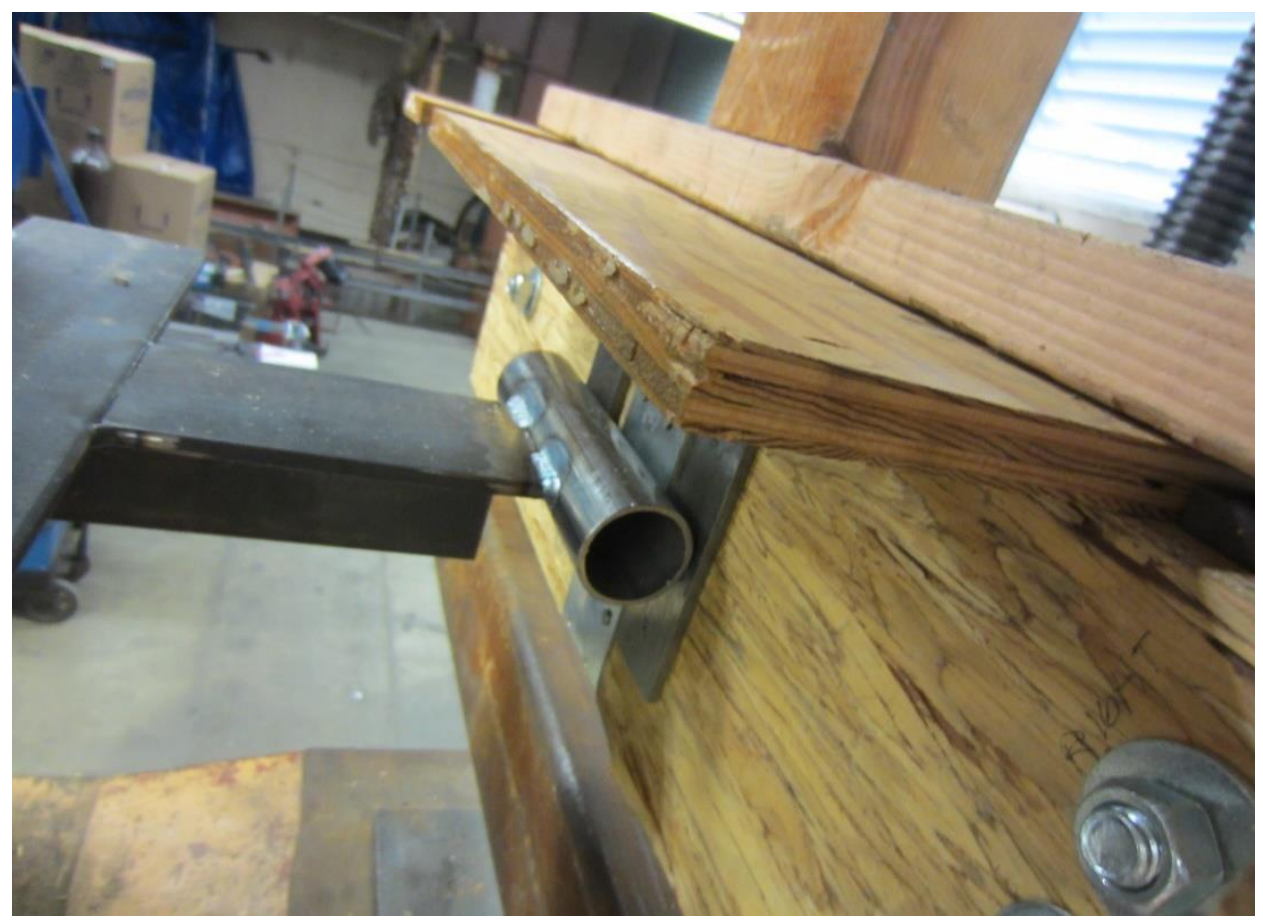

Figure $C$-32. TSC2 - Specimen mounted in UTM, rear view with lateral restraint. 


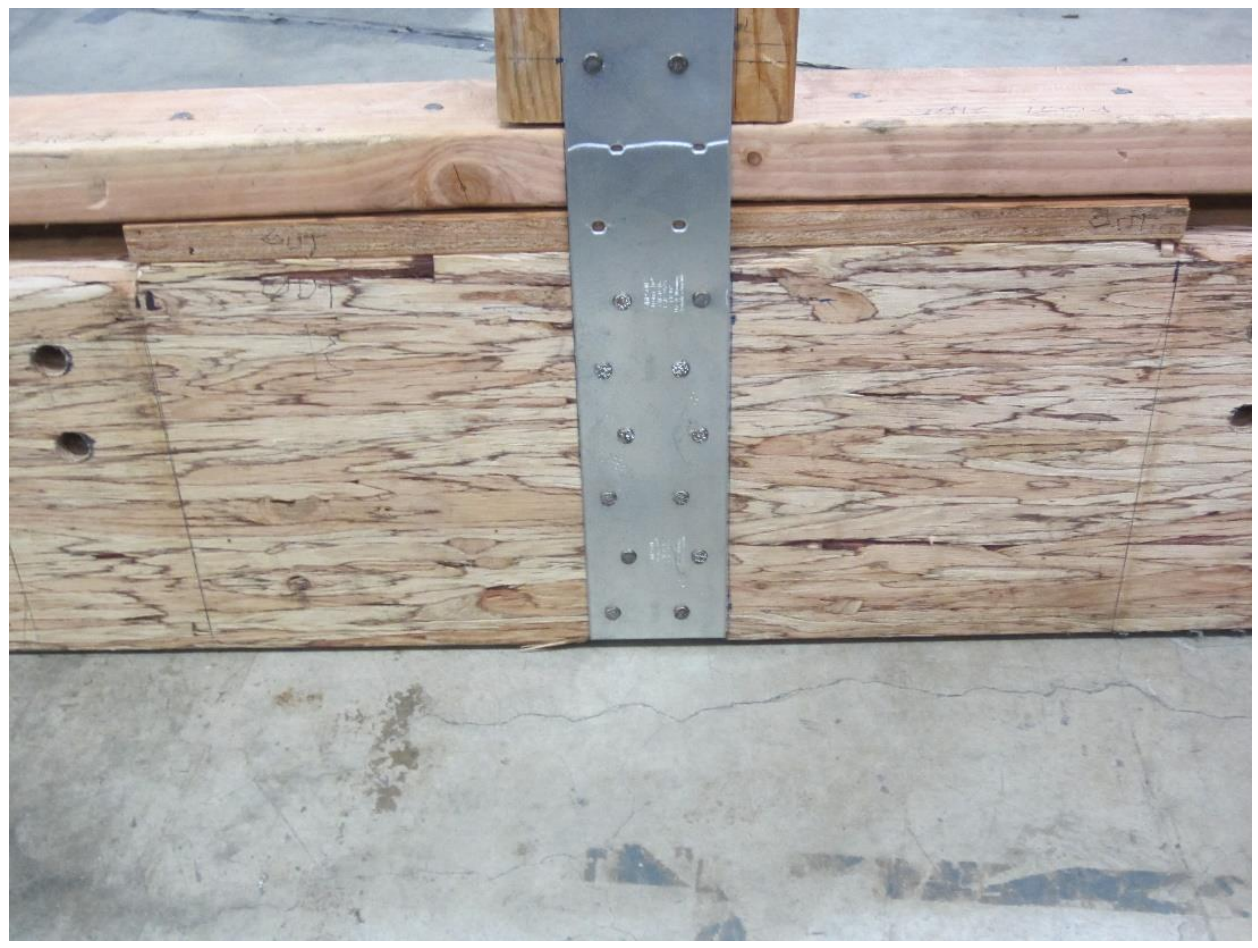

Figure C-33. TSC2 - Specimen after fracture, disassembled. 